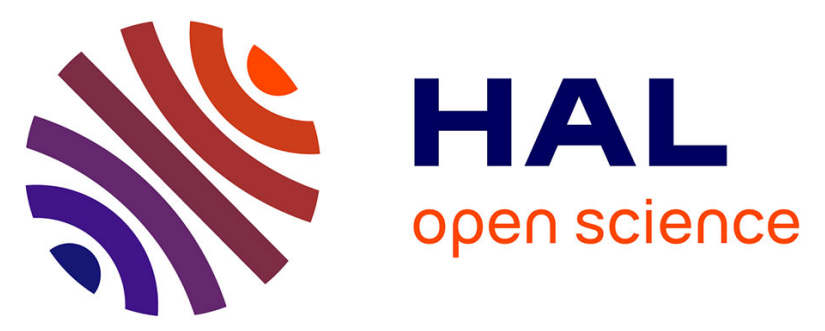

\title{
The update of the line positions and intensities in the line list of carbon dioxide for the HITRAN2020 spectroscopic database
}

E.V. Karlovets, I.E. Gordon, L.S. Rothman, R. Hashemi, R.J. Hargreaves, G.C. Toon, A. Campargue, V.I. Perevalov, P. Čermák, M. Birk, et al.

\section{To cite this version:}

E.V. Karlovets, I.E. Gordon, L.S. Rothman, R. Hashemi, R.J. Hargreaves, et al.. The update of the line positions and intensities in the line list of carbon dioxide for the HITRAN2020 spectroscopic database. Journal of Quantitative Spectroscopy and Radiative Transfer, 2021, 276, pp.107896. 10.1016/j.jqsrt.2021.107896 . hal-03433127

\section{HAL Id: hal-03433127 \\ https://hal.science/hal-03433127}

Submitted on 17 Nov 2021

HAL is a multi-disciplinary open access archive for the deposit and dissemination of scientific research documents, whether they are published or not. The documents may come from teaching and research institutions in France or abroad, or from public or private research centers.
L'archive ouverte pluridisciplinaire HAL, est destinée au dépôt et à la diffusion de documents scientifiques de niveau recherche, publiés ou non, émanant des établissements d'enseignement et de recherche français ou étrangers, des laboratoires publics ou privés. 


\section{Journal of Quantitative Spectroscopy and Radiative Transfer The update of the line positions and intensities in the line list of carbon dioxide for the HITRAN2020 spectroscopic database \\ --Manuscript Draft--}

\begin{tabular}{|c|c|}
\hline \multicolumn{2}{|l|}{ Manuscript Number: } \\
\hline Article Type: & VSI:HITRAN2020 \\
\hline Keywords: & $\begin{array}{l}\text { Carbon dioxide; CO2 line lists; HITRAN database; HITRAN2020; spectroscopic line } \\
\text { parameters }\end{array}$ \\
\hline Corresponding Author: & $\begin{array}{l}\text { Ekaterina Karlovets } \\
\text { Harvard-Smithsonian Center for Astrophysics } \\
\text { Cambridge, MA United States }\end{array}$ \\
\hline First Author: & E.V. Karlovets \\
\hline \multirow[t]{14}{*}{ Order of Authors: } & E.V. Karlovets \\
\hline & I.E. Gordon \\
\hline & L.S. Rothman \\
\hline & R. Hashemi \\
\hline & R.J. Hargreaves \\
\hline & G.C. Toon \\
\hline & A. Campargue \\
\hline & V.I. Perevalov \\
\hline & P. Čermák \\
\hline & M. Birk \\
\hline & G. Wagner \\
\hline & J.T. Hodges \\
\hline & J. Tennyson \\
\hline & S.N. Yurchenko \\
\hline Abstract: & $\begin{array}{l}\text { This paper describes the updates of the line positions and intensities for the carbon } \\
\text { dioxide transitions in the } 2020 \text { edition of the HITRAN spectroscopic database. The new } \\
\text { line list for all } 12 \text { naturally abundant isotopologues of carbon dioxide replaces the } \\
\text { previous one from the HITRAN2016 edition. This update is primarily motivated by } \\
\text { several issues related to deficient HITRAN2016 line positions and intensities that have } \\
\text { been identified from laboratory and atmospheric spectra. Critical validation tests for the } \\
\text { spectroscopic data were carried out to find problems caused by inaccuracies in CO2 } \\
\text { line parameters. New sources of data were selected for the bands that were deemed } \\
\text { problematic in the HITRAN2016 edition. Extra care was taken to retain the consistency } \\
\text { in the data sources within the bands. The comparisons with the existing theoretical and } \\
\text { semi-empirical databases (including ExoMol, NASA Ames, and CDSD-296) and with } \\
\text { available experimental works were carried out. The HITRAN2020 database has been } \\
\text { extended by including additional CO2 bands above } 8000 \mathrm{~cm}-1 \text {, and magnetic dipole } \\
\text { lines of CO2 were introduced in HITRAN for the first time by including the v2+v3 band } \\
\text { in the 3.3- } \mu \text { m region. Although the main topic of this article are line positions and } \\
\text { intensities, for consistency a recent algorithm for the line-shape parameters proposed } \\
\text { in Hashemi et al. JQSRT (2020) was reapplied (after minor revisions) to the line list. }\end{array}$ \\
\hline \multirow[t]{3}{*}{ Suggested Reviewers: } & $\begin{array}{l}\text { Yan Tan } \\
\text { tanyan@ustc.edu.cn }\end{array}$ \\
\hline & $\begin{array}{l}\text { Livio Gianfrani } \\
\text { livio.gianfrani@unicampania.it }\end{array}$ \\
\hline & Keyoon Sung \\
\hline
\end{tabular}


Keeyoon.Sung@jpl.nasa.gov

Powered by Editorial Manager ${ }^{\circledR}$ and ProduXion Manager ${ }^{\circledR}$ from Aries Systems Corporation 


\section{Highlights}

- The new HITRAN2020 line list for all 12 naturally abundant isotopologues of carbon dioxide replaces the previous one from the HITRAN2016 edition;

- Evaluation of the HITRAN $\mathrm{CO}_{2}$ line lists by comparison to laboratory and atmospheric spectra below $8310 \mathrm{~cm}^{-1}$ was carried out;

- The updates made for the bands having mixed CDSD and UCL-IAO line intensities in the HITRAN2016 line list below $8000 \mathrm{~cm}^{-1}$ are presented;

- The $\mathrm{CO}_{2}$ bands in the (1.4-2.1) $\mu \mathrm{m}$ region were improved;

- New $\mathrm{CO}_{2}$ bands above $8000 \mathrm{~cm}^{-1}$ were added to the HITRAN2020 edition from the new hightemperature UCL-4000 ${ }^{12} \mathrm{C}^{16} \mathrm{O}_{2}$ line list (ExoMol database) and the CRDS spectra for the ${ }^{16} \mathrm{O}^{12} \mathrm{C}^{18} \mathrm{O}$ isotopologue;

- The magnetic dipole 01111-00001 band of the ${ }^{12} \mathrm{C}^{16} \mathrm{O}_{2}$ isotopologue in the $3.3 \mu \mathrm{m}$ region was introduced into HITRAN for the first time; 


\section{The update of the line positions and intensities in the line list of carbon dioxide for the HITRAN2020 spectroscopic database}

2

33 Number of pages: 44

34 Number of tables: 2

* Corresponding author:

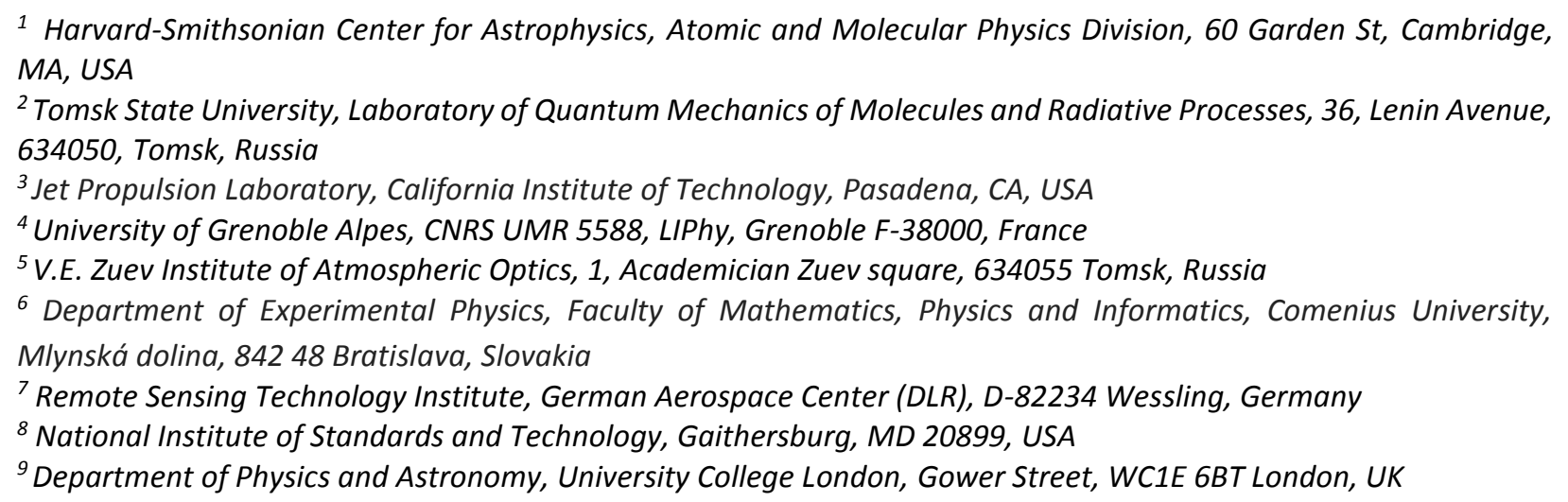

Key words: Carbon dioxide; $\mathrm{CO}_{2}$ line lists; HITRAN; spectroscopic line parameters.

E-mails: ekarlovets@gmail.com (E.V.Karlovets), igordon@cfa.harvard.edu (I.E.Gordon) 
Abstract

This paper describes the updates of the line positions and intensities for the carbon 44 dioxide transitions in the 2020 edition of the HITRAN spectroscopic database. The new line list 45 for all 12 naturally abundant isotopologues of carbon dioxide replaces the previous one from the 46 HITRAN2016 edition. This update is primarily motivated by several issues related to deficient 47 HITRAN2016 line positions and intensities that have been identified from laboratory and 48 atmospheric spectra. Critical validation tests for the spectroscopic data were carried out to find problems caused by inaccuracies in $\mathrm{CO}_{2}$ line parameters. New sources of data were selected for the bands that were deemed problematic in the HITRAN2016 edition. Extra care was taken to retain the consistency in the data sources within the bands. The comparisons with the existing theoretical and semi-empirical databases (including ExoMol, NASA Ames, and CDSD-296) and with available experimental works were carried out. The HITRAN2020 database has been extended by including additional $\mathrm{CO}_{2}$ bands above $8000 \mathrm{~cm}^{-1}$, and magnetic dipole lines of $\mathrm{CO}_{2}$ were introduced in HITRAN for the first time by including the $v_{2}+v_{3}$ band in the 3.3- $\mu \mathrm{m}$ region. Although the main topic of this article are line positions and intensities, for consistency a recent algorithm for the line-shape parameters proposed in Hashemi et al. JQSRT (2020) was reapplied (after minor revisions) to the line list. spectroscopic parameters of carbon dioxide $\left(\mathrm{CO}_{2}\right)$ transitions. Atmospheric $\mathrm{CO}_{2}$ is the key gaseous contributor to the greenhouse effect in the terrestrial atmosphere. Its continuous increase in the atmosphere over the last two centuries from anthropogenic sources is considered the principal driver of climate change. The Martian and Venusian (and those of many rocky exoplanets) atmospheres consist mostly of carbon dioxide with mole fractions of over $95 \%$.

67 Monitoring $\mathrm{CO}_{2}$ is important in combustion. Currently, there are several satellite-based observatories, including GOSAT[1-3] , GOSAT-2 [4] , OCO-2 [5,6] , OCO-3 [7], MIPAS [8], and ACE [9] as well as ground-based networks TCCON [10] and NDACC [11], monitoring atmospheric $\mathrm{CO}_{2}$. 
71 regarding controlling of the anthropogenic contribution to the greenhouse effect and ultimately

72 the climate change. All aforementioned $\mathrm{CO}_{2}$ remote sensing activities depend on the reliability

73 of the reference $\mathrm{CO}_{2}$ spectroscopy.

74 The HITRAN molecular spectroscopic database is the widely recognized standard 75 providing the spectroscopic data for atmospheric applications. Among many other molecules, it 76 includes the necessary calculated and experimental parameters for all naturally abundant 77 isotopologues of carbon dioxide. The HITRAN2016 [12] $\mathrm{CO}_{2}$ line list for 12 stable isotopologues contains 559874 transitions. Most of the issues related to spectral completeness (at least below $798000 \mathrm{~cm}^{-1}$ ) and insufficient accuracy of line parameters were resolved in HITRAN2016 [12]. 80 However, there is still a lot of room for improvement to meet the ever-increasing demands of 81 the scientific community. Since the release of the HITRAN2016 database[12] ,many new 82 experimental and theoretical data have become available, and they can be used as sources for 83 improving line positions, line intensities, and line-shape parameters of $\mathrm{CO}_{2}$. The HITRAN-related 84 updates, including the $\mathrm{CO}_{2}$-air and $\mathrm{CO}_{2}-\mathrm{CO}_{2}$ line-shape parameters together with the speed 85 dependence of the broadening parameters, their temperature-dependent exponents, the full 86 and first-order line mixing as well as their temperature dependencies have been published in 87 Hashemi et al. [13]. In the present work, we will mainly focus on the issues associated with deficiencies in line positions and intensities in HITRAN2016. Most of these problematic cases have been identified in new laboratory and atmospheric spectra, mainly from the Kitt Peak National Observatory, 91 MkIV balloon, cavity ring down spectroscopy (CRDS) measurements, and the Total Carbon 92 Column Observing Network (TCCON) [10,14-16]. A general review of the $\mathrm{CO}_{2}$ bands affected by 93 these issues was performed and alternative sources of data for each $\mathrm{CO}_{2}$ problematic band were 94 considered. Apart from new experimental data, the additional resources for improvements were 95 provided by two recent comprehensive $\mathrm{CO}_{2}$ line lists, namely the 2019 version of the semi96 empirical CDSD-296 [17] list and the ExoMol variational nuclear motion line list [18], hereafter 97 referred to as UCL-4000 Using these spectroscopic data, we improved and extended the $\mathrm{CO}_{2}$ line 98 lists for all 12 stable isotopologues of carbon dioxide. 
The updates of the line positions, intensities, and line-shape parameters were incorporated into the carbon dioxide line list of the 2020 edition of the HITRAN spectroscopic database [16]. The remainder of this paper is organized as follows. In Section 2, we present an overview of $\mathrm{CO}_{2}$ line lists in the HITRAN2016, ExoMol, Ames, and CDSD-296 spectroscopic databases. In Section 3, we describe evaluations of the HITRAN $\mathrm{CO}_{2}$ line list based on laboratory and atmospheric measurements between 670 and $8310 \mathrm{~cm}^{-1}$. For wavenumbers below $8000 \mathrm{~cm}^{-}$ ${ }^{1}$, we discuss line intensity updates to the HITRAN2016 line list for bands provided by the Carbon Dioxide Spectroscopic Databank (CDSD) based on global fits of semi-empirical models to measurements and those obtained by the ab initio calculations of University College London (UCL). In Section 4, we discuss new measurements with sub-percent relative uncertainty [19-22] that were used to improve some $\mathrm{CO}_{2}$ bands in the 1.4 to $2.1-\mu \mathrm{m}$ region. In Section 5, we present new $\mathrm{CO}_{2}$ bands above $8000 \mathrm{~cm}^{-1}$ that have been included in the HITRAN2020 edition from the latest high-temperature line list of the ExoMol [18] database (with appropriate cut-off) for the main $\mathrm{CO}_{2}$ isotopologue and the CRDS spectra [14] for the ${ }^{16} \mathrm{O}^{12} \mathrm{C}^{18} \mathrm{O}$ isotopologue. The line parameters of the $\mathrm{v}_{2}+\mathrm{v}_{3}$ magnetic dipole band of the ${ }^{12} \mathrm{C}^{16} \mathrm{O}_{2}$ isotopologue, which have been introduced into HITRAN for the first time, will be presented in Section 6. The revision which updates the air- and self-broadened line-shape parameters of $\mathrm{CO}_{2}$, described in Ref. [13], will be discussed in Section 7. The presentation of the final version of the HITRAN2020 $\mathrm{CO}_{2}$ line list will be given in Section 8, followed by closing discussion and conclusions in Section 9.

\section{Review of the current carbon dioxide line lists}

The present section describes the status of the most currently used spectroscopic databases of carbon dioxide: HITRAN2016 [12], NASA Ames [23], and the recent ExoMol [18] and CDSD-296 [17] line lists. New laboratory and atmospheric spectra helped to expose several problems in the HITRAN2016 $\mathrm{CO}_{2}$ line list occurring in various spectral regions (for more details, see Section 3). The CDSD-296, ExoMol, and NASA Ames line lists were used to update, extend or improve the line positions and intensities, including a number of problematic bands, in the 2020 version of the HITRAN spectroscopic database [24]. 
The $\mathrm{CO}_{2}$ line list for the 12 stable isotopologues in the 2016 version of HITRAN [12] contained $559874 \mathrm{CO}_{2}$ transitions and covered the wavenumber range of $0.757-14075.298 \mathrm{~cm}^{-1}$.

129 The HITRAN2016 data for the ${ }^{14} \mathrm{C}^{16} \mathrm{O}_{2}$ radioactive isotopologue in HITRAN2016 were provided as 130 static files rather than through the relational-database structure featured in HITRANonline [25]

131 . The HITRAN2016 carbon dioxide line list, below $8000 \mathrm{~cm}^{-1}$, comprised CDSD line positions [26] 132 and $a b$ initio line intensities from UCL [27-29] except for the bands that were identified as 133 "sensitive"[27], where CDSD (circa 2015) intensity values were preferred. Most of the line 134 parameters for wavenumbers in the region above $8000 \mathrm{~cm}^{-1}$ were taken from the 2015 version 135 of the CDSD-296 database [26]. An extended and improved version of the CDSD for atmospheric 136 applications (CDSD-296) was published in 2019 [17]. This database contains a computed line list 137 based on global modelling of the line positions and intensities using the method of effective 138 operators $[30,31]$. The global model of the $\mathrm{CO}_{2}$ absorption spectrum is a polyad model with a 139 block diagonal structure, each polyad being characterized by the polyad number $P=2 V_{1}+V_{2}+3 V_{3}$ 140 (where $V_{i}$ are the vibrational quantum numbers). For each $\mathrm{CO}_{2}$ isotopologue, the effective 141 Hamiltonians and effective dipole moment parameters were fitted to measured line positions 142 and intensities, respectively. More than 530000 spectral lines for the 12 stable isotopologues of $143 \mathrm{CO}_{2}$ covering the $345-14075 \mathrm{~cm}^{-1}$ spectral range were included in this database. The reference 144 temperature is $296 \mathrm{~K}$, and the intensity cut-off is $10^{-30} \mathrm{~cm} /$ molecule. A comparison between the 145 line positions of common lines from the HITRAN2016 and CDSD-296 [17] databases versus 146 wavenumber in the $0-14075 \mathrm{~cm}^{-1}$ spectral region is presented in Fig. 1 . This plot shows the good 147 agreement between the line positions from HITRAN2016 (mostly based on the previous CDSD 148 version [26]) and those from the new version of the CDSD-296 [17]. As a result, most of the line 149 positions for the $12 \mathrm{CO}_{2}$ isotopologues between 345 and $14075 \mathrm{~cm}^{-1}$ in HITRAN2020 have been 150 updated using the CDSD-296 [17] line positions. It should be noted that the slightly updated 151 version of the CDSD-296 database (uploaded at ftp.iao.ru as pub/CDSD-296/cdsd152 296_version_1.rar) was used. This version differs from the CDSD-296 published in Tashkun et al. 153 [17] in the following ways: (i) the $\Delta P=6$ region of the ${ }^{16} \mathrm{O}^{12} \mathrm{C}^{18} \mathrm{O}$ isotopologue was recalculated 154 using the new set of effective dipole moment parameters; (ii) a total of 226 lines with vibrational 155 quantum number $\Delta / 2=4$ of the ${ }^{12} \mathrm{C}^{16} \mathrm{O}_{2},{ }^{13} \mathrm{C}^{16} \mathrm{O}_{2}$, and ${ }^{16} \mathrm{O}^{12} \mathrm{C}^{18} \mathrm{O}$ isotopologues were added. The 
156 lower-state energies and the uncertainty codes were also transferred from the CDSD-296 line list 157 to the HITRAN2020 line list.

158 The recent high-temperature line list from the ExoMol database (named UCL-4000) for 159 the main isotopologue of $\mathrm{CO}_{2}\left({ }^{12} \mathrm{C}^{16} \mathrm{O}_{2}\right)$ was published in Yurchenko et al. [15]. This line list 160 contains almost $2.5 \times 10^{9}$ transitions involving about $3.5 \times 10^{6}$ states. The wavenumber range of the $161 \mathrm{CO}_{2}$ list is from 0 to $20000 \mathrm{~cm}^{-1}$ with the lower-state energies up to $16000 \mathrm{~cm}^{-1}$ and $J \leq 202$. These 162 results were generated using UCL's ab initio dipole moment surface (DMS) [32] and the semi163 empirical potential energy surface (PES) Ames-2 [22] with the variational program TROVE [33]. 164 The UCL-4000 line list was converted to HITRAN format and compared with the HITRAN2016 line 165 list. As a result, more than 3600 spectral lines above $8000 \mathrm{~cm}^{-1}$ were added to the HITRAN2020 166 spectroscopic database [24] (see Section 5).

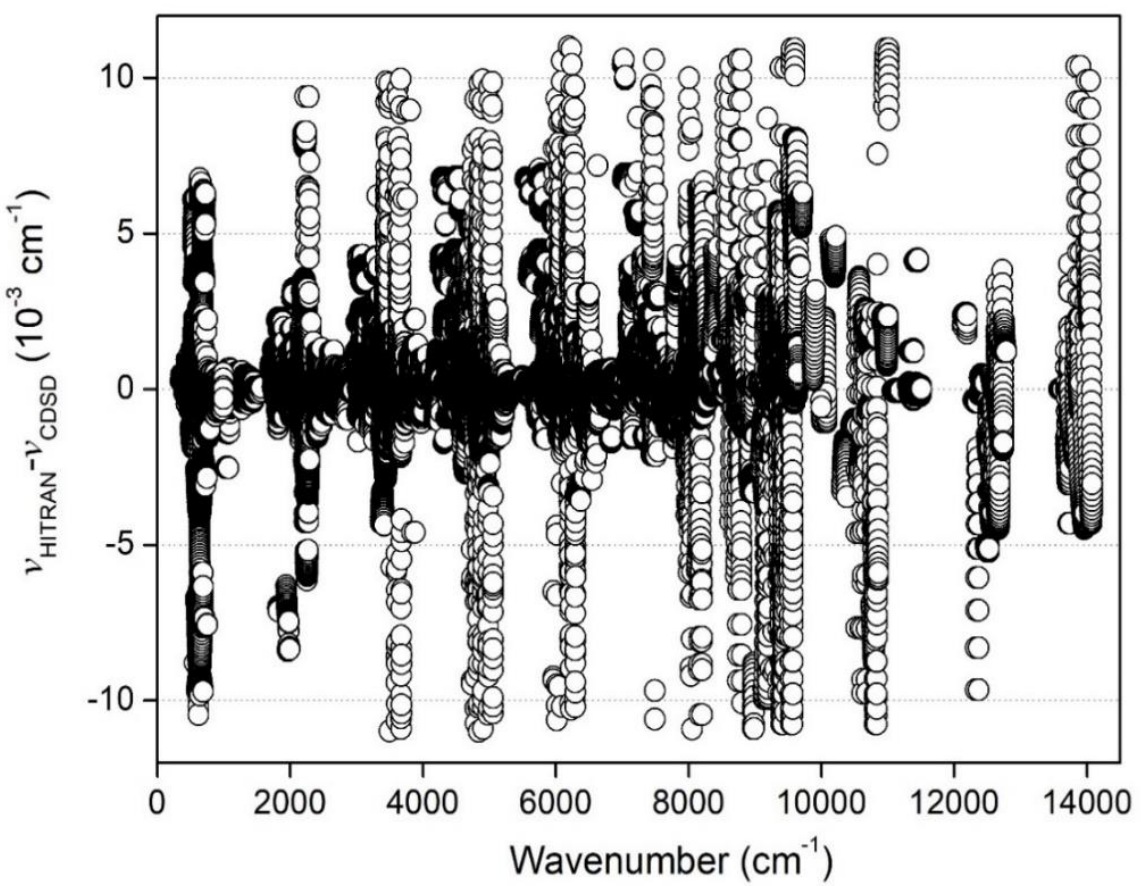

181

182 183 184
Fig. 1. Differences between the line positions from the HITRAN2016 [12] and CDSD-296 [17] databases. 
The NASA Ames line lists for $13 \mathrm{CO}_{2}$ isotopologues were published by Huang et al. [23]. They were computed at $296 \mathrm{~K}$ using the empirically refined Ames- 2 potential energy surface and

187 pure $a b$ initio DMS-2 dipole moment surface with $J \leq 150$ and the lower-state energy up to 24000 $\mathrm{cm}^{-1}$. Critical validation tests of the available spectroscopic data were carried out using the existing theoretical and semi-empirical databases, including ExoMol, NASA Ames, and CDSD-296 $[17,18,23]$ and with published experimental works [14,34-42] .

Accordingly, the present work allowed revealing some problems with the HITRAN2016 $\mathrm{CO}_{2}$ line list and thus allowed improving and extending the line lists for all 12 stable isotopologues in the final version of the HITRAN2020 $\mathrm{CO}_{2}$ line list.

In this section, we present the general review of problematic bands identified in new laboratory and atmospheric spectra, mainly those obtained from the Kitt Peak National Observatory, MkIV balloon, CRDS, and TCCON [10,14-16]. Most of the issues have been associated with deficient line positions and intensities for which critical validation tests were performed and alternative sources of data for each problematic band were suggested.

Several $\mathrm{CO}_{2}$ line lists, including HITRAN 2008 [43], HITRAN2012 [44], and HITRAN2016 [12], were evaluated by fitting laboratory (mainly Kitt Peak) and atmospheric solar absorption spectra (MkIV and TCCON) between 670 and $8310 \mathrm{~cm}^{-1}[15,16]$. The studied region was divided into several windows, most encompassing at least one complete $\mathrm{CO}_{2}$ absorption band or a subbranch. The GFIT spectral fitting algorithm [45] was used in all cases assuming a Voigt line profile and no line mixing. The line lists were evaluated in terms of the RMS fitting residuals and the window-to-window consistency of the retrieved gas amounts. There was no analysis of the separate isotopologues. The results showed progressive overall RMS fit improvements through use of each successive HITRAN version. This analysis showed that the HITRAN2O20 $\mathrm{CO}_{2}$ line list is

210 substantially better than all previous HITRAN versions. In particular, in HITRAN2016, there were

211 a few regions where it is worse than a previous version in terms of RMS fitting residuals (around $2121800 \mathrm{~cm}^{-1}, 4800 \mathrm{~cm}^{-1}$, and $6400 \mathrm{~cm}^{-1}$ ). As an example, Fig. 2 shows the absolute RMS residuals of 213 the fits for 41 windows averaged over the 137 Kitt Peak and 12 JPL laboratory spectra in the 670- 
$2148310 \mathrm{~cm}^{-1}$ spectral region. The pressure range is from $0.013 \mathrm{kPa}-93 \mathrm{kPa}$ (0.1 Torr to 700 Torr)

215 except for 2 Kitt Peak spectra (1.71 kPa and $1.89 \mathrm{kPa}$ ) covering 600-1400 $\mathrm{cm}^{-1}$. However, in this

216 plot, the HITRAN2020 line_list gives worse fits in the $3730 \mathrm{~cm}^{-1}$ window in Kitt Peak lab spectra

217 than most previous line lists. This is due to the SBHWs being too small in this region (the Kit Peak

218 lab spectra include some with 200 Torr of pure $\mathrm{CO}_{2}$ ). This SBHW issue has no affect on fits to

219 atmospheric spectra. The large discrepancies were also identified in the $4800 \mathrm{~cm}^{-1}$ regions, where

220 the HITRAN2016 line list was worse than previous editions in terms of RMS fitting residuals. The

221 same situation in this region was observed in the MkIV balloon spectra (low pressure). The Kitt

222 Peak laboratory spectrum revealed rotationally-dependent errors at the $10-15 \%$ level in the $a b$

223 initio intensities for the $40002-01101$ band of the ${ }^{12} \mathrm{C}^{16} \mathrm{O}_{2}$ isotopologue. Fits to a Kitt Peak

224 laboratory spectrum in the $4800 \mathrm{~cm}^{-1}$ region and zooms into four large residuals are presented

225 in Fig.3. Also, it was shown that the scatter factor of the 40002-01101 band is slightly elevated

226 (1.4 to 1.7). In addition to that, for low $J$, around $J=1$ to 3 , there is a visible spike in the scatter

227 factor, which suggests a J-localized resonance. Indeed, by analyzing predictions within the

228 effective operator model [30], it was found that the 40002 and 21113 vibrational levels of the $P=$

2298 polyads are interacting through a Coriolis interaction. This interaction causes systematic 230 problems with the $a b$ initio intensities [27] for the transitions involving either of these two 231 vibrational states. 
232

233

234

235

236

237

238
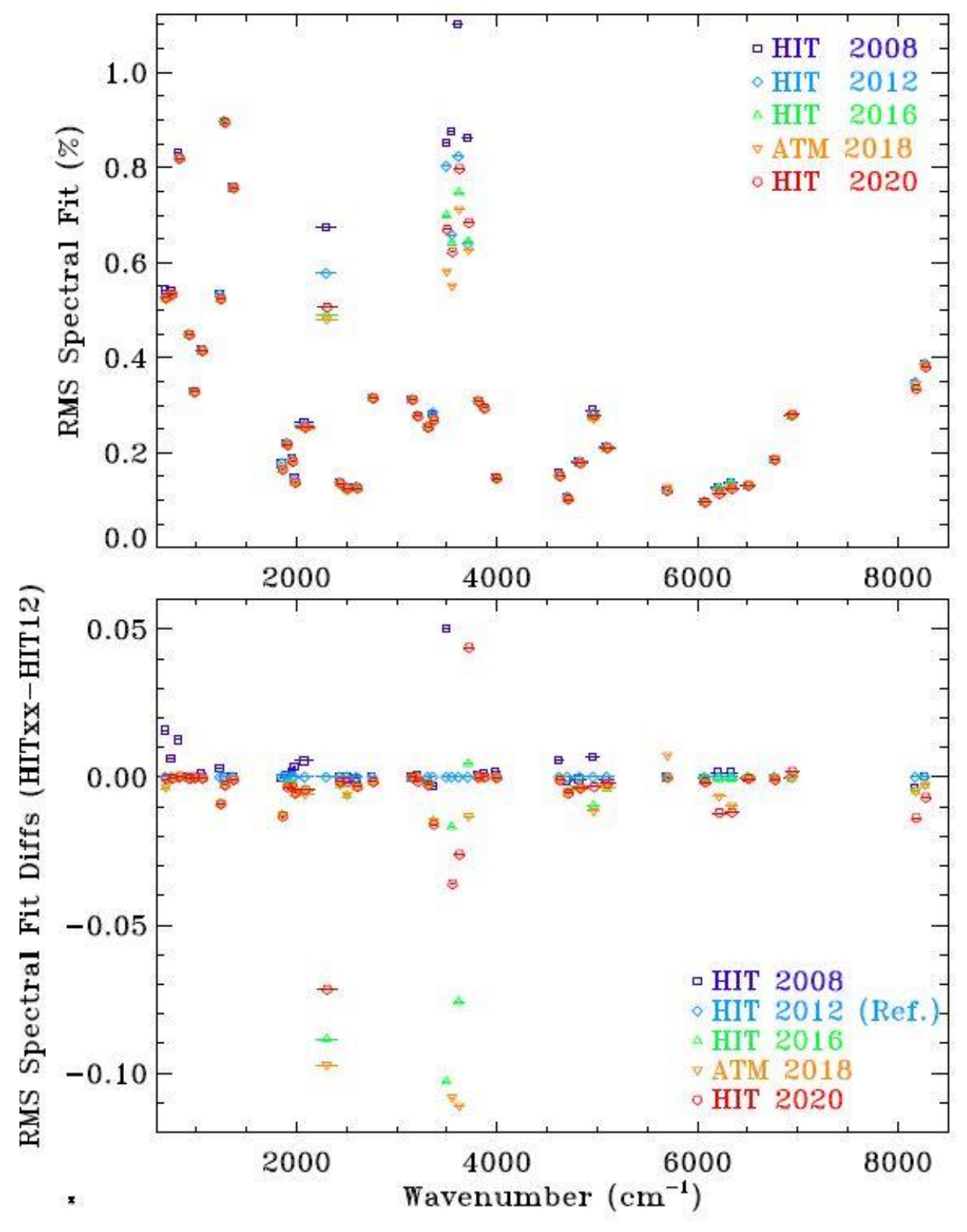

Fig. 2. The upper panel shows the absolute value of the mean $R M S$ fit for 5 different $\mathrm{CO}_{2}$ line lists: HIT2008: HITRAN2008 [43]; HIT2012: HITRAN2012 [44], HIT2016: HITRAN2016[12], ATM2018: $523230 \mathrm{CO}_{2}$ lines [15], HIT2020: HITRAN2020 [24]. The lower panel shows the differences from HITRAN2012 [44]. 


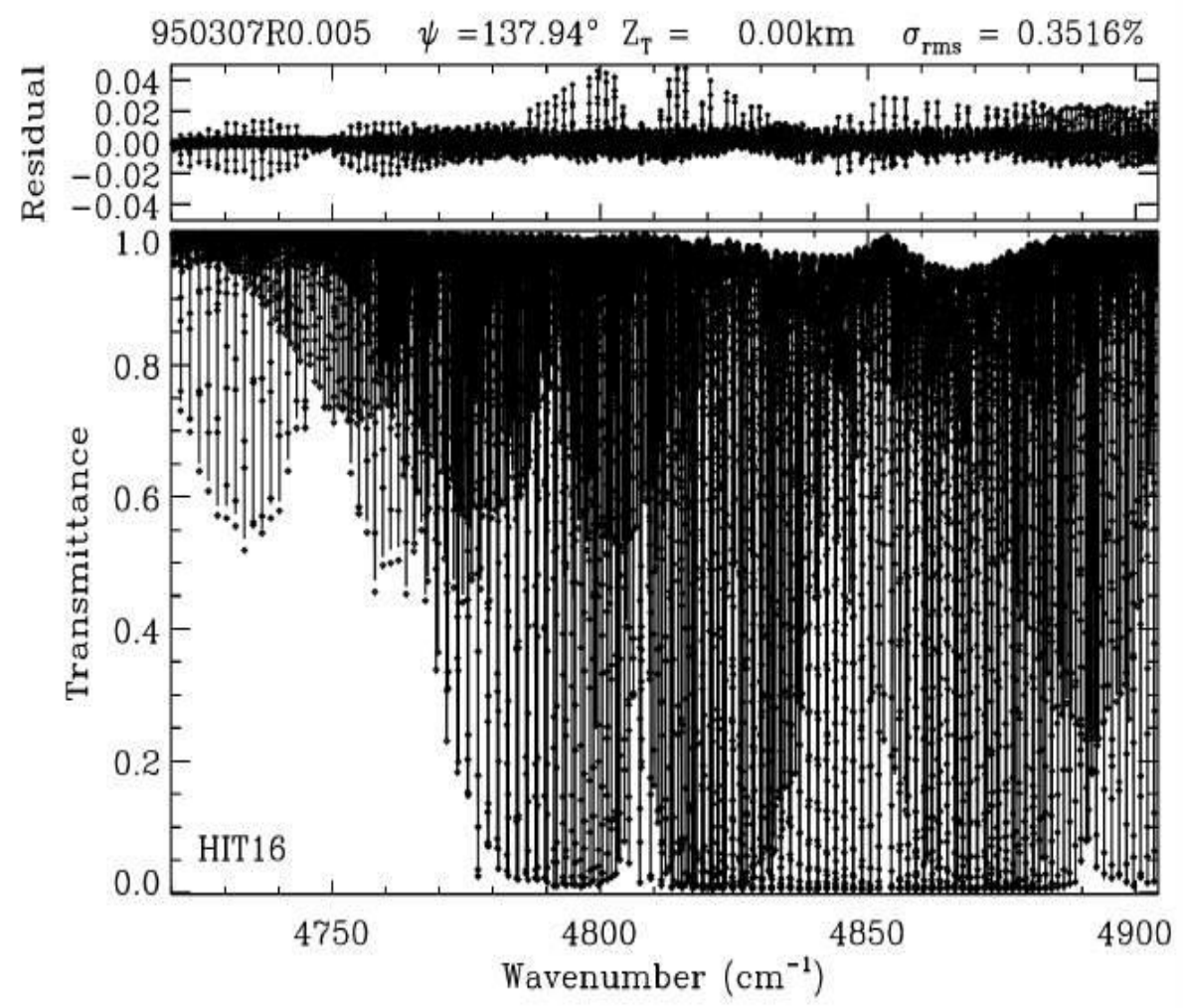
240 Fig.3. The fits to a Kitt Peak laboratory spectrum in the $4800 \mathrm{~cm}^{-1}$ region using the HITRAN2016
241 linelist [12]. The positive residuals arise from the $40002-01101$ band of the ${ }^{12} \mathrm{C}^{16} \mathrm{O}_{2}$ isotopologue.

For the HITRAN2016 CO 2 line list, there are 24 bands involving the 40002 and 21113 244 vibrational levels affected by Coriolis interaction. To quantify the impact of this perturbation on 245 intensities, validation tests for the $40002-01101,21113-01101$, and $21113-11102$ bands of 246 the ${ }^{12} \mathrm{C}^{16} \mathrm{O}_{2}$ isotopologue were carried out using the published experimental values [34,35] and 247 data from the various carbon dioxide spectroscopic databases [12,17,23] (Fig. 4). This comparison 248 showed that the CDSD-296 line intensities [17] are preferable for the $40002-01101$ and 21113 24911102 bands whereas, in the case of the 21113-01101 band, the ab initio intensities from AMES 250 [23] are the best choice. However, because of the lack of measurements we could not make 251 similar comparisons for the numerous remaining bands affected by these Coriolis interactions. 252 We hope that new experimental data will become available for further validation tests of bands 253 involving the 40002 and 21113 vibrational levels. 


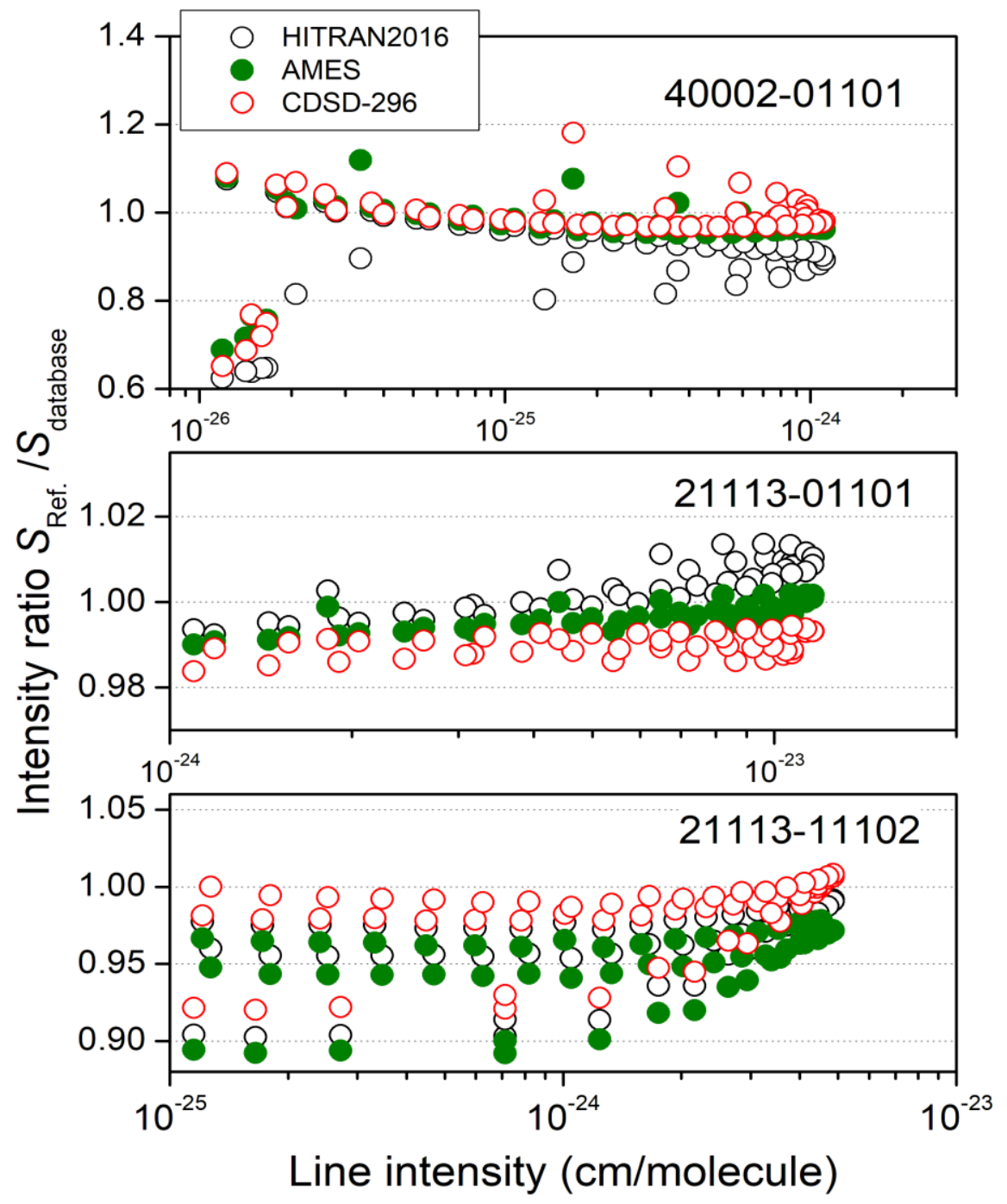

Fig.4. Ratio of the experimental line intensities of the $40002-01101,21113-01101$, and 21113 - 11102 bands (centers: $4808 \mathrm{~cm}^{-1}, 4809 \mathrm{~cm}^{-1}$, and $3544 \mathrm{~cm}^{-1}$, respectively) from Refs [34,35] to those from the various $\mathrm{CO}_{2}$ spectroscopic databases $[12,17,23]$.

283 HITRAN2016 database produces $\mathrm{CO}_{2}$ retrieved amounts that are $5 \%$ larger than those based on 284 previous line lists. The VMR Scale Factors (VSF) obtained by averaging each retrieved single285 spectrum VFS value over all 19 MkIV balloon spectra that were fitted for each window are plotted versus wavenumber in Fig. 5. The MkIV instrument simultaneously records the region $600 \mathrm{~cm}^{-1}$ 
to $5650 \mathrm{~cm}^{-1}$, so derived VSFs should have good window-to-window consistency. The upper circle indicates anomalously high HITRAN2016 values in the $1800-2000 \mathrm{~cm}^{-1}$ spectral region corroborating observation in laboratory spectra.

291

292

293

294

295

296

297

298

299

300

301

302

303

304

305

306

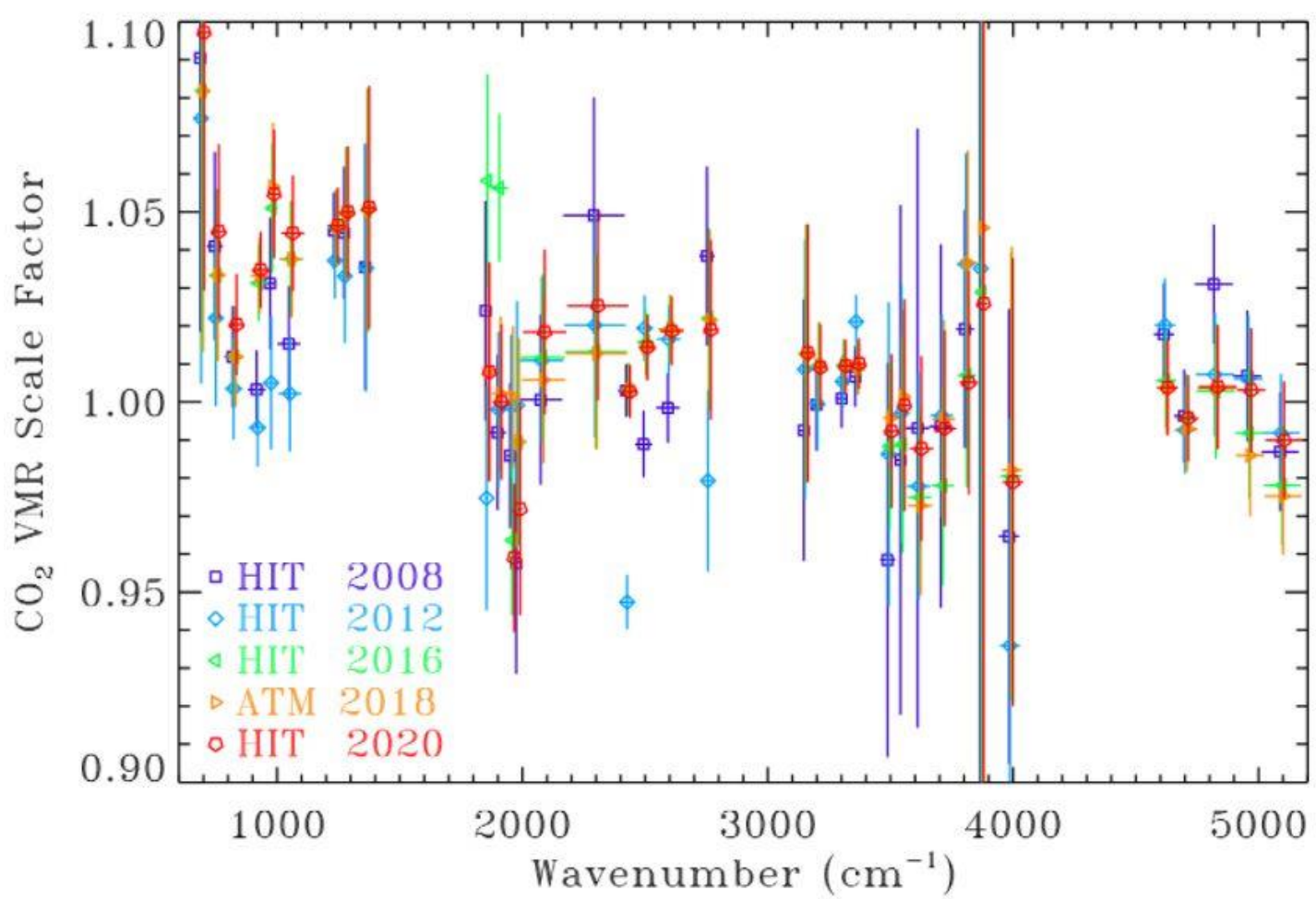

Fig.5. The VMR Scale Factors (VSF) obtained by averaging each retrieved single-spectrum VFS value over all 19 MkIV balloon spectra that were fitted for each window. The measured VSF values are plotted versus wavenumber. See the designations of the databases in the caption of Fig. 2.

It was found that the most significant deviations in this region correspond to the 11102 00001 band near $1933 \mathrm{~cm}^{-1}$. The $11101-00001$ and $11102-00001$ bands borrow intensities from the strong 00011 - 00001 band via Coriolis interaction. It was shown in Ref. [17] that the ab initio AMES line intensities [23] for the 11101 - 00001 band deviate considerably from the observations. A comparison of the 11102 - 00001 line intensities with the published measurements $[36,37]$ and the different $\mathrm{CO}_{2}$ databases $[12,17,23]$ for the ${ }^{12} \mathrm{C}^{16} \mathrm{O}_{2},{ }^{13} \mathrm{C}^{16} \mathrm{O}_{2}$, and ${ }^{16} \mathrm{O}^{12} \mathrm{C}^{18} \mathrm{O}$ isotopologues is presented in Fig. 6. Replacement of line intensities of the $\mathrm{CO}_{2}$ bands considered in the HITRAN2016 database with CDSD-296 [17] rectifies the above-mentioned discrepancy in the $1800-2000 \mathrm{~cm}^{-1}$ region. For consistency, the line intensities of the 11101 - 
00001 band for other $\mathrm{CO}_{2}$ isotopologues were also replaced by the intensities from the CDSD database in the HITRAN2020 line list. The 20003-01101 and 12202-01101 hot bands of ${ }^{12} \mathrm{C}^{16} \mathrm{O}_{2}$ located near $1900 \mathrm{~cm}^{-1}$ were also increased by $5 \%$ to match the ATM values [15]. The intensity origin for these bands in HITRAN2016: 20003-01101 - UCL ab initio [27] and 12202-01101 - UCL $a b$ initio and CDSD2015 [26,27]. Also, the comparison of the ATM and CDSD2019 line intensities

312 showed a deviation up to $30 \%$ for the $20003-01101$ band of the ${ }^{12} \mathrm{C}^{16} \mathrm{O}_{2}$ isotopologue.

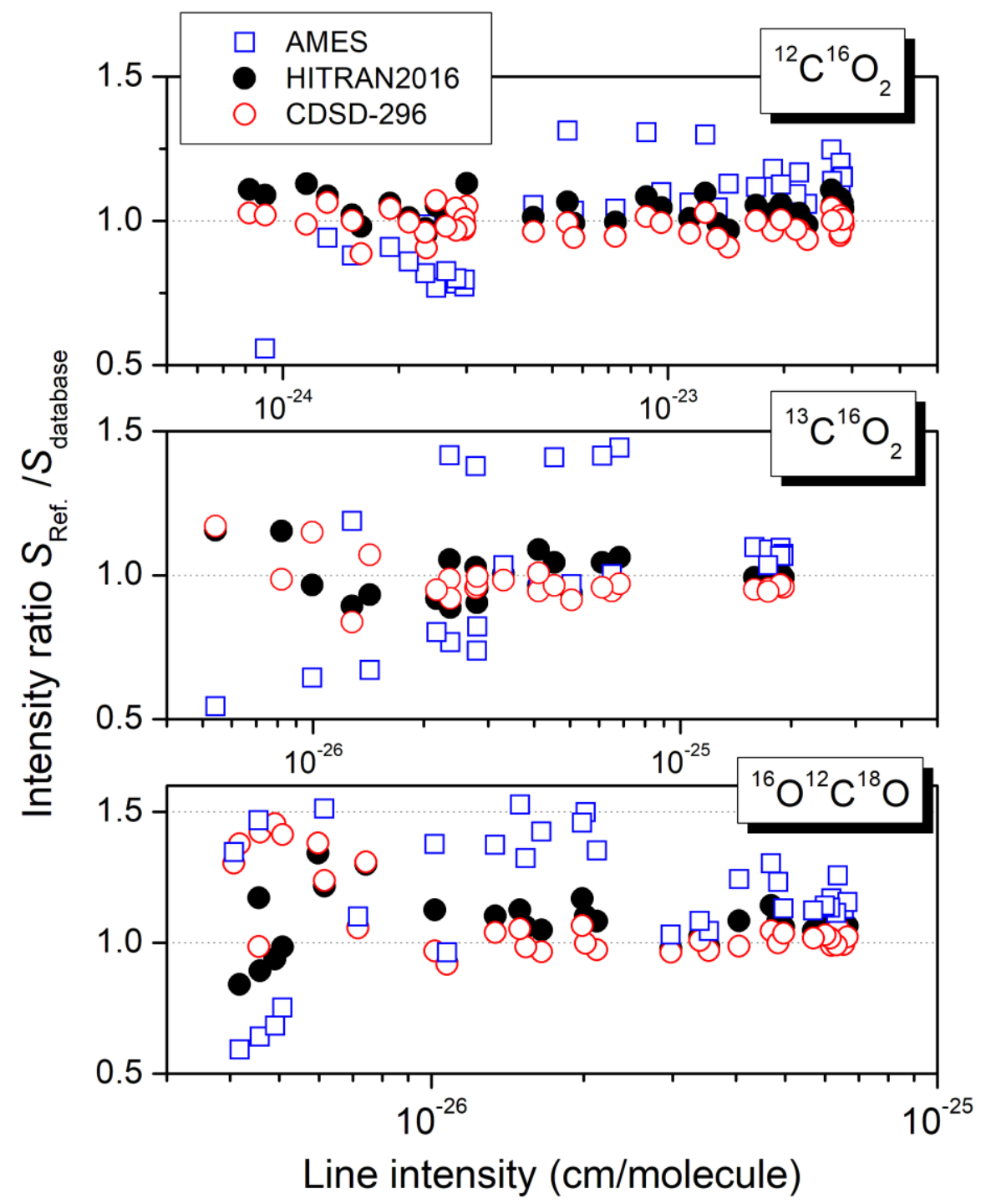

314

315

316

317
Fig. 6. The comparison of line intensities between the published measurements from Refs [36,37] and the different $\mathrm{CO}_{2}$ databases $[12,17,23]$ for the $11102-00001$ bands of the ${ }^{12} \mathrm{C}^{16} \mathrm{O}_{2},{ }^{13} \mathrm{C}^{16} \mathrm{O}_{2}$, and ${ }^{16} \mathrm{O}^{12} \mathrm{C}^{18} \mathrm{O}$ isotopologues with centers: $1933 \mathrm{~cm}^{-1}, 1897 \mathrm{~cm}^{-1}$, and $1903 \mathrm{~cm}^{-1}$, respectively. 
The TCCON observations considered here cover the 3950 to $9500 \mathrm{~cm}^{-1}$ spectral region.

320 These measurements are made with a Fourier transform spectrometer with an InGaAs detector

321 and optical path difference (OPD) of $45 \mathrm{~cm}$, corresponding to a resolution of $0.02 \mathrm{~cm}^{-1}$. Use of the

322 HITRAN2016 line lists reduces the $\mathrm{CO}_{2}$ retrieved from the 6220 and $6338 \mathrm{~cm}^{-1}$ windows by $0.5 \%$

323 and $1.5 \%$ respectively, by comparison to results obtained with the other line lists, thus

324 introducing a new inconsistency of 1.5\%. TCCON CO 2 windows are circled in Fig.7. This issue is 325 associated with the 30012 - 00001 and 30013 - 00001 line parameters and is discussed in detail 326 in Section 4.

327

328

329

330

331

332

333

334

335

336

337

338

339

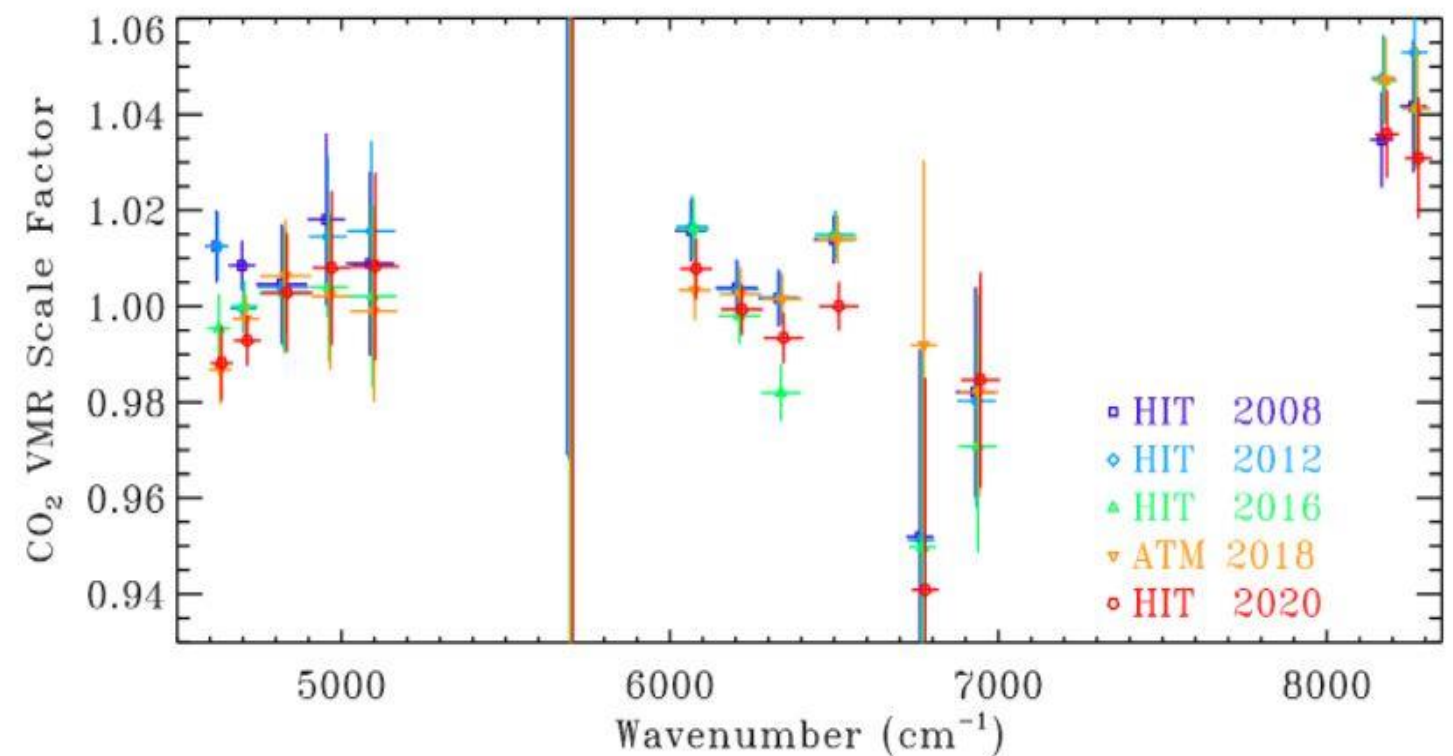

Fig.7. Retrieved VMR Scale Factors (VSF) obtained by averaging single-spectrum based on fitting each spectral window from the TCCON spectra. Results are plotted versus wavenumber. See the designations of the databases in the caption of Fig. 2.

The comparison of the fits to 136 Kitt Peak lab spectra with those modeled using the HITRAN2016 CO 2 line list shows large residuals in the 3500 and $4800 \mathrm{~cm}^{-1}$ spectral windows due to inaccuracies of line positions of the 10012-0001, 20012-00001, and 20013-00001 bands of the ${ }^{13} \mathrm{C}^{16} \mathrm{O}_{2}$ isotopologue. The comparison showed that the HITRAN2012 [44] line positions for the 20012-00001 and 20013-00001 bands led to better residuals than those of the HITRAN2016 and CDSD-296 [17] databases. As a result, the line positions of the 20012 - 00001 and $20013-00001$ bands of the ${ }^{13} \mathrm{C}^{16} \mathrm{O}_{2}$ isotopologue were replaced with the corresponding HITRAN2012 line positions into the HITRAN2020 CO 2 line list. In the case of the 10012-00001 band, we subtracted 
$3400.0009 \mathrm{~cm}^{-1}$ from the CDSD [17] line positions used for this band in HITRAN2020 to match the 341 ATM values [15].

342 Also, inaccuracies in the positions of some ${ }^{16} \mathrm{O}^{12} \mathrm{C}^{18} \mathrm{O}$ lines of the $01121-01101$ hot band 343 (P13e, P14e, P14f, Q12f, Q13e, Q13f, R11e, R12e, and R12f) were evidenced in the HITRAN2016 344 line list between 4600 and $4625 \mathrm{~cm}^{-1}$. This issue was identified by comparison with fits to Kitt 345 Peak spectra and was solved by replacing the line positions with positions from the CDSD-296 346 database [17] in the HITRAN2020 $\mathrm{CO}_{2}$ line list.

347 As mentioned above, below $8000 \mathrm{~cm}^{-1}$, most line intensities in the HITRAN2016 database 348 came from the UCL-IAO line lists [27-29] which are based on ab initio calculations. Because of 349 excessive uncertainty in the $a b$ initio line positions, the HITRAN 2016 line list is, in general, a 350 combination of the CDSD- based line positions [26] and the UCL variational line intensities [27351 29]. In the case of the so-called "sensitive bands" (as defined by Zak et al. [27-29]) ab initio 352 intensities were replaced with those from CDSD when available. This substitution resulted in 353 some cases where transitions in a given band would have intensities from both $a b$ initio 354 calculations as well as those from CDSD. Although this approach was justified in many cases, a 355 number of inconsistencies in the rotational distribution of intensities in HITRAN2016 were 356 revealed in CRDS spectra of ${ }^{18} \mathrm{O}$ and ${ }^{13} \mathrm{C}$ enriched and natural $\mathrm{CO}_{2}$ near $1.74 \mu \mathrm{m}[39,40,46]$. In 357 these works, the anomalies involve the perpendicular bands of the $\Delta P=9$ series of transitions. As 358 shown in Fig 8, the mixing of CDSD and UCL $a b$ initio intensities for the 41104-00001 bands of $359{ }^{12} \mathrm{C}^{16} \mathrm{O}_{2}$ and ${ }^{13} \mathrm{C}^{16} \mathrm{O}_{2}$ isotopologues leads to an apparent inconsistency in the rotational dependence with strong intensity variation between successive $J$ values or even missing 361 transitions. A similar situation was found in the case of the $41104-00001$ band of ${ }^{16} \mathrm{O}^{12} \mathrm{C}^{18} \mathrm{O}$ 362 isotopologue (See Fig. 9). A comparison of the measurements from Refs $[39,40,46]$ to various 363 carbon dioxide spectroscopic databases is presented in Fig. 10. As can be seen from this figure, 364 the AMES intensity values for this band are all close to the experimental ones. As a result, for 365 HITRAN2020, the AMES intensities of the $41104-00001$ bands of the ${ }^{12} \mathrm{C}^{16} \mathrm{O}_{2},{ }^{13} \mathrm{C}^{16} \mathrm{O}_{2}$, and $366{ }^{16} \mathrm{O}^{12} \mathrm{C}^{18} \mathrm{O}$ isotopologues were preferred to the mixed intensity values in the HITRAN2016 line list. 367 Similar validation tests using the values available in the literature and from the different $368 \mathrm{CO}_{2}$ databases were carried out for other bands affected by the problem due to the mixing of 
369 intensities of CDSD and $a b$ initio origin in the HITRAN line list. These bands were systematically 370 searched (see Fig. 5 of Ref.[39]), and when problems were identified, alternative sources of data

371 for each such bands were suggested. For the ${ }^{12} \mathrm{C}^{16} \mathrm{O}_{2},{ }^{13} \mathrm{C}^{16} \mathrm{O}_{2},{ }^{16} \mathrm{O}^{12} \mathrm{C}^{18} \mathrm{O}$, and ${ }^{16} \mathrm{O}^{13} \mathrm{C}^{18} \mathrm{O}$ 372 isotopologues, we present in Table 1 the set of bands that were checked and affected by this 373 issue along with the alternative intensity sources for these bands used in HITRAN2020. 374 The substitution of the suggested intensity sources for the bands presented in Table 1 was 375 performed for the corresponding bands of all the $\mathrm{CO}_{2}$ isotopologues in HITRAN2020 where 376 experimental data exists. In the absence of experimental reference data, the replacement of the 377 intensity source was performed only for the corresponding band of the specific isotopologue. In 378 the case of the 31104e-01101e and 11112e-11101e hot bands of the ${ }^{16} \mathrm{O}^{12} \mathrm{C}^{18} \mathrm{O}$ and ${ }^{13} \mathrm{C}^{16} \mathrm{O}_{2}$ 379 isotopologues, respectively (see Fig.11), we cannot offer an alternative source for replacing the 380 mixed line intensities, since there is no experimental data to verify them. Nevertheless, we kept 381 the HITRAN2016 line intensities for the 31114e-01101e band of ${ }^{16} \mathrm{O}^{12} \mathrm{C}^{18} \mathrm{O}$ isotopologue in 382 HITRAN2020. In the future we will consider using UCL $a b$ initio [28] line intensities for this band. 383 In the case of the 11112e-11101e hot band of the ${ }^{13} \mathrm{C}^{16} \mathrm{O}_{2}$ isotopologue, the UCL and CDSD-296 384 databases $[17,27]$ give similar line intensities although there is an inconsistency in the rotational 385 dependence with substantial intensity variation between successive $J$ values of the $P$ branch. 386 Validation of this band is a challenge for future experiments. 


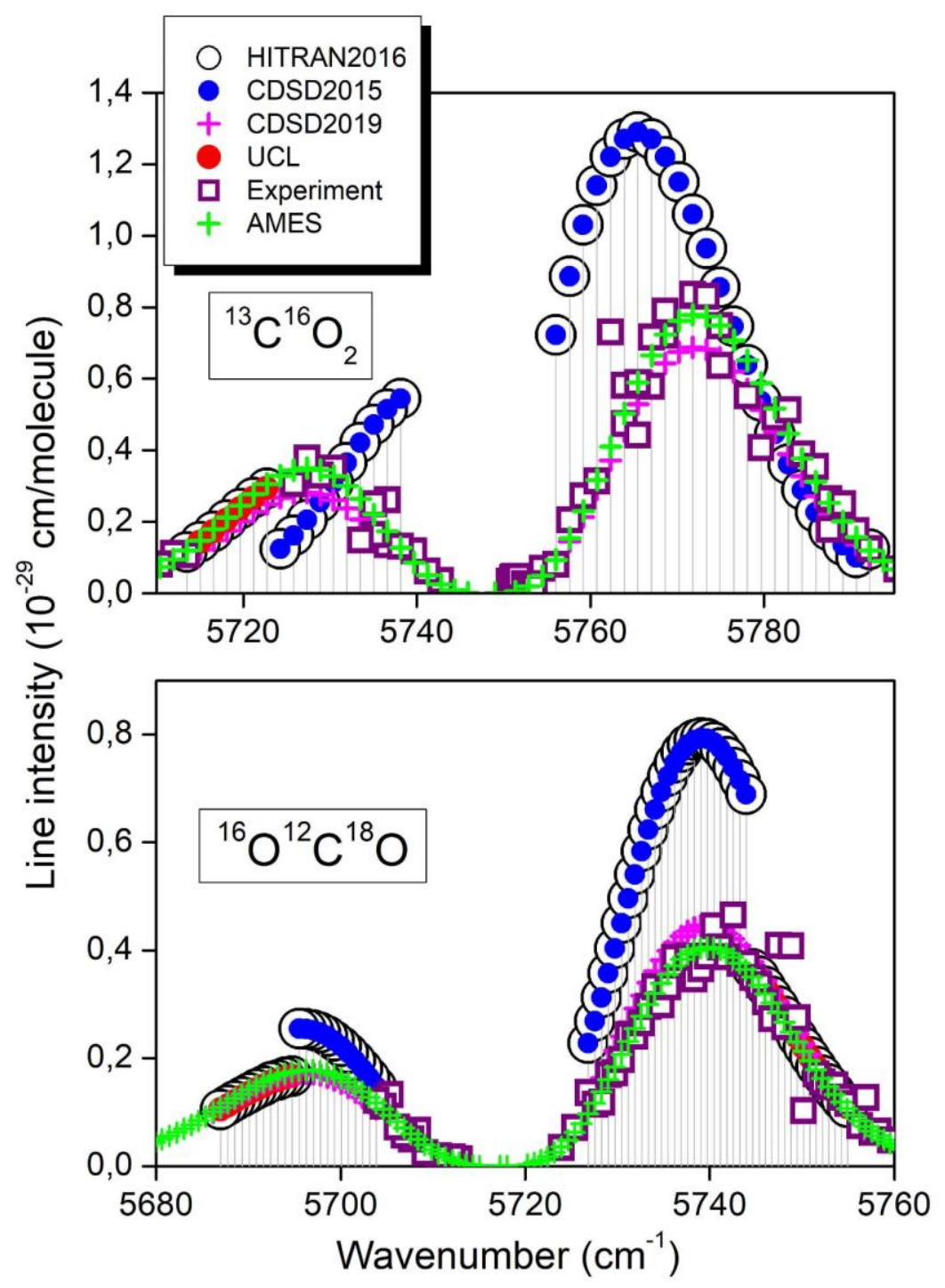

Fig. 8. Comparison of the CRDS measurements (purple squares) of the 41104 - 00001 band of 391 ${ }^{13} \mathrm{C}^{16} \mathrm{O}_{2}$ [46] and ${ }^{16} \mathrm{O}^{12} \mathrm{C}^{18} \mathrm{O}$ [40] to various databases: HITRAN2016 [44], CDSD-296 (CDSD2015) [26], CDSD-296 (CDSD2019) [17], UCL [27,28], and AMES [23] line lists. 


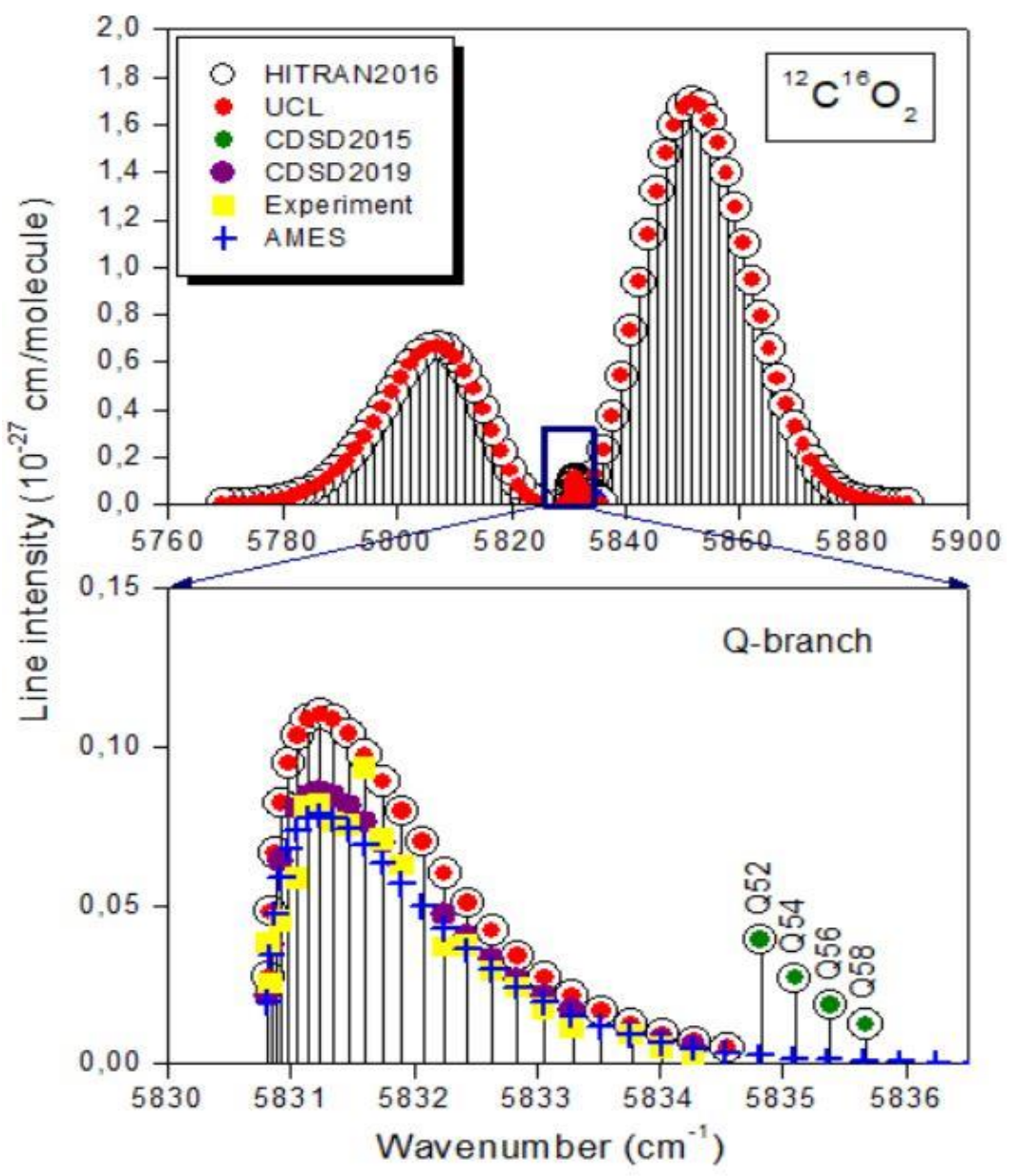

397

398

399

400

401

402

403

404

405

406

407

408

409

410

411
Fig.9. Overview comparison of the $Q$-branch of the $41104-00001$ band of ${ }^{12} \mathrm{C}^{16} \mathrm{O}_{2}$ [39] to the HITRAN2016[12], CDSD-296 (CDSD2015) [26], CDSD-296 (CDSD2019) [17], UCL [27] and AMES [23] line lists. The lower panel highlights the $Q$ branch where the HITRAN2016 list uses UCL and CDSD2015 as intensity sources for $J$ below 50 and above 52, respectively, leading to the observed intensity jump between $Q(50)$ and $Q(52)$. The CRDS measurements [39] validate the AMES intensity values which were taken as the unique source for HITRAN2020 of this band. 
412 Table 1. The bands for the ${ }^{12} \mathrm{C}^{16} \mathrm{O}_{2},{ }^{13} \mathrm{C}^{16} \mathrm{O}_{2},{ }^{16} \mathrm{O}^{12} \mathrm{C}^{18} \mathrm{O}$, and ${ }^{16} \mathrm{O}^{13} \mathrm{C}^{18} \mathrm{O}$ isotopologues where 413 intensities were from mixed sources in HITRAN2016 and the new sources of intensities chosen 414 for HITRAN2020.

415

\begin{tabular}{|c|c|c|c|c|}
\hline \multirow{2}{*}{ Band } & \multirow{2}{*}{$\begin{array}{l}\text { Band center } \\
\qquad\left(\mathrm{cm}^{-1}\right)\end{array}$} & \multicolumn{2}{|c|}{ Intensity origin } & \multirow{2}{*}{ Experimental works } \\
\hline & & HITRAN2016 & HITRAN2020 & \\
\hline \multicolumn{5}{|c|}{${ }^{12} \mathrm{C}^{16} \mathrm{O}_{2}$ isotopologue } \\
\hline 21103-02201 & 1846.33 & {$[26,27]$} & {$[26,27]$} & - \\
\hline $13302-02201$ & 1907.85 & {$[26,27]$} & [27] & - \\
\hline 20002-01101 & 2003.76 & {$[26,27]$} & [17] & [41] \\
\hline $21102-10002$ & 2054.72 & {$[26,27]$} & {$[27,28]$} & - \\
\hline $22201-11101$ & 2120.50 & {$[26,27]$} & [17] & [42] \\
\hline $40002-21103$ & 2295.65 & {$[26,27]$} & [27] & - \\
\hline $30004-01101$ & 3125.10 & {$[26,27]$} & [17] & [34] \\
\hline $31104-10002$ & 3131.52 & {$[26,27]$} & [27] & - \\
\hline $22203-01101$ & 3156.20 & {$[26,27]$} & [27] & - \\
\hline $31103-10002$ & 3306.48 & {$[26,27]$} & [27] & - \\
\hline $22202-01101$ & 3342.10 & {$[26,27]$} & [27] & - \\
\hline $23302-02201$ & 3344.01 & {$[26,27]$} & [27] & - \\
\hline $31102-10001$ & 3365.31 & {$[26,27]$} & [17] & [34] \\
\hline $30002-01101$ & 3398.45 & {$[26,27]$} & [27] & - \\
\hline 21101-00001 & 3501.45 & {$[26,27]$} & [27] & - \\
\hline $40002-11102$ & 3544.64 & {$[26,27]$} & [27] & - \\
\hline 01121-10002 & 4031.07 & {$[26,27]$} & [27] & - \\
\hline $31104-00001$ & 4416.15 & {$[26,27]$} & [17] & [35] \\
\hline $41103-10001$ & 4613.12 & {$[26,27]$} & [27] & - \\
\hline $25501-02201$ & 4696.61 & {$[26,27]$} & [27] & - \\
\hline $10021-01101$ & 5346.31 & {$[26,27]$} & [17] & [47] \\
\hline $50006-01101$ & 5572.65 & {$[26,27]$} & [27] & - \\
\hline $50005-01101$ & 5768.12 & {$[26,27]$} & [27] & [39] \\
\hline $42204-01101$ & 5805.64 & {$[26,27]$} & [17] & [39] \\
\hline $41104-00001$ & 5830.79 & {$[26,27]$} & [23] & [39] \\
\hline $50004-01101$ & 5920.94 & {$[26,27]$} & [27] & - \\
\hline $50003-01101$ & 6057.89 & {$[26,27]$} & [27] & [48] \\
\hline
\end{tabular}




\begin{tabular}{|c|c|c|c|c|}
\hline \multicolumn{7}{|c|}{${ }^{13} \mathrm{C}^{16} \mathrm{O}_{2}$ isotopologue } \\
\hline $04421-01101$ & 1946.12 & {$[26,29]$} & {$[27,28]$} & - \\
\hline $11112-11101$ & 2110.13 & {$[26,27]$} & {$[27]$} & - \\
\hline \multicolumn{7}{|c|}{${ }^{16} \mathrm{O}^{12} \mathrm{C}^{18} \mathrm{O}$ isotopologue } \\
\hline $31104-30004$ & 616.12 & {$[26,28]$} & {$[17,28]$} & - \\
\hline $21101-10002$ & 2195.21 & {$[27,28]$} & {$[28]$} & - \\
\hline $21101-00001$ & 3454.63 & {$[27,28]$} & {$[28]$} & - \\
\hline $31104-01101$ & 3677.44 & {$[26,28]$} & {$[28]$} & - \\
\hline \multicolumn{7}{|c|}{${ }^{16} \mathrm{O}^{13} \mathrm{C}^{18} \mathrm{O}$ isotopologue } \\
\hline $12202-01101$ & 1856.75 & {$[26,28]$} & {$[28]$} & \\
\hline
\end{tabular}

416

417

418

419

420

421

422

423

424

425

426

427

428

429 


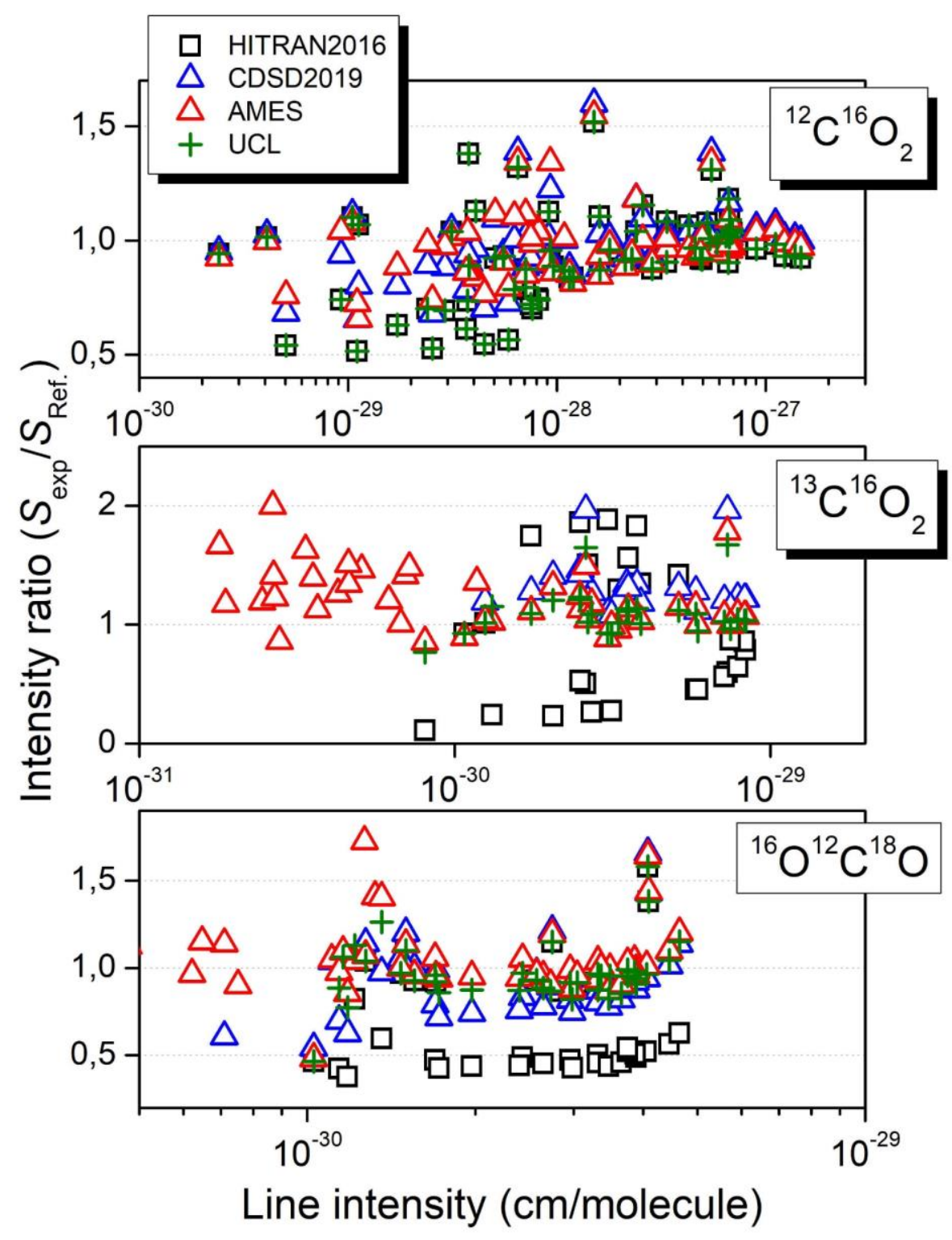

430

431

432

433

434

435

436

437

438

439

440

441

442
Fig.10. Ratios of the measured line intensities of the $41104-00001$ band of the ${ }^{12} \mathrm{C}^{16} \mathrm{O}_{2},{ }^{13} \mathrm{C}^{16} \mathrm{O}_{2}$ and ${ }^{16} \mathrm{O}^{12} \mathrm{C}^{18} \mathrm{O}[39,40,46]$ isotopologues to the HITRAN2016 [12], CDSD-296 (CDSD2019) [17], UCL $[27,28]$ and AMES [23] line lists. 

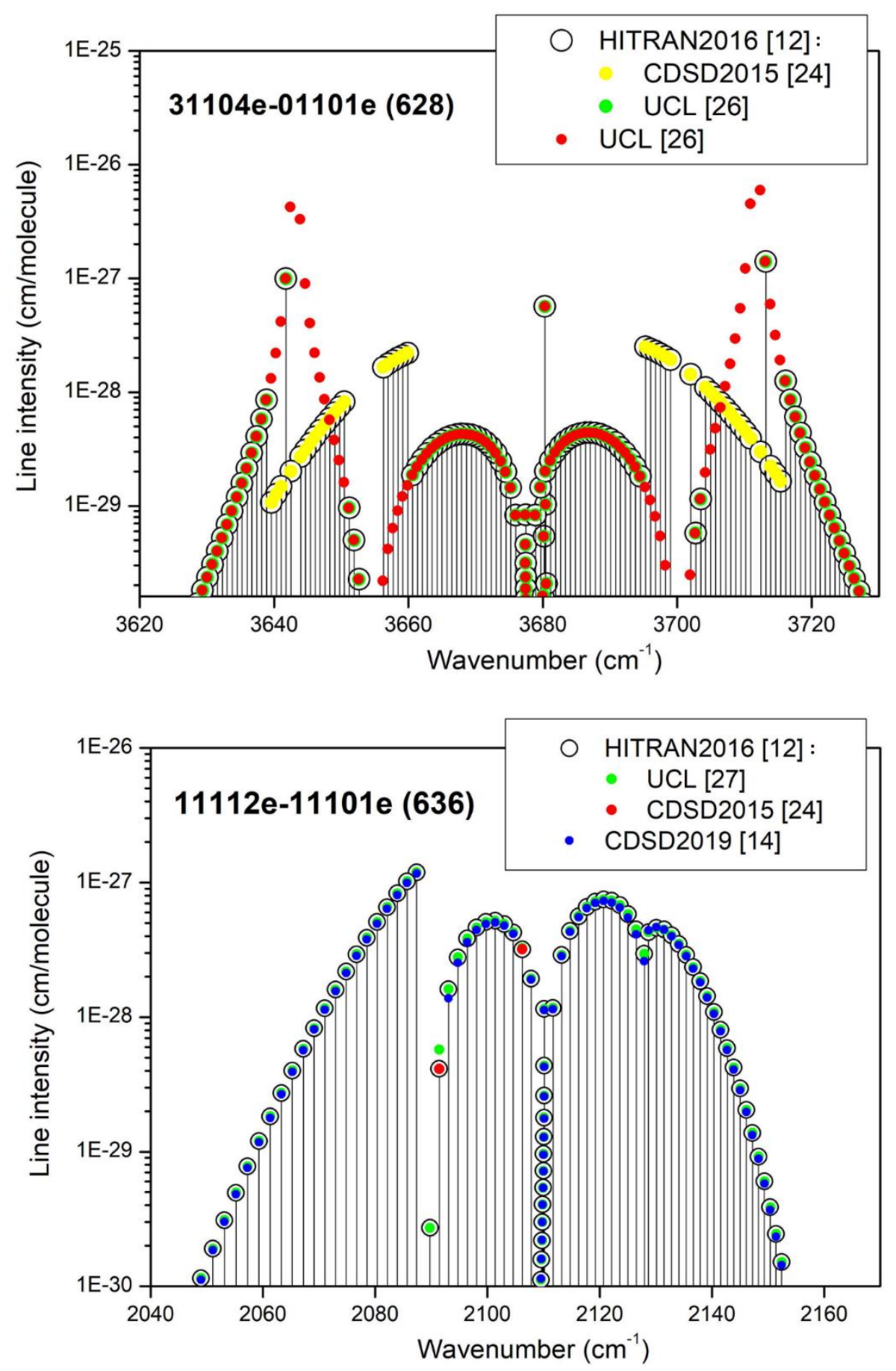

443 444 445 446 447 448 449 


\section{New experimental data with sub-percent uncertainty}

Accurate line parameters of the spectral lines are generally required for the most

452 demanding atmospheric applications. In particular, the accurate values of the line intensities with 453 uncertainties as low as 0.3\%-0.5\% [49] are necessary for forward models used in retrievals of $\mathrm{CO}_{2}$ 454 concentrations from some remote sensing missions. A number of very accurate measurements 455 have become available after the release of HITRAN2016 in the NIR region: the most recent CRDS 456 measurements from NIST $[19,20]$ and FTS measurements from DLR reported in Birk et al. [22] 457 (with the corresponding measurements and line parameter database provided on Zenodo [21]). 458 The results obtained in these works were used to improve the HITRAN line intensities of the ${ }^{12} \mathrm{C}^{16} \mathrm{O}_{2}$ isotopologue.

460 The accurate CRDS line intensity measurements for the 3001i-00001 $(i=2-4)$ bands

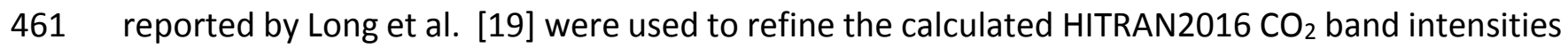
462 near $1.6 \mu \mathrm{m}$. This region is actively used for spectroscopic measurements of atmospheric $\mathrm{CO}_{2}$ 463 concentrations. For instance, the 30013-00001 band is targeted by the OCO-2 and OCO-3 464 missions [5,7], while the 30012-00001 band is used for the LIDAR missions [50]. It was shown in 465 Ref. [19] that the band-integrated CRDS intensity measurements and the $a b$ initio calculations 466 of Zak et al. [27] agree at the $0.06 \%$ level for the 30013-00001 and 30014-00001 bands, but 467 there is a systematic discrepancy of about 1.1\% for the 30012-00001 band. We note that the 468 HITRAN2016 line intensities are from the $a b$ initio UCL results [27], and they have relative 469 uncertainties < 2 \% for the 30012 - 00001 and 30013 - 00001 bands and < $5 \%$ for the 30014 47000001 band, respectively. In contrast, the current $\mathrm{CO}_{2}$ spectroscopic databases [17,23] show a 471 significant spread in their line intensities at about or above 1\%. Following these results [19], the 472 HITRAN2016 line intensities for the 3001i-00001 ( $i=2-4)$ bands were scaled to the recommended 473 band-dependent scaling constant factors, while preserving the original J-dependence of the $a b$ 474 initio calculations. The comparison of the HITRAN2016 and HITRAN2020 line intensities of the $47530012-00001$ band of ${ }^{12} \mathrm{C}^{16} \mathrm{O}_{2}$ isotopologue to the experimental values reported in Long et al. [19] 476 is plotted in Fig.12.

477 In Fleurbaey et al. [20], it was shown that a constant scaling of $1.0069 \pm 0.0002$ of 478 HITRAN2016 values in the 20013-00001 band of $\mathrm{CO}_{2}$ near $2.06 \mu \mathrm{m}$ is consistent with the 
479 experiment. Therefore, we have performed this scaling in HITRAN2020. In Refs [19,20], the 480 reported relative uncertainty in intensity is better than $0.1 \%$, thus the uncertainty code $8(<1 \%)$ 481 for the line intensities was given for the corresponding bands in the HITRAN2020 line list.

482 Bruker IFS 125HR Fourier-transform spectrometer measurements have been conducted 483 at the German Aerospace Center (DLR) to measure pure carbon dioxide transmittance spectra in 484 the 6000-7000 $\mathrm{cm}^{-1}$ spectral region, including the $30011-00001,30012-00001,30013-00001$, 48530014 - 00001, and 00031 - 00001 bands [22] . In this work, line intensity uncertainties of 0.15\% 486 were reported. The scaling factor 1.0061 was used for the HITRAN2016 line intensities of the 48730011 - 00001 band of the ${ }^{12} \mathrm{C}^{16} \mathrm{O}_{2}$ isotopologue to match with DLR measurements [22]. The 48830013 - 00001 and 30014 - 00001 HITRAN2016 line intensities and NIST measurements were 489 found to be in good agreement with the DLR measurements. However, for the 30012 - 00001 490 band, the differences outside of the stated uncertainties with both NIST measurements and 491 HITRAN2016 were reported. The difference for the 30012-00001 band was 1.6\%, whereas for 492 Long et al. [19] the difference was about 1\%. It should be noted that these differences are outside 493 the stated uncertainty budget. In addition, the DLR data showed systematic differences of 494 relative line intensities to HITRAN2016 within the $3001 i-00001(i=2,3)$ bands on the order of $0.3 \%$. 495 In the HITRAN2016 edition, the line intensities of the $00031-00001$ band of the ${ }^{12} \mathrm{C}^{16} \mathrm{O}_{2}$ 496 isotopologue near $1.4 \mu \mathrm{m}$ used CDSD-296 [26] as an intensity source because this band was 497 identified as "sensitive" in the $a b$ initio calculations [27]. The comparison of the CDSD line 498 intensities with the DLR measurements [20] showed rotationally-dependent deviations up to $4 \%$. 499 To improve the 00031-00001 line intensities in the HITRAN2020 line list, we scaled the UCL line 500 intensities [27] by the factor of 1.1217 to match the line intensities reported by Birk et al. [22] 501 (See Fig. 12). It should be noted that two lines (P20 and R18) were absent in the UCL line list [27], 502 so that the intensities of these corresponding lines were updated from Birk et al. [22]. 

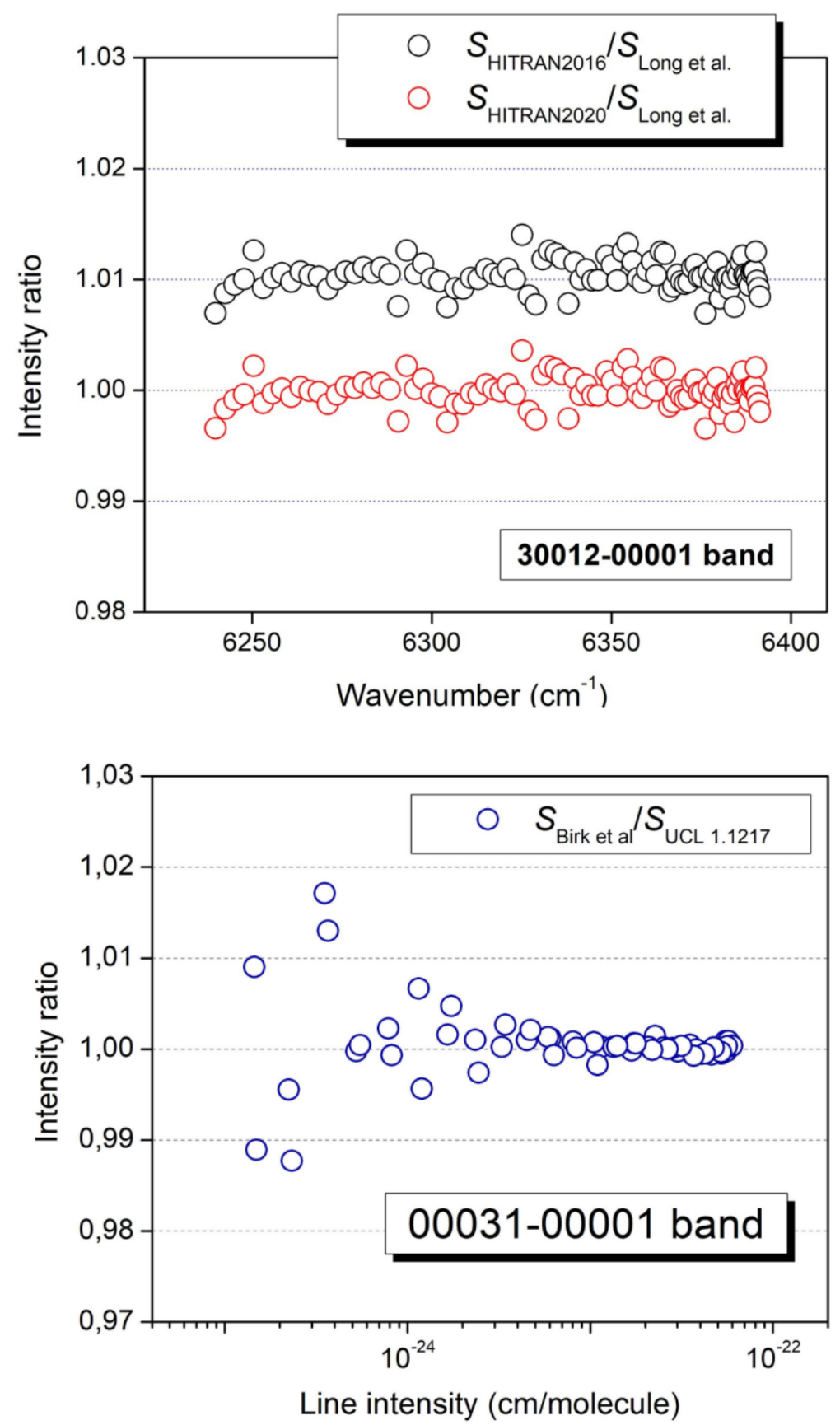

508

509 Fig. 12. Upper panel: Comparison of the HITRAN2016 and HITRAN2020 line intensities of the $51030012-00001$ band of ${ }^{12} \mathrm{C}^{16} \mathrm{O}_{2}$ isotopologue to the experimental values measured by Long et al. 511 [19]. Lower panel: Comparison of the measured line intensities reported in Birk et al. [22] and the $512 \mathrm{UCL}$ intensities scaled by the factor of 1.1217 for the 00031-00001 band of the ${ }^{12} \mathrm{C}^{16} \mathrm{O}_{2}$ 513 isotopologue.

514 
The weak 10032 - 10002 and 01131 - 01101 hot bands of the ${ }^{12} \mathrm{C}^{16} \mathrm{O}_{2}$ isotopologue located

near $6900 \mathrm{~cm}^{-1}$ were also compared to the DLR measurements [22]. It was found that the

517 HITRAN2016 line intensities of the 10032 - 10002 band should be scaled by a factor of 1.1346

518 while the line intensities of the 01131 - 01101 band having the intensity origin from CDSD-296K

519 [26] should be scaled by a factor of 1.0022 .

\section{New bands above $8000 \mathrm{~cm}^{-1}$}

The recent high-temperature ExoMol UCL-4000 line list containing almost $2.5 \times 10^{9}$

523 transitions at $T=4000 \mathrm{~K}$ for the ${ }^{12} \mathrm{C}^{16} \mathrm{O}_{2}$ isotopologue was published in Ref. [18]. To compare this

524 line list with HITRAN2016, we converted UCL-4000 to HITRAN format at $296 \mathrm{~K}$ and applied an

525 intensity cut-off of $10^{-30} \mathrm{~cm} /$ molecule using the ExoMol_to_HITRAN.py program downloaded

526 from http://exomol.com/software/[51]. This code transfers the position, intensity, Einstein A,

527 lower state energy, and upper/lower level statistical weights into the correct location for a

528 HITRAN default format ".par" file. It works by looking at the "trans" file to get the upper and

529 lower state ID. We edited this program to extract the $m_{1}, m_{2}, l_{2}, m_{3}$ HITRAN quantum numbers

530 from the ExoMol files. In the case where the states were not assigned, the vibrational

531 assignments were replaced with "-2-2-2-20". When it was possible, we also performed additional

532 assignments using the CDSD-296 [17] and Ames [23] databases. Fig. 13 gives an overview

533 comparison of the HITRAN 2016 line list to the UCL-4000 line list for the ${ }^{12} \mathrm{C}^{16} \mathrm{O}_{2}$ isotopologue

534 from 0 to $20000 \mathrm{~cm}^{-1}$. It should be noted that the ${ }^{12} \mathrm{C}^{16} \mathrm{O}_{2}$ line list in HITRAN2016 was limited to

535 the spectral range 158.302 to $14075.298 \mathrm{~cm}^{1}$. In Fig.13, only the new bands from the UCL-4000

536 line list, which are missing in the HITRAN spectroscopic database, are presented. They are

537 highlighted in blue. Most of these bands are located above $8000 \mathrm{~cm}^{-1}$. Over 3600 spectral lines

538 with line intensities from $1.8 \times 10^{-28}$ to $9.9 \times 10^{-30} \mathrm{~cm} /$ molecule from the UCL-4000 line list were 539 included in the HITRAN2020 spectroscopic database. The line positions in the UCL-4000 dataset

540 [18] are calculated from the energy levels derived from the HITRAN2016 database. Due to

541 diversity of data in HITRAN some inconsistencies could occur when deriving upper state energy

542 levels, which could result in the deviations. It is important to point out that the UCL-4000 line list

543 has an issue regarding the matching of line positions. As an example, this case is shown in Fig. 
544 14, where the comparison of the line positions for the $50015-00001$ and $60014-10002$ bands 545 of the ${ }^{12} \mathrm{C}^{16} \mathrm{O}_{2}$ isotopologue is presented. We traced the source of the discrepancies in UCL-4000 546 to the procedure used to substitute the variational (upper) state energies with the empirical 547 values. The substituted energies were taken from HITRAN2016, either as the lower state energy 548 term values $E^{\prime \prime}$ or as $E^{\prime}=E^{\prime \prime}+v$ (where $v$ is the transition wavenumber). The examples of these 549 upper state energies, including those shown in Fig. 14, were affected by inconsistency of the 550 original line positions from different sources. Most of such inconsistency cases identified in the 551 present analysis have been improved in HITRAN2020 and will be propagated to UCL-4000 after 552 the release of HITRAN 2020. In case of the small number of states ( 20$)$ that are still affected by 553 small inconsistencies in HITRAN 2020's upper states, all for the transitions well above the 8000 $554 \mathrm{~cm}^{-1}$, the CDSD synthetic data [17] will be used.

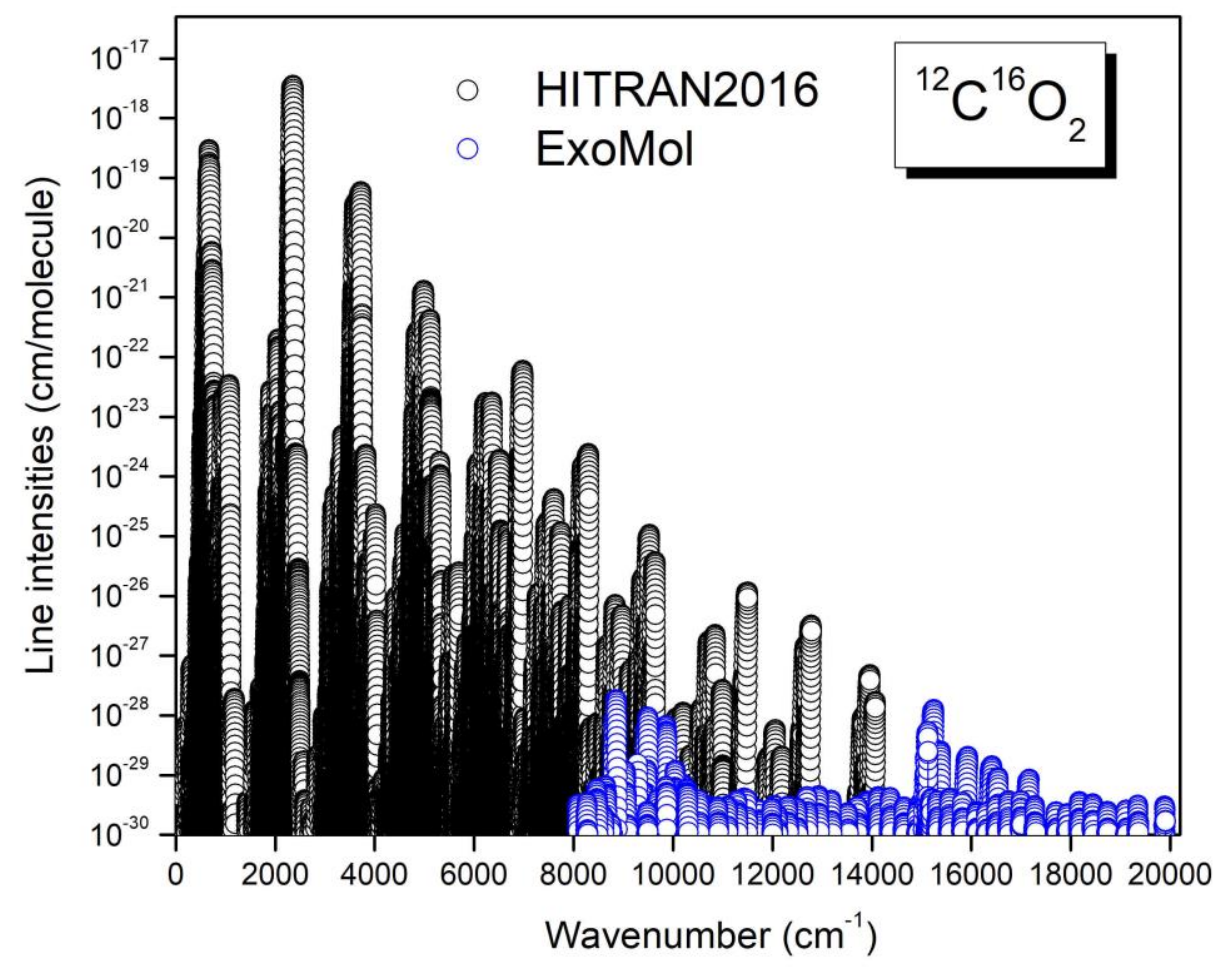

Fig. 13. Overview comparison of the HITRAN2016 [12] and ExoMol UCL-4000 [18] carbon dioxide 558 


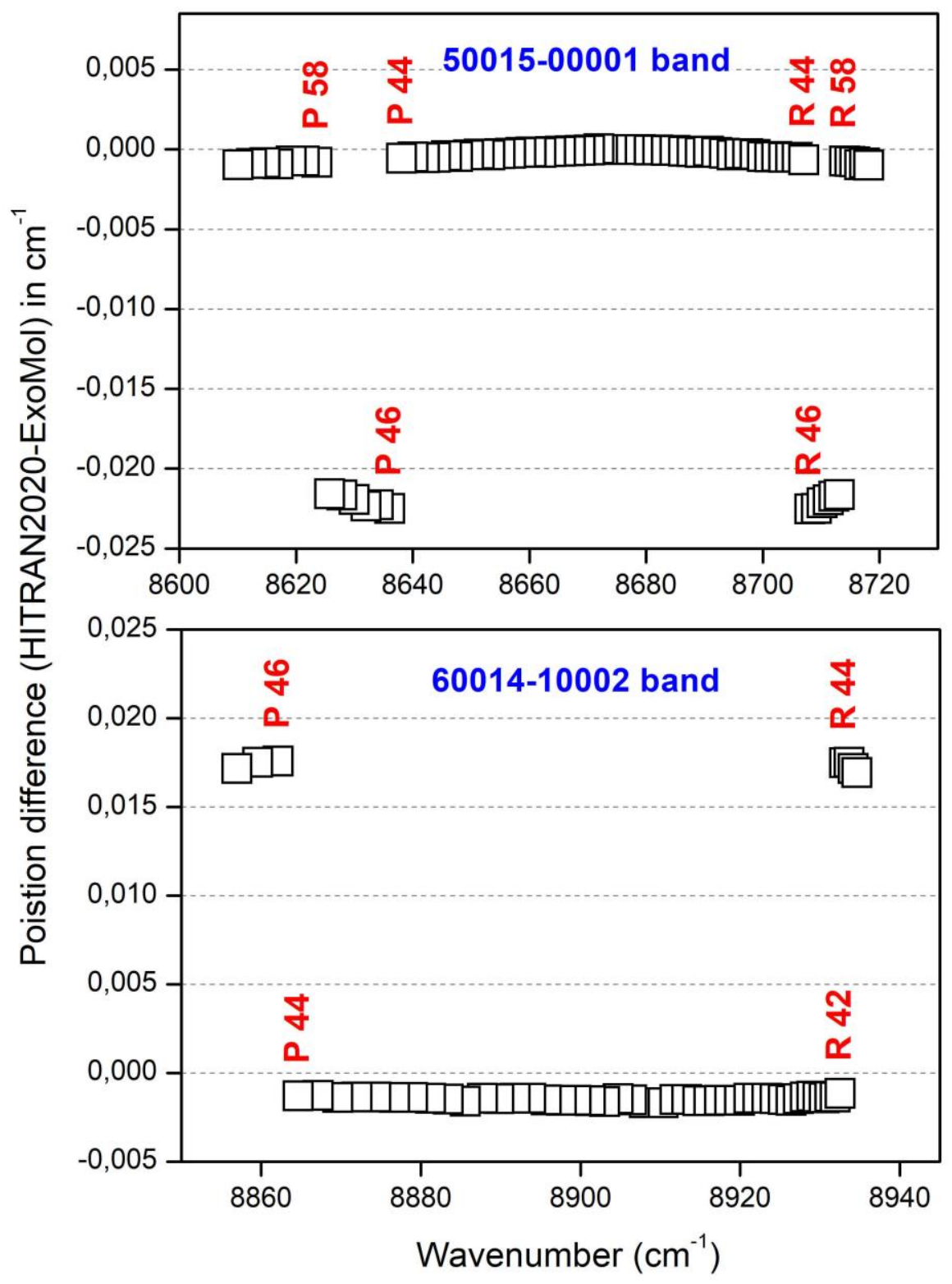

Fig. 14. Difference between the HITRAN2020 and UCL-4000 ExoMol line positions for the 50015 - 00001 and 60014 - 10002 bands of the main $\mathrm{CO}_{2}$ isotopologue.

564 band centres as $8374.23 \mathrm{~cm}^{-1}$ and $8497.45 \mathrm{~cm}^{-1}$, respectively, were missing in the HITRAN2016

565 [12] and CDSD-296 [17] spectroscopic databases. These bands were assigned in the analysis of 566

CRDS spectra of natural $\mathrm{CO}_{2}$ near $1.18 \mu \mathrm{m}$ [14] and included in the new $\mathrm{CO}_{2}$ line list. We also 
567 calculated the energy levels (thereby obtaining line positions) for the 30022 - 00001 and 30023 -

56800001 bands of ${ }^{16} \mathrm{O}^{12} \mathrm{C}^{18} \mathrm{O}$ up to $J_{\max }=34$ using the spectroscopic constants of the lower and upper

569 state obtained in Refs [14,52] and equation (1).

570

571

$$
F_{v}(J)=G_{v}+B_{v} J(J+1)-D_{v} J^{2}(J+1)^{2}+H_{v} J^{3}(J+1)^{3}
$$

572 where $G_{\mathrm{v}}$ is the vibrational term value, $B_{\mathrm{v}}$ is the rotational constant, $D_{\mathrm{v}}$ and $H_{\mathrm{v}}$ are the centrifugal 573 distortion constants, $J$ is the angular momentum quantum number.

574 Also, it was shown in Ref. [14] that the R-branch intensities of the very weak 00041 57501101 hot band of the ${ }^{12} \mathrm{C}^{16} \mathrm{O}_{2}$ isotopologue, which are missing in CDSD-296 [17], are in good 576 agreement with the NASA Ames intensities [23] while HITRAN2016 values were largely 577 overestimated. For the HITRAN2020 database, the line intensities of the 30022-00001, 30023578 00001, and 00041-01101 bands were updated using the line intensities from NASA Ames [23]. 579 Fig.15 shows the good agreement between the CRDS line intensities from Ref. [14] and the 580 calculated values from the AMES line list [23]. The uncertainty codes for line positions and 581 intensities were updated to 4 for these bands in the HITRAN2020 line list, corresponding to ( $\geq$ $5820.0001 \mathrm{~cm}^{-1}$ and $\left.<0.001 \mathrm{~cm}^{-1}\right)$ and $(\geq 10 \%$ and $<20 \%)$, respectively. 


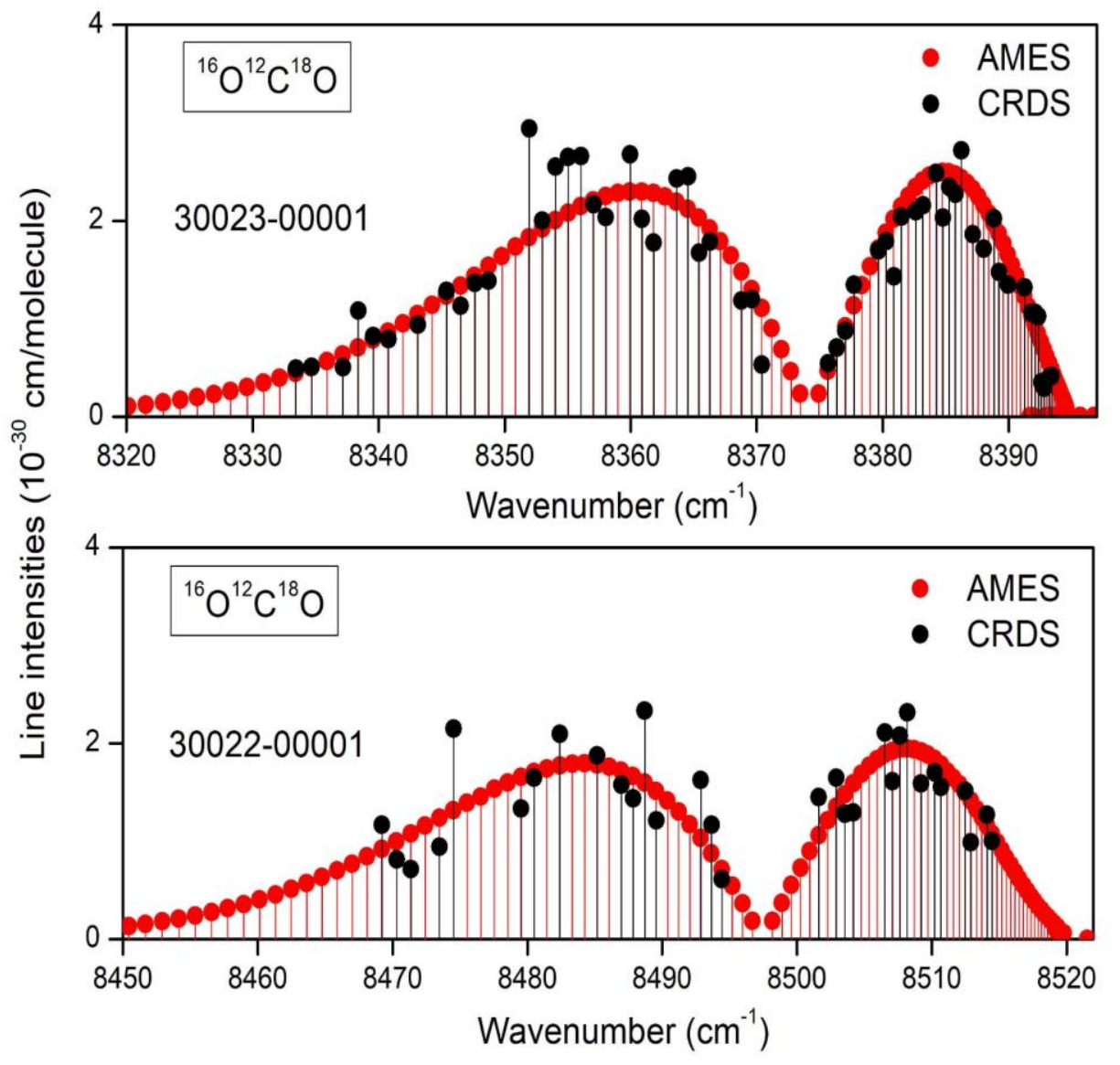

584 Fig.15. Comparison CRDS [14] and AMES [23] line intensities of the $30022-00001$ and 30023 58500001 bands of the ${ }^{16} \mathrm{O}^{12} \mathrm{C}^{18} \mathrm{O}$ isotopologue.

\section{Addition of magnetic dipole band of ${ }^{12} \mathrm{C}^{16} \mathrm{O}_{2}$ at $3.3 \mu \mathrm{m}$}

The HITRAN2020 database has been extended by including the $01111-00001\left(v_{2}+v_{3}\right)$

590 magnetic dipole band of the principal isotopologue of carbon dioxide. These line parameters

591 were introduced into HITRAN for the first time; all previous editions of HITRAN provided only $\mathrm{CO}_{2}$

592 electric dipole transitions. Interestingly, the first observation of the $v_{2}+v_{3}$ band has been reported

593 at $3.3 \mu \mathrm{m}$ in the atmosphere of Mars [53] by the ExoMars Trace Gas Orbiter ACS instrument [54].

594 This band is forbidden as an electric dipole absorption. However, it is allowed through electric 595 quadrupole and the magnetic dipole mechanisms, which are typically much weaker than those 
596 allowed through the electric dipole mechanism. The maximum line intensities in the 0111159700001 band are on the order of $6 \times 10^{-28} \mathrm{~cm} /$ molecule. The detailed studies of this band providing 598 the selection rules for the vibration-rotation transitions are presented in Refs $[53,55]$. The 599 vibrational transition magnetic dipole moment of the 01111-00001 band was fitted to the line 600 intensities measured with a Bruker IFS 125 HR FTS and a $30 \mathrm{~m}$ base multipass gas cell of the 601 V.E.Zuev Institute of Atmospheric Optics SB RAS [56]. The line positions and intensities of this 602 band were computed using the vibrational transition magnetic dipole moment and the set of the 603 effective Hamiltonian parameters reported by Majcherova et al. [57]. We included the calculated 604 line parameters up to $J=64$ of the 01111-00001 band of ${ }^{12} \mathrm{C}^{16} \mathrm{O}_{2}$ in the HITRAN2020 line list. The 605 calculated line intensities were consistent with an intensity cut-off $10^{-30} \mathrm{~cm} / \mathrm{molecule}$ at $296 \mathrm{~K}$. 606 The calculated line intensities agree well with the values measured independently by Optical607 Feedback-Cavity Enhanced Absorption Spectroscopy (OFCEAS) in Fleurbaey et al. [58] for five R608 branch lines of this band (R26-R32 and R36). An overview of the 01111-00001 magnetic dipole 609 band of the main $\mathrm{CO}_{2}$ isotopologue with band center $3004.012 \mathrm{~cm}^{-1}$ is displayed in Fig. 16. The 610 corresponding uncertainty codes for the line positions and intensities were used for the 0111161100001 band of ${ }^{12} \mathrm{C}^{16} \mathrm{O}_{2}$ : code $4(\geq 0.0001$ and $<0.001)$ and code $4(\geq 10 \%$ and $<20 \%)$, respectively. 612 It should be noted, that to distinguish the magnetic dipole transitions in the traditional HITRAN 613 ".par" format, the letter "m" was introduced into the quantum field dedicated to upper state 614 rotational ("local") quanta (see HITRAN2004 paper [59]).

615 We should also mention that in their OFCEAS study of the $v_{2}+v_{3}$ band, Fleurbaey et al. [58] 616 reported together with the detection of the magnetic dipole lines, the measurement of weaker 617 electric quadrupole of the same $v_{2}+v_{3}$ band. This detection was made possible by accurate $a b$ 618 initio predictions of the $\mathrm{E} 2$ line intensities ${ }^{12} \mathrm{C}^{16} \mathrm{O}_{2}$ in the $0-10000 \mathrm{~cm}^{-1}$ range [60]. Overall, the $a b$ 619 initio intensities of the very weak quadrupole lines are validated by this OFCEAS values (maximum 620 line intensities on the order of $10^{-28} \mathrm{~cm} /$ molecule). There is also evidence for these quadrupole 621 lines in the ACS Mars spectrum [60]. The weak electric quadrupole lines are not included in the 622 present version of the HITRAN database and will be considered for forthcoming editions. 


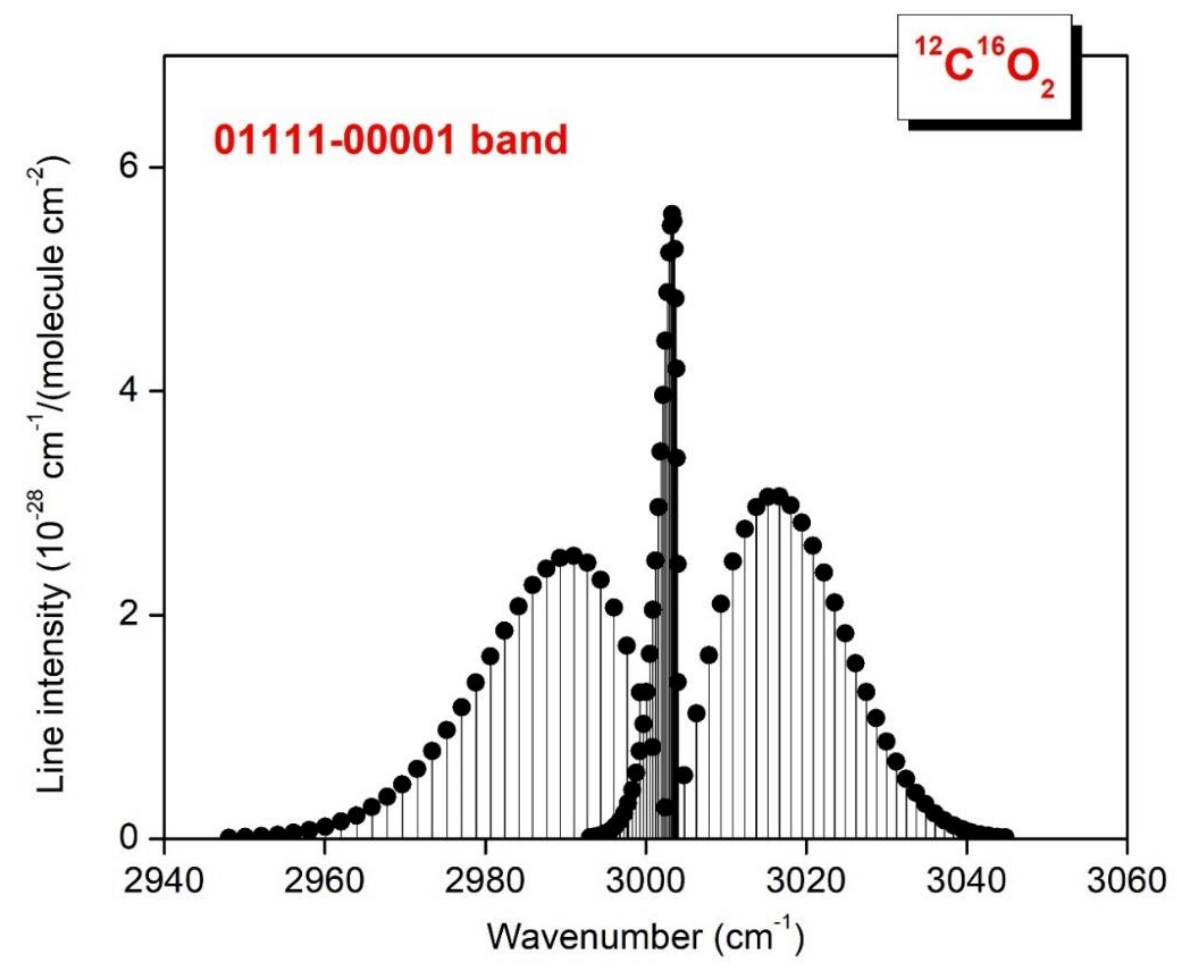

624

625

626

627

628

629

630

631

632

633

634

635

636

637

638

639

640

Fig. 16. The 01111-00001 magnetic dipole band of the main $\mathrm{CO}_{2}$ isotopologue $[56,58]$. The band center of this band is $3004.012 \mathrm{~cm}^{-1}$.

7. The line-shape parameters for the HITRAN2020 $\mathrm{CO}_{2}$ line list

A major update of the line-shape parameters of $\mathrm{CO}_{2}$ broadened by air and $\mathrm{CO}_{2}$ is described in Ref. [13]; this involved both enhancing the HITRAN database and improving completeness. A systematic extrapolation method was introduced for producing the air- and self- half width (broadening) Voigt profile parameters for unmeasured transitions_[61], based on the measurements reported in Ref. [62] The temperature-dependent exponents of the air- and selfbroadening parameters were generated based on existing measurements and a semi-empirical calculation method using the measurements given in Refs [63,64]. Air- and self-pressure shifts for every line of $\mathrm{CO}_{2}$ were calculated using the semi-empirical approach proposed by Hartmann [65] and fits using carefully selected experimental data.

Besides providing the standard 160-character ".par" parameter, the HITRAN2020 database will include additional parameters for the speed-dependent Voigt (SDV) profile $[66,67]$ 
641 in a separate set. The list of the SDV parameters was provided in Table 1 of Ref. [13]. The air- and

642 self-speed dependence of the broadening parameters with their temperature dependence will

643 be added for all the lines of $\mathrm{CO}_{2}$, and they can be downloaded using customized output format

644 on www.hitran.org. One can also retrieve these parameters with the HITRAN Application

645 Programming Interface (HAPI) [68] using the SDVoigt parameters group.

646 The $\mathrm{CO}_{2}$ line-mixing package, developed by Lamouroux et al. [69] and available at

647 HITRANonline, was updated using the new spectroscopic parameters obtained in the present

648 study and the parameters found in Ref. [13].The full and the first-order line-mixing parameters

649 have been calculated with the latter being and the first-order line-mixing parameters will be 650 provided for every line of $\mathrm{CO}_{2}$ in HITRAN. The new data were verified using different sets of 651 laboratory spectra to compare with the absorption coefficient calculated by the line-mixing 652 package program. The uncertainties better than $0.5 \%$ were achieved for the regions examined 653 compared to HITRAN2016 (we refer to figures 16-19 in Ref. [13]), which should be beneficial for $654 \mathrm{CO}_{2}$ retrieval missions, including OCO-2, ACE, and GOSAT. 545084 transitions. It covers the spectral range from $0.757 \mathrm{~cm}^{-1}$ to $19908.186 \mathrm{~cm}^{-1}$ with $\mathrm{J} \leq 128$ 659 and with the lower-state energies up to $6533.030 \mathrm{~cm}^{-1}$. Most of the line positions were replaced 660 with line positions from CDSD-296 [17]. For the problematic line intensities identified in new 661 laboratory and atmospheric spectra, critical validation tests were performed to improve their 662 accuracy of the $\mathrm{CO}_{2}$ lists. The line-shape parameters of $\mathrm{CO}_{2}$ broadened by air and $\mathrm{CO}_{2}$ were 663 updated. A summary of the $\mathrm{CO}_{2}$ line list in the HITRAN2020 edition compared to the HITRAN2016 664 is given in Table 2. The HITRAN2020 carbon dioxide line list generated in HITRAN format is 665 available on the HITRANonline website www.hitran.org. and Supplementary material of this 666 paper. An overview of the line lists in HITRAN2020 and HITRAN2016 is plotted in Fig.17. 


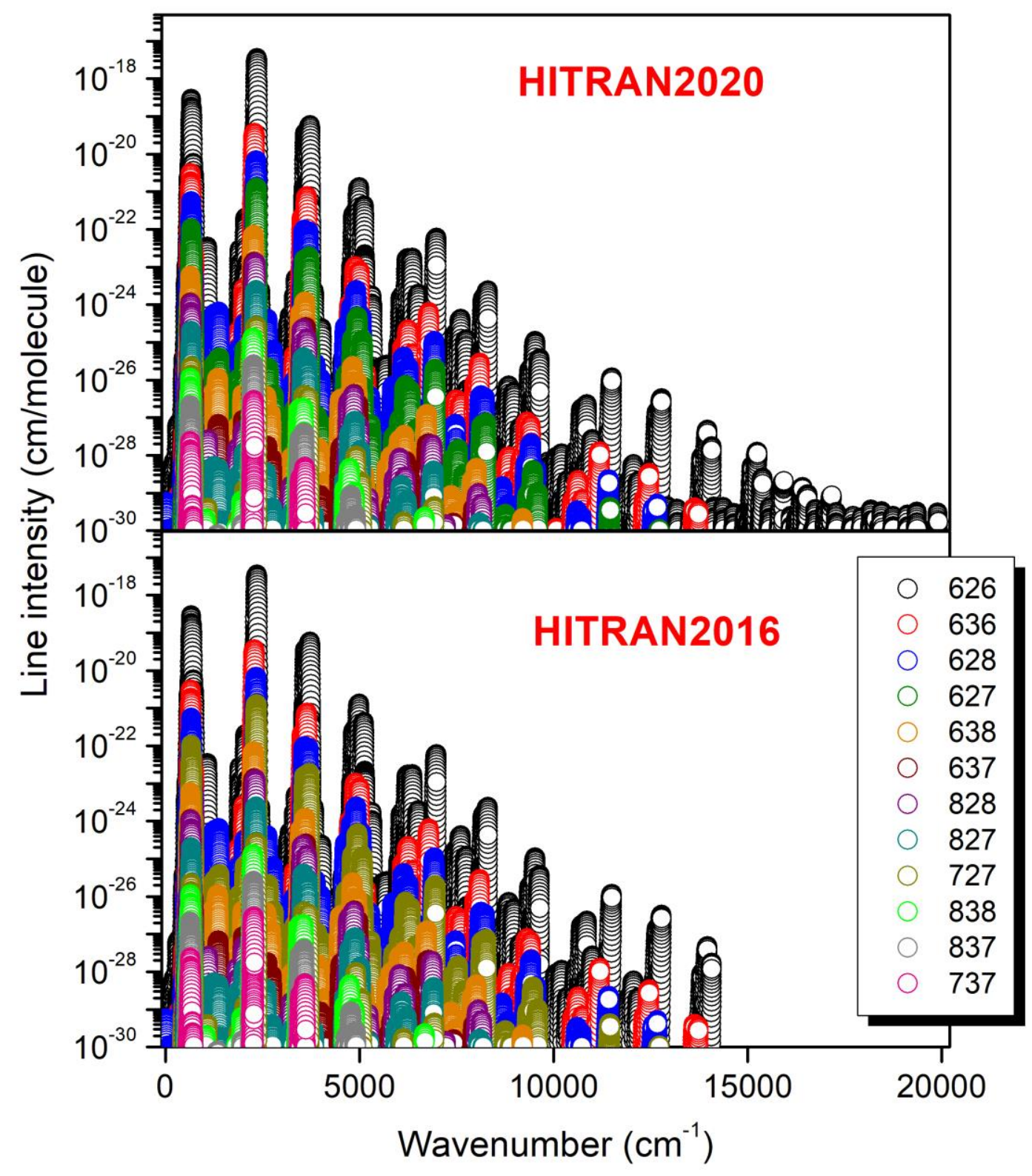

667

668 Fig. 17. An overview of the HITRAN2016 and HITRAN2020 line lists for the 12 stable $\mathrm{CO}_{2}$ 669 isotopologues: ${ }^{12} \mathrm{C}^{16} \mathrm{O}_{2}(626),{ }^{13} \mathrm{C}^{16} \mathrm{O}_{2}(636),{ }^{16} \mathrm{O}^{12} \mathrm{C}^{18} \mathrm{O}(628),{ }^{16} \mathrm{O}^{12} \mathrm{C}^{17} \mathrm{O}(627),{ }^{16} \mathrm{O}^{13} \mathrm{C}^{18} \mathrm{O}(638)$, $670{ }^{16} \mathrm{O}^{13} \mathrm{C}^{17} \mathrm{O}(637),{ }^{12} \mathrm{C}^{18} \mathrm{O}_{2}$ (828), ${ }^{18} \mathrm{O}^{12} \mathrm{C}^{17} \mathrm{O}(827),{ }^{12} \mathrm{C}^{17} \mathrm{O}_{2}(727),{ }^{13} \mathrm{C}^{18} \mathrm{O}_{2}(838),{ }^{18} \mathrm{O}^{13} \mathrm{C}^{17} \mathrm{O}(837)$, and $671{ }^{13} \mathrm{C}^{17} \mathrm{O}_{2}$ (737) (The numbers in parentheses are the AFGL shorthand code for the isotopologues).

672 
Table 2. Comparison of HITRAN2020 and HITRAN2016 line lists for the 12 stable $\mathrm{CO}_{2}$ isotopologues.

674

\begin{tabular}{|c|c|c|c|c|c|c|c|c|}
\hline \multirow{2}{*}{ Formula } & \multirow{2}{*}{$\begin{array}{l}\text { AFGL } \\
\text { code }\end{array}$} & \multirow{2}{*}{ Abundance } & \multicolumn{3}{|c|}{ HITRAN2016 } & \multicolumn{3}{|c|}{ HITRAN2020 } \\
\hline & & & Number of lines & Spectral region $\left(\mathrm{cm}^{-1}\right)$ & $Q(296 K)$ & Number of lines & Spectral region $\left(\mathrm{cm}^{-1}\right)$ & $Q(296 K)$ \\
\hline${ }^{12} \mathrm{C}^{16} \mathrm{O}_{2}$ & 626 & 0.984204 & 173024 & $158.302-14075.298$ & 286.094 & 174446 & $158.302-19908.186$ & 286.094 \\
\hline${ }^{13} \mathrm{C}^{16} \mathrm{O}_{2}$ & 636 & 0.011057 & 70577 & $332.649-13734.963$ & 576.644 & 69870 & $332.649-13734.963$ & 576.644 \\
\hline${ }^{16} \mathrm{O}^{12} \mathrm{C}^{18} \mathrm{O}$ & 628 & 0.003947 & 127850 & $1.473-12677.181$ & 607.713 & 122140 & $1.473-12677.182$ & 607.713 \\
\hline${ }^{16} \mathrm{O}^{12} \mathrm{C}^{17} \mathrm{O}$ & 627 & $7.339890 \times 10^{-4}$ & 77941 & $0.757-12726.562$ & 3542.610 & 73942 & $0.757-12726.562$ & 3542.610 \\
\hline${ }^{16} \mathrm{O}^{13} \mathrm{C}^{18} \mathrm{O}$ & 638 & $4.434460 \times 10^{-5}$ & 43782 & $2.945-9212.609$ & 1225.270 & 41058 & $2.945-9212.608$ & 1225.270 \\
\hline${ }^{16} \mathrm{O}^{13} \mathrm{C}^{17} \mathrm{O}$ & 637 & $8.246230 \times 10^{-6}$ & 25175 & $9.086-8061.741$ & 7140.024 & 23607 & $9.086-8061.739$ & 7140.024 \\
\hline${ }^{12} \mathrm{C}^{18} \mathrm{O}_{2}$ & 828 & $3.957340 \times 10^{-6}$ & 10522 & $482.813-8162.743$ & 323.424 & 10498 & $482.814-8162.752$ & 323.424 \\
\hline${ }^{17} \mathrm{O}^{12} \mathrm{C}^{18} \mathrm{O}$ & 728 & $1.471800 \times 10^{-6}$ & 15878 & 491.181-8193.172 & 3766.044 & 14623 & 498.617-8193.172 & 3766.044 \\
\hline${ }^{12} \mathrm{C}^{17} \mathrm{O}_{2}$ & 727 & $1.368470 \times 10^{-7}$ & 6518 & $535.384-6932.693$ & 10971.91 & 6493 & 535.384-6932.693 & 10971.91 \\
\hline${ }^{13} \mathrm{C}^{18} \mathrm{O}_{2}$ & 838 & $4.446000 \times 10^{-8}$ & 2916 & $539.626-6686.983$ & 652.242 & 2926 & $539.620-6686.983$ & 652.242 \\
\hline${ }^{17} \mathrm{O}^{13} \mathrm{C}^{18} \mathrm{O}$ & 738 & $1.653540 \times 10^{-8}$ & 4190 & $549.473-4914.496$ & 7593.900 & 3980 & $549.473-4914.496$ & 7593.900 \\
\hline${ }^{13} \mathrm{C}^{17} \mathrm{O}_{2}$ & 737 & $1.537500 \times 10^{-9}$ & 1501 & $575.853-3614.084$ & 22129.96 & 1501 & $575.853-3614.084$ & 22129.96 \\
\hline \multicolumn{3}{|c|}{ Total } & 559874 & & & 545084 & & \\
\hline
\end{tabular}

675

676 Note: AFGL code is the shorthand notation for the isotopologue, abundance is the terrestrial value assumed by HITRAN, and $Q(296$

$677 \mathrm{~K}$ ) is the partition sum at the reference temperature of $296 \mathrm{~K}$.

678 


\section{Conclusion}

This work presents an improved and extended version of the HITRAN2020 spectroscopic

681 database for the carbon dioxide molecule. The database includes updates of the line positions

682 and intensities described in this work, and line shape parameters (described in Hashemi et al.

683 [13]) for 12 stable $\mathrm{CO}_{2}$ isotopologues. Critical validation tests for the spectroscopic data, including

684 the comparisons with the most advanced theoretical and semi-empirical databases $[17,18,23,27]$

685 and accurate experimental measurements, were carried out. Evaluation of the $\mathrm{HITRN}_{2} \mathrm{CO}_{2}$ line 686 lists by comparison to laboratory and atmospheric spectra below $8310 \mathrm{~cm}^{-1}$ and the description 687 of the updates made for the bands having mixed CDSD and UCL-IAO line intensities in the 688 HITRAN2016 line list below $8000 \mathrm{~cm}^{-1}$ are presented. Recent experimental measurements with 689 sub-percent uncertainty [19-22] were used to improve the $\mathrm{CO}_{2}$ bands in the (1.4-2.1) $\mu \mathrm{m}$ region. 690 Several new $\mathrm{CO}_{2}$ bands (more than 3600 transitions) above $8000 \mathrm{~cm}^{-1}$ were added to the 691 HITRAN2020 edition from the new high-temperature $\mathrm{UCL}-4000{ }^{12} \mathrm{C}^{16} \mathrm{O}_{2}$ line list from the ExoMol 692 [18]database. Also, the updated $\mathrm{CO}_{2}$ line list has been extended by including new experimentally 693 observed bands [14] corresponding to the ${ }^{16} \mathrm{O}^{12} \mathrm{C}^{18} \mathrm{O}$ isotopologue. The magnetic dipole 0111169400001 band of the ${ }^{12} \mathrm{C}^{16} \mathrm{O}_{2}$ isotopologue in the $3.3 \mu \mathrm{m}$ region was introduced into HITRAN for the 695 first time. Updated self- and air-broadened line shape parameters of $\mathrm{CO}_{2}$, as described in Ref. 696 [13] and involved in the enhancement of the HITRAN databases, were also revised. These updates 697 of the $\mathrm{CO}_{2}$ line parameters in HITRAN2020 are expected to have an important impact on the 698 capabilities of current and future remote-sensing missions. The updated line lists for $12 \mathrm{CO}_{2}$ 699 isotopologues are available as Supplementary material of this paper or can be downloaded from 700 the HITRAN website (www.hitran.org).

\section{Acknowledgments}

703 This work was supported by NASA grant funding from AURA NNX17AI78G. The National Institute of Standards and Technology (NIST) received support from the NASA Science Team for the OCO 705 Missions (NRA) NNH17ZDA001N-OCO2 and the NIST Greenhouse Gas and Climate Science Measurements Program. This work was also supported by the Ministry of Science and Higher Education of the Russian Federation. The work performed at UCL was supported by the STFC Projects No. ST/M001334/1 and ST/R000476/1. Part of this work was performed at the Jet 
[1] Butz A, Guerlet S, Hasekamp O, Schepers D, Galli A, Aben I, et al. Toward accurate $\mathrm{CO}_{2}$ and $\mathrm{CH}_{4}$ observations from GOSAT. Geophysical Research Letters 2011;38:2-7. https://doi.org/10.1029/2011GL047888.

[2] Alexe M, Bergamaschi P, Segers A, Detmers R, Butz A, Hasekamp O, et al. Inverse modelling of $\mathrm{CH}_{4}$ emissions for 2010-2011 using different satellite retrieval products from GOSAT and SCIAMACHY. Atmospheric Chemistry and Physics 2015;15:113-33.

[3] Yokota T, Yoshida Y, Eguchi N, Ota Y, Tanaka T, Watanabe H, et al. Global Concentrations https://doi.org/10.5194/acp-15-113-2015. of $\mathrm{CO}_{2}$ and $\mathrm{CH}_{4}$ Retrieved from GOSAT : First Preliminary Results. Scientific Online Letters on the Atmosphere 2009;5:160-3. https://doi.org/10.2151/sola.2009-041.

[4] Nakajima, M., Suto, H., Yotsumoto, K., Abe, M., Kuze, A., Shiomi, K. et al. Overview of the GOSAT-2 Mission, Proceedings of the 29th ISTS Nagoya-Aichi, Japan 2013:60.

[5] Fabiano Oyafuso, Vivienne H.Payne,Brian J.Drouin,V. Malathy Devi, D. Chris Benner. High accuracy absorption coefficients for the Orbiting Carbon Observatory-2 (OCO-2) mission: Validation of updated carbon dioxide cross-sections using atmospheric spectra. Journal of Quantitative Spectroscopy and Radiative Transfer 2017;203:213-23. https://doi.org/https://doi.org/10.1016/j.jqsrt.2017.06.012.

[6] Eldering, A., Wennberg, P. O., Crisp, D., Schimel, D. S., Gunson, M. R., Chatterjee, A. et al. The Orbiting Carbon Observatory-2 early science investigations of regional carbon dioxide fluxes. Science 2017;358:188. https://doi.org/10.1126/science.aam5745.

[7] Eldering A, Taylor TE, O'Dell CW, Pavlick R. The OCO-3 mission: Measurement objectives and expected performance based on 1 year of simulated data. Atmospheric Measurement Techniques 2019;12:2341-70. https://doi.org/10.5194/amt-12-23412019.

[8] Fischer H, Birk M, Blom C, Carli B, Carlotti M, von Clarmann T, et al. MIPAS: An instrument for atmospheric and climate research. Atmospheric Chemistry and Physics 2008;8:2151-88. https://doi.org/10.5194/acp-8-2151-2008.

[9] Bernath PF, McElroy CT, Abrams MC, Boone CD, Butler M, Camy-Peyret C, et al. Atmospheric chemistry experiment (ACE): Mission overview. Geophysical Research Letters 2005;32:1-5. https://doi.org/10.1029/2005GL022386.

[10] Wunch D, Toon GC, Blavier JFL, Washenfelder RA, Notholt J, Connor BJ, et al. The total carbon column observing network. Philosophical Transactions of the Royal Society A: Mathematical, Physical and Engineering Sciences 2011;369:2087-112. https://doi.org/10.1098/rsta.2010.0240.

[11] Hase F. Improved instrumental line shape monitoring for the ground-based, highresolution FTIR spectrometers of the Network for the Detection of Atmospheric Composition Change. Atmospheric Measurement Techniques 2012;5:603-10. https://doi.org/10.5194/amt-5-603-2012.

753 Gordon IE, Rothman LS, Hill C, Kochanov RV, Tan Y, Bernath PF, et al. The HITRAN2016 molecular spectroscopic database. Journal of Quantitative Spectroscopy and Radiative Transfer 2017;203:3-69. https://doi.org/10.1016/j.jqsrt.2017.06.038. 
754

755

756

757

758

759

760

761

762

763

764

765

766

767

768

769

770

771

772

773

774

775

776

777

778

779

780

781

782

783

784

785

786

787

788

789

790

791

792

793

794

795

796

[13]__ Hashemi R, Gordon IE, Tran H, Kochanov RV, Karlovets EV, Tan Y, Lamouroux J, et al. Revising the line-shape parameters for air- and self- broadened $\mathrm{CO}_{2}$ lines toward a subpercent accuracy level. JQSRT 2020;256:107283. https://doi.org/https://doi.org/10.1016/j.jqsrt.2020.107283.

[14] Karlovets EV, Kassi S, Campargue A. Journal of Quantitative Spectroscopy \& Radiative Transfer High sensitivity CRDS of $\mathrm{CO}_{2}$ in the $1.18 \mu \mathrm{m}$ transparency window . Validation tests of current spectroscopic databases 2020;247:1-8.

https://doi.org/10.1016/j.jqsrt.2020.106942.

[15] Toon GC. $\mathrm{CO}_{2}$ Spectroscopy Evaluation: 670 to $8310 \mathrm{~cm}^{-1}$, Reports and Presentations for the HITRAN meeting, Jun 2020, Jet Propulsion Laboratory, California Institute of Technology (2020).

[16] Toon GC. $\mathrm{CO}_{2}$ Spectroscopy Evaluation: 670 to $7000 \mathrm{~cm}^{-1}$, Reports and Presentations for the ACE STM, Oct 2018, Jet Propulsion Laboratory, California Institute of Technology (2018).

[17] Tashkun SA, Perevalov VI, Gamache RR, Lamouroux J. CDSD-296, high-resolution carbon dioxide spectroscopic databank: An update. Journal of Quantitative Spectroscopy and Radiative Transfer 2019;228:124-31. https://doi.org/10.1016/j.jqsrt.2019.03.001.

[18] Yurchenko SN, Mellor TM, Freedman RS, Tennyson J. ExoMol line lists-XXXIX. Rovibrational molecular line list for $\mathrm{CO}_{2}$. Monthly Notices of the Royal Astronomical Society 2020;496:5282-91. https://doi.org/10.1093/mnras/staa1874.

[19] Long DA, Reed ZD, Fleisher AJ, Mendonca J, Roche S, Hodges JT. High-Accuracy NearInfrared Carbon Dioxide Intensity Measurements to Support Remote Sensing. Geophysical Research Letters 2020;47:e2019GL086344. https://doi.org/10.1029/2019GL086344.

[20] Fleurbaey H, Yi H, Adkins EM, Fleisher AJ, Hodges JT. Cavity ring-down spectroscopy of $\mathrm{CO}_{2}$ near $\lambda=2.06 \mu \mathrm{m}$ : Accurate transition intensities for the Orbiting Carbon Observatory-2 (OCO-2) "strong band." Journal of Quantitative Spectroscopy and Radiative Transfer 2020;252:107104. https://doi.org/10.1016/j.jqsrt.2020.107104.

[21] Birk M, Röske C, Wagner C. Measurement and line parameter database $\mathrm{CO}_{2} 6000-7000$ $\mathrm{cm}^{-1}$, Zenodo 2021.

[22] Birk $\mathrm{M}$, Röske $\mathrm{C}$, Wagner $\mathrm{C}$. High accuracy $\mathrm{CO}_{2}$ Fourier transform measurements in the range $6000-7000 \mathrm{~cm}^{-1}$. Journal of Quantitative Spectroscopy and Radiative Transfer Submitted to HITRAN2020 Special Issue 2021.

[23] Huang X, Richard S. Freedman B, Lee TJ. Ames-2016 line lists for 13 isotopologues of $\mathrm{CO}_{2}$ : Updates, consistency, and remaining issues. Journal of Quantitative Spectroscopy and Radiative Transfer 2017;203:224-41. https://doi.org/10.1016/j.jinf.2020.02.020.

[24] Gordon IE, Rothman LS, Hargreaves, Hashemi R, Karlovets EV, Skinner FM, Conway EK, Hill C, et al. The HITRAN2020 molecular spectroscopic database. Journal of Quantitative Spectroscopy and Radiative Transfer Submitted to HITRAN2020 Special Issue 2021.

[25] Hill C, Gordon IE, Kochanov RV, Barrett L, Wilzewski JS, Rothman LS. HITRANonline: An online interface and the flexible representation of spectroscopic data in the HITRAN database. Journal of Quantitative Spectroscopy and Radiative Transfer 2016;177:4-14. https://doi.org/10.1016/j.jqsrt.2015.12.012. 
[26] Tashkun SA, Perevalov VI, Gamache RR, Lamouroux J. CDSD-296, high resolution carbon dioxide spectroscopic databank: Version for atmospheric applications. Journal of Quantitative Spectroscopy and Radiative Transfer 2015;152:45-73. https://doi.org/10.1016/j.jqsrt.2014.10.017.

[27] Zak E, Tennyson J, Polyansky OL, Lodi L, Zobov NF, Tashkun SA, et al. A room temperature $\mathrm{CO}_{2}$ line list with ab initio computed intensities. Journal of Quantitative Spectroscopy and Radiative Transfer 2016;177:31-42. https://doi.org/10.1016/j.jqsrt.2015.12.022.

[28] Zak EJ, Tennyson J, Polyansky OL, Lodi L, Zobov NF, Tashkun SA, et al. Room temperature linelists for $\mathrm{CO}_{2}$ asymmetric isotopologues with ab initio computed intensities. Journal of Quantitative Spectroscopy and Radiative Transfer 2017;203:265-81. https://doi.org/10.1016/j.jqsrt.2017.01.037.

[29] Zak EJ, Tennyson J, Polyansky OL, Lodi L, Zobov NF, Tashkun SA, et al. Room temperature linelists for $\mathrm{CO}_{2}$ symmetric isotopologues with ab initio computed intensities. Journal of Quantitative Spectroscopy and Radiative Transfer 2017;189:267-80. https://doi.org/10.1016/j.jqsrt.2015.12.022.

[30] Teffo JL, Sulakshina ON, Perevalov VI. Effective Hamiltonian for rovibrational energies and line intensities of carbon dioxide. Journal of Molecular Spectroscopy 1992;156:4864. https://doi.org/10.1016/0022-2852(92)90092-3.

[31] Teffo JL, Lyulin OM, Perevalov VI, Lobodenko El. Application of the effective operator approach to the calculation of ${ }^{12} \mathrm{C}^{16} \mathrm{O}_{2}$ line intensities. Journal of Molecular Spectroscopy 1998;187:28-41. https://doi.org/10.1006/jmsp.1997.7455.

[32] Polyansky OL, Bielska K, Ghysels M, Lodi L, Zobov NF, Hodges JT, et al. High-Accuracy $\mathrm{CO}_{2}$ Line Intensities Determined from Theory and Experiment. Physical Review Letters 2015;114:1-5. https://doi.org/10.1103/PhysRevLett.114.243001.

[33] Yurchenko SN, Thiel W, Jensen P. Theoretical ROVibrational Energies (TROVE): A robust numerical approach to the calculation of rovibrational energies for polyatomic molecules. Journal of Molecular Spectroscopy 2007;245:126-40. https://doi.org/10.1016/j.jms.2007.07.009.

[34] Chris Benner, V. Malathy Devi, Curtis P. Rinsland and Penelope S. Ferry-Leeper. Absolute intensities of $\mathrm{CO}_{2}$ lines in the $3140-3410-\mathrm{cm}^{-1}$ spectral region. Applied Optics 1988;27:1588-97. https://doi.org/https://doi.org/10.1364/AO.27.001588.

[35] Toth RA, Brown LR, Miller CE, Devi VM, Benner DC. Spectroscopic database of $\mathrm{CO}_{2}$ line parameters: $4300-7000 \mathrm{~cm}^{-1}$. Journal of Quantitative Spectroscopy and Radiative Transfer 2008;109:906-21. https://doi.org/10.1016/j.jqsrt.2007.12.004.

[36] Tomoaki Tanaka, Masashi Fukabori, Takafumi Sugita, Hideaki Nakajima et al. Spectral line parameters for $\mathrm{CO}_{2}$ bands in the 4.8- to 5.3- $\mu \mathrm{m}$ region. Journal of Molecular Spectroscopy 2006;239:1-10. https://doi.org/https://doi.org/10.1016/j.jms.2006.05.013.

[37] Rinsland CP, Benner DC, Devi VM. Measurements of absolute line intensities in carbon dioxide bands near $5.2 \mu \mathrm{m}$. Applied Optics 1985;24:1644. https://doi.org/10.1364/ao.24.001644.

[38] Karlovets EV, Kassi S, Tashkun SA, Perevalov VI, Campargue A. High sensitivity Cavity Ring Down spectroscopy of carbon dioxide in the 1.19-1.26 $\mu \mathrm{m}$ region. Journal of Quantitative Spectroscopy and Radiative Transfer 2014;144:137-153. https://doi.org/10.1016/j.jqsrt.2014.04.001. 
[39] Čermák P, Karlovets EV, Mondelain D, Kassi S, Perevalov VI, Campargue A. High sensitivity $\mathrm{CRDS}$ of $\mathrm{CO}_{2}$ in the $1.74 \mu \mathrm{m}$ transparency window. A validation test for the spectroscopic databases. Journal of Quantitative Spectroscopy and Radiative Transfer 2018;207:95-103. https://doi.org/10.1016/j.jqsrt.2017.12.018.

[40] Karlovets EV, Čermák P, Mondelain D, Kassi S, Campargue A, Tashkun SA, et al. Analysis and theoretical modeling of the ${ }^{18} \mathrm{O}$ enriched carbon dioxide spectrum by CRDS near 1.74 $\mu \mathrm{m}$. Journal of Quantitative Spectroscopy and Radiative Transfer 2018;217:73-85. https://doi.org/10.1016/j.jqsrt.2018.05.017.

[41] Rinsland CP, Benner DC. Absolute intensities of spectral lines in carbon dioxide bands near $2050 \mathrm{~cm}^{-1}$. Applied Optics 1984;23:4523-8.

https://doi.org/https://doi.org/10.1364/AO.23.004523.

[42] Rinsland CP, Benner DC and Devi VM. Absolute line intensities in $\mathrm{CO}_{2}$ bands near $4.8 \mu \mathrm{m}$. Applied Optics 1986;25:1204-14. https://doi.org/https://doi.org/10.1364/AO.25.001204.

[43] Rothman LS, Gordon IE, Barbe A, Benner DC, Bernath PF, Birk M, et al. The HITRAN 2008 molecular spectroscopic database. Journal of Quantitative Spectroscopy and Radiative Transfer 2009;110:533-72. https://doi.org/10.1016/j.jqsrt.2009.02.013.

[44] Rothman LS, Gordon IE, Babikov Y, Barbe A, Chris Benner D, Bernath PF, et al. The HITRAN2012 molecular spectroscopic database. Journal of Quantitative Spectroscopy and Radiative Transfer 2013;130:4-50. https://doi.org/10.1016/j.jqsrt.2013.07.002.

[45] Wunch D, Toon GC, Blavier JFL, Washenfelder RA, Notholt J, Connor BJ, et al. GFIT. Philosophical Transactions of the Royal Society A: Mathematical, Physical and Engineering Sciences 2011;369:2087-112. https://doi.org/10.1098/rsta.2010.0240.

[46] Karlovets EV, Sidorenko AD, Mondelain D, Kassi S, Campargue A, Sidorenko AD, et al. The ${ }^{13} \mathrm{CO} 2$ absorption spectrum by CRDS near $1.74 \mu \mathrm{m}$. Journal of Molecular Spectroscopy 2018;354:54-9. https://doi.org/10.1016/j.jms.2018.10.003.

[47] Lawrence P.Giver, Linda R.Brown, Charles Chackerian, Richard S. Freedman. The rovibrational intensities of five absorption bands of ${ }^{12} \mathrm{C}^{16} \mathrm{O}_{2}$ between 5218 and $5349 \mathrm{~cm}^{-1}$. Journal of Quantitative Spectroscopy and Radiative Transfer 2003;78:417-36. https://doi.org/10.1016/S0022-4073(02)00277-7.

[48] Perevalov BV, Kassi S, Romanini D, Perevalov VI, Tashkun SA, Campargue A. CW-cavity ringdown spectroscopy of carbon dioxide isotopologues near $1.5 \mu \mathrm{m}$. Journal of Molecular Spectroscopy 2006;238:241-55. https://doi.org/10.1016/j.jms.2006.05.009.

[49] Miller CE, Crisp D, DeCola PL, Olsen SC, Randerson JT, Michalak AM, et al. Precision requirements for space-based $\mathrm{XCO}_{2}$ data. Journal of Geophysical Research Atmospheres 2007;112:1-19. https://doi.org/10.1029/2006JD007659.

[50] Campbell JF, Lin B, Dobler J, Pal S, Davis K, Erxleben W, McGregor D, O'Dell C, Bell E, et al. Field Evaluation of Column $\mathrm{CO}_{2}$ Retrievals From Intensity-Modulated Continuous-Wave Differential Absorption Lidar Measurements During the ACT-America Campaign. Earth and Space Science 2020;7:e2019EA000847. https://doi.org/10.1029/2019EA000847.

[51] Tennyson J, Yurchenko SN, Al-Refaie AF, Clark VHJ, Chubb KL, Conway EK, Dewan A, Gorman MN, Hill C, et al. The 2020 release of the ExoMol database: molecular line lists for exoplanet and other hot atmospheres. Journal of Quantitative Spectroscopy and Radiative Transfer 2020; 255, 107228. https://doi.org/ 10.1016/j.jqsrt.2020.107228. 
884

885

886

887

888

889

890

891

892

893

894

895

896

897

898

899

900

901

902

903

904

905

906

907

908

909

910

911

912

913

914

915

916

917

918

919

920

921

922

923

924

925

926

[52] Rothman LS, Hawkins RL, Wattson RB, Gamache RR. Energy levels, intensities, and linewidths of atmospheric carbon dioxide bands. Journal of Quantitative Spectroscopy and Radiative Transfer 1992;48:537-66. https://doi.org/10.1016/0022-4073(92)90119-0.

[53] Trokhimovskiy A, Perevalov V, Korablev O, Fedorova A, Olsen KS, Bertaux JL, et al. First observation of the magnetic dipole $\mathrm{CO}_{2}$ main isotopologue absorption band at $3.3 \mu \mathrm{m}$ in the atmosphere of Mars by the ExoMars Trace Gas Orbiter ACS instrument. Astronomy \& Astrophysics 2020;639:1-7. https://doi.org/10.1051/0004-6361/202038134.

[54] Korablev O, Montmessin F, Trokhimovskiy A, Fedorova AA, Shakun AV, Grigoriev AV, et al. The Atmospheric Chemistry Suite (ACS) of Three Spectrometers for the ExoMars 2016 Trace Gas Orbiter. Space Science Reviews 2018;214:7. https://doi.org/10.1007/s11214017-0437-6.

[55] Perevalov VI, Trokhimovskiy AY, Lukashevskaya AA, Korablev OI, et al. Magnetic dipole and electric quadrupole absorption in carbon dioxide. Journal of Quantitative Spectroscopy and Radiative Transfer 2021;259:107408. https://doi.org/10.1016/j.jqsrt.2020.107408.

[56] Borkov YG, Solodov AM, Solodov AA, Perevalov VI. Line intensities of the 01111-00001 magnetic dipole absorption band of ${ }^{12} \mathrm{C}^{16} \mathrm{O}_{2}$ : Laboratory measurements. Journal of Molecular Spectroscopy 2021;376:111418. https://doi.org/https://doi.org/10.1016/j.jms.2021.111418.

[57] Majcherova Z, MacKo P, Romanini D, Perevalov VI, Tashkun SA, Teffo JL, et al. Highsensitivity CW-cavity ringdown spectroscopy of ${ }^{12} \mathrm{CO}_{2}$ near $1.5 \mu \mathrm{m}$. Journal of Molecular Spectroscopy 2005;230:1-21. https://doi.org/10.1016/j.jms.2004.09.011.

[58] Fleurbaey H, Grilli R, Mondelain D, Kassi S, Yachmenev A, Yurchenko SN, Campargue A. Electric-quadrupole and magnetic-dipole conitributions to the $\mathrm{v}_{2}+\mathrm{v}_{3}$ band of carbon dioxide near $3.3 \mu \mathrm{m}$. Journal of Quantitative Spectroscopy and Radiative Transfer 2021;266:107558. https://doi.org/10.1016/j.jqstt.2021.107558.

[59] Rothman LS, Jacquemart D, Barbe A, Benner DC, Birk M, Brown LR, et al. The HITRAN 2004 molecular spectroscopic database. Journal of Quantitative Spectroscopy and Radiative Transfer 2005;96:139-204. https://doi.org/10.1016/j.jqsrt.2004.10.008.

[60] Yachmenev A, Küpper J, Campargue A, Yurchenko SN, and Tennyson. Quadrupole transitions in carbon dioxide. J Chem Physics, 2021 (in press).

[61] Voigt W. Über das Gesetz Intensitätsverteilung innerhalb der Linien eines Gasspektrums. München; Berlin: Sitzber. Bayr Akad., 1912, 603 p.

[62] Hashemi R, Rozario H, Ibrahim A, Predoi-Cross A. Line shape study of the carbon dioxide laser band. Can J Phys 2013;91(11):924-36. https://doi.org/10.1139/ cjp- 2013- 0051.

[63] Ma H, Sun M, Zha S, Liu Q, Cao Z, Huang $Y$ et al. Temperature dependence of line parameters of $\mathrm{CO}_{2}$ near $2.004 \mu \mathrm{m}$ studied by tunable diode laser spectroscopy. Chin Phys B 2018;27(2):023301. https://doi.org/10.1088/1674-1056/27/2/023301.

[64] Predoi-Cross A, Liu W, Murphy R, Povey C, Gamache R, Laraia A et al. Measurement and computations for temperature dependences of self-broadened carbon dioxide transitions in the 30012-00001 and 30013-00001 bands. Journal of Quantitative Spectroscopy and Radiative Transfer 2010;111(9):1065-79. https://doi.org/10.1016/j.jqsrt.2010.01.003. 
927 [65] Hartmann J-M. A simple empirical model for the collisional spectral shift of airbroadened $\mathrm{CO}_{2}$ lines. Journal of Quantitative Spectroscopy and Radiative Transfer 2009;110(18):2019-26. https://doi.org/10.1016/j.jqsrt.2009.05.016.

[66] Pickett HM. Effects of velocity averaging on the shapes of absorption lines. J Chem Phys 1980;73(12):6090-4. https://doi.org/10.1063/1.440145.

[67] Pine AS. Line shape asymmetries in Ar-broadened HF $(v=10)$ in the Dicke arrowing regime. J Chem Phys 1994;101(5):3444-52. https://doi.org/10.1063/1.467529.

[68] Kochanov RV, Gordon IE, Rothman LS, Wcisło P, Hill C, Wilzewski JS. HITRAN Application Programming Interface (HAPI): A comprehensive approach to working with spectroscopic data. Journal of Quantitative Spectroscopy and Radiative Transfer 2016;177:15-30. https://doi.org/10.1016/j.jqsrt.2016.03.005.

[69] Lamouroux J, Régalia L, Thomas X, Auwera JV, Gamache RR, Rothman LS, Gordon IE, Hartmann J-M. $\mathrm{CO}_{2}$ Line-mixing database and software update and its tests in the $2.1 \mu \mathrm{m}$ and $4.3 \mu \mathrm{m}$ regions. Journal of Quantitative Spectroscopy and Radiative Transfer 2015;151:88-96. https://doi.org/10.1016/ j.jqsrt.2014.09.017. 


\section{Fig. 1. \\ . 1.}

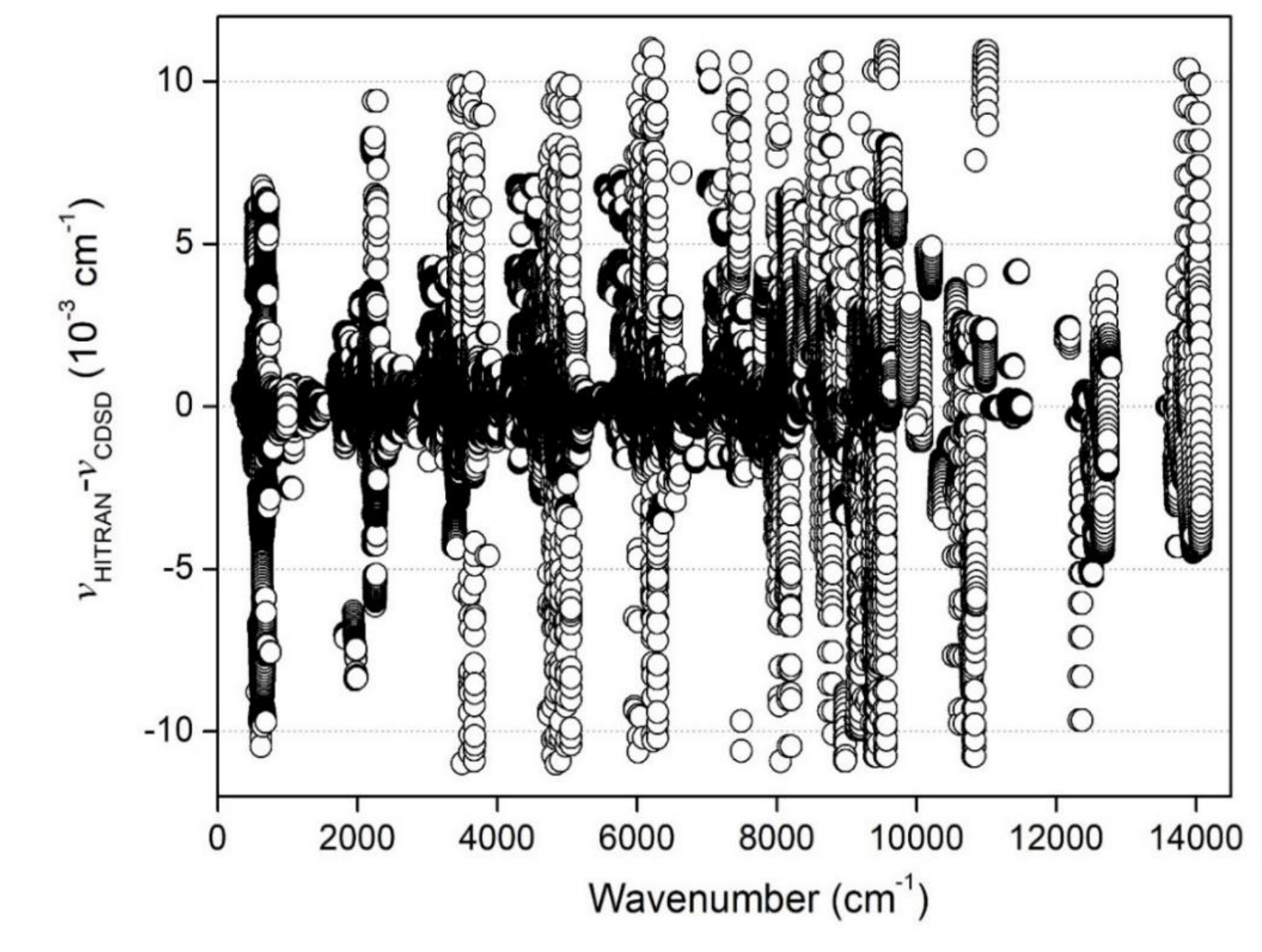




\section{Fig. 2.}
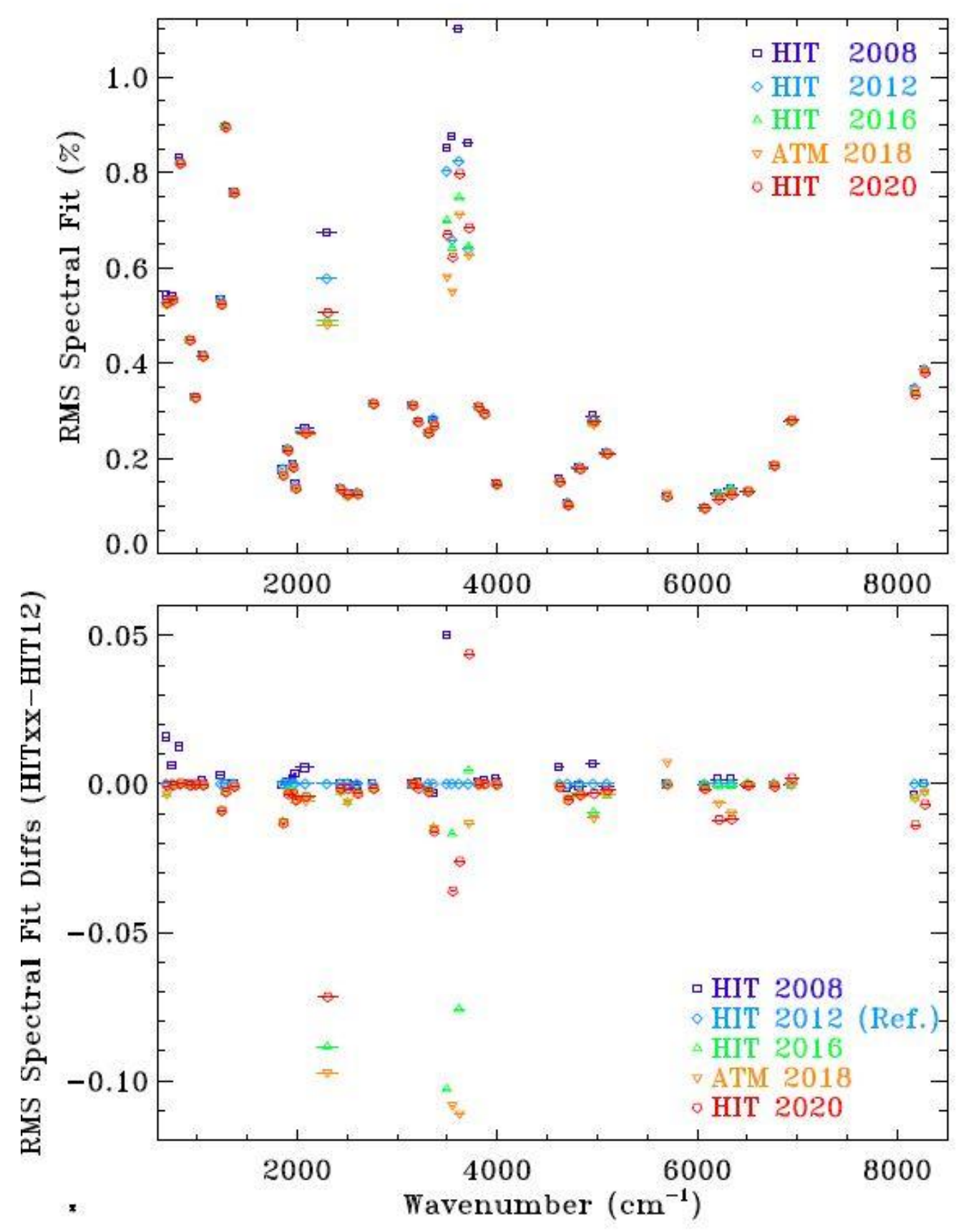
Fig. 3.

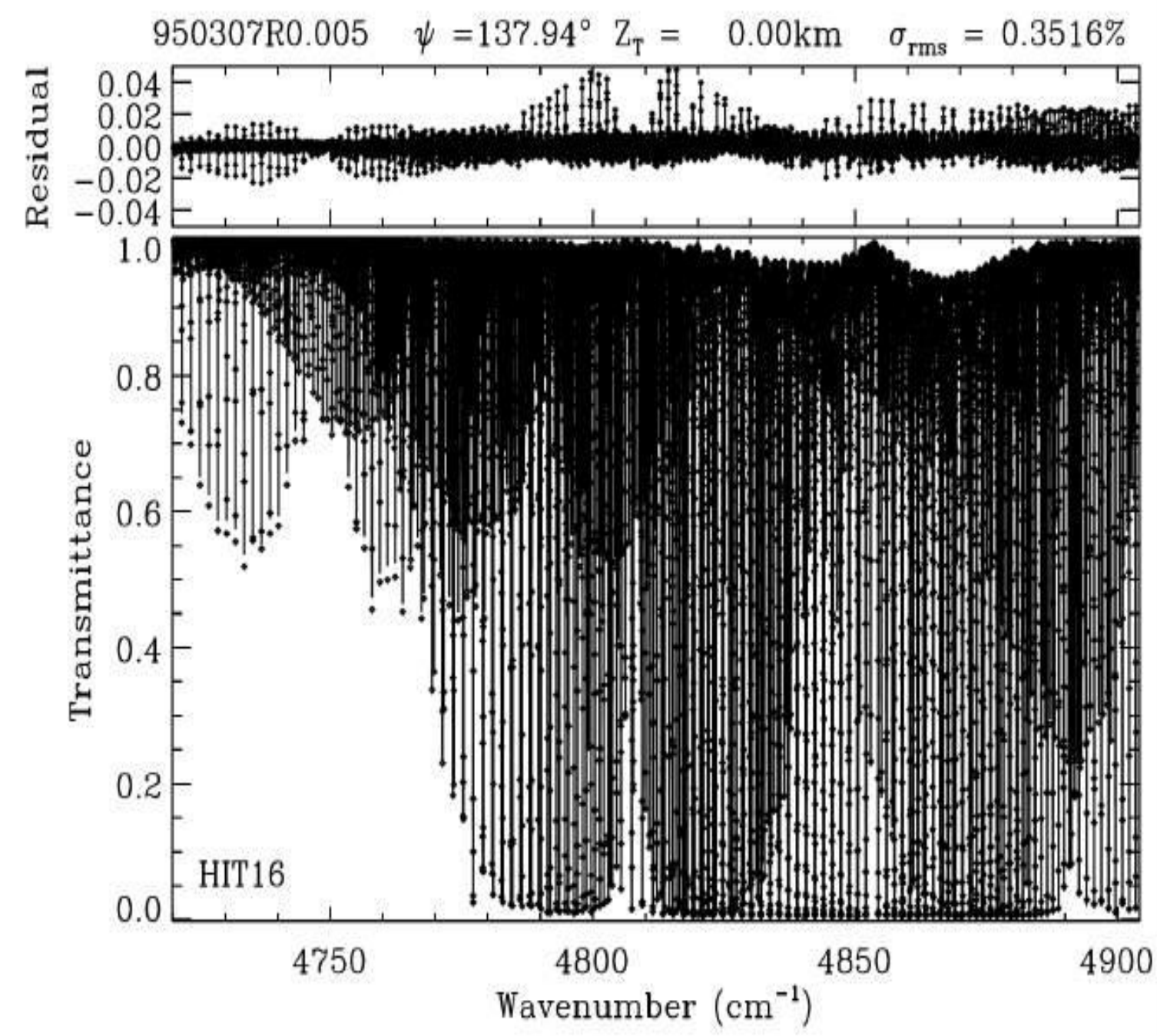


Fig. 4.

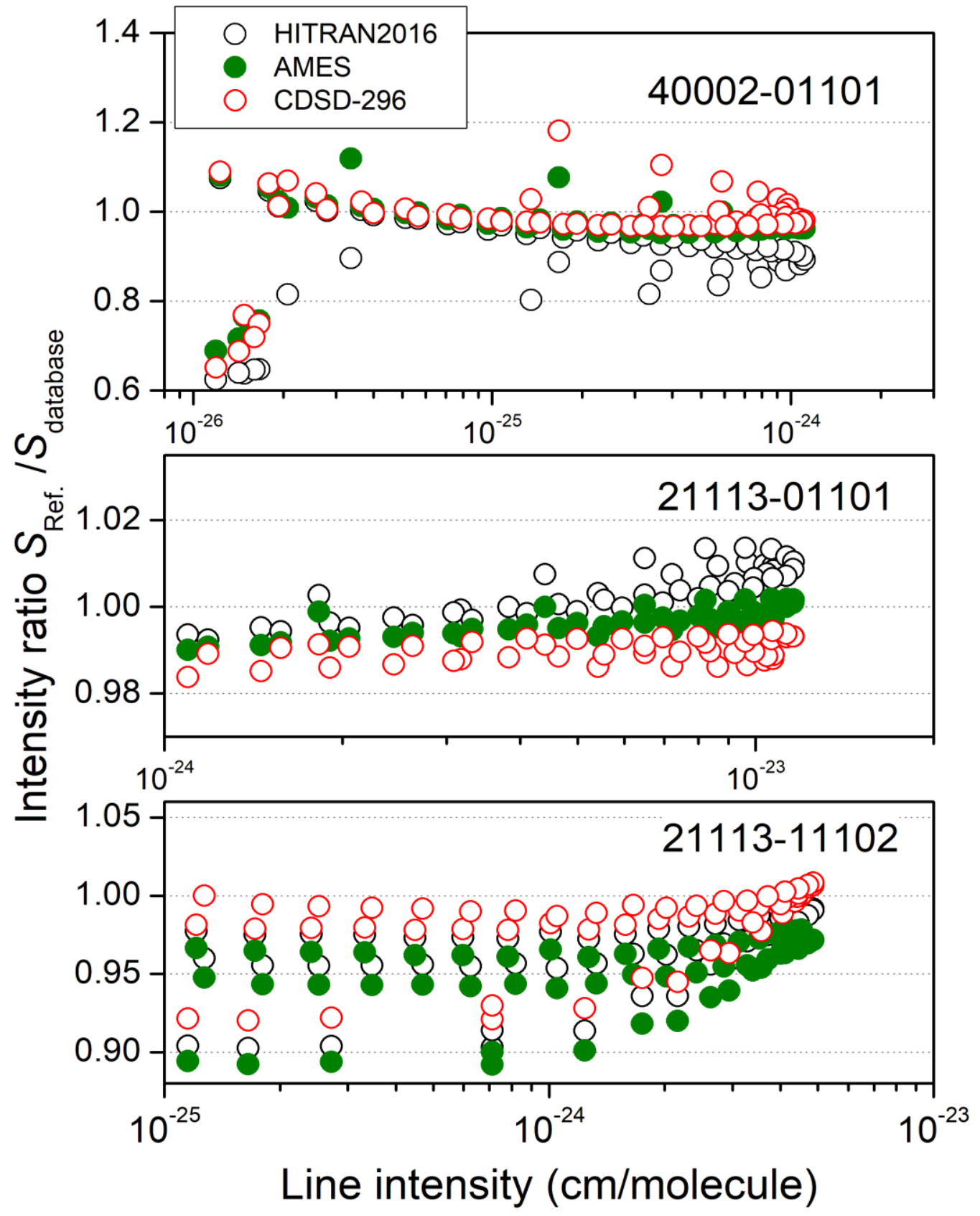




\section{Fig. 5.}

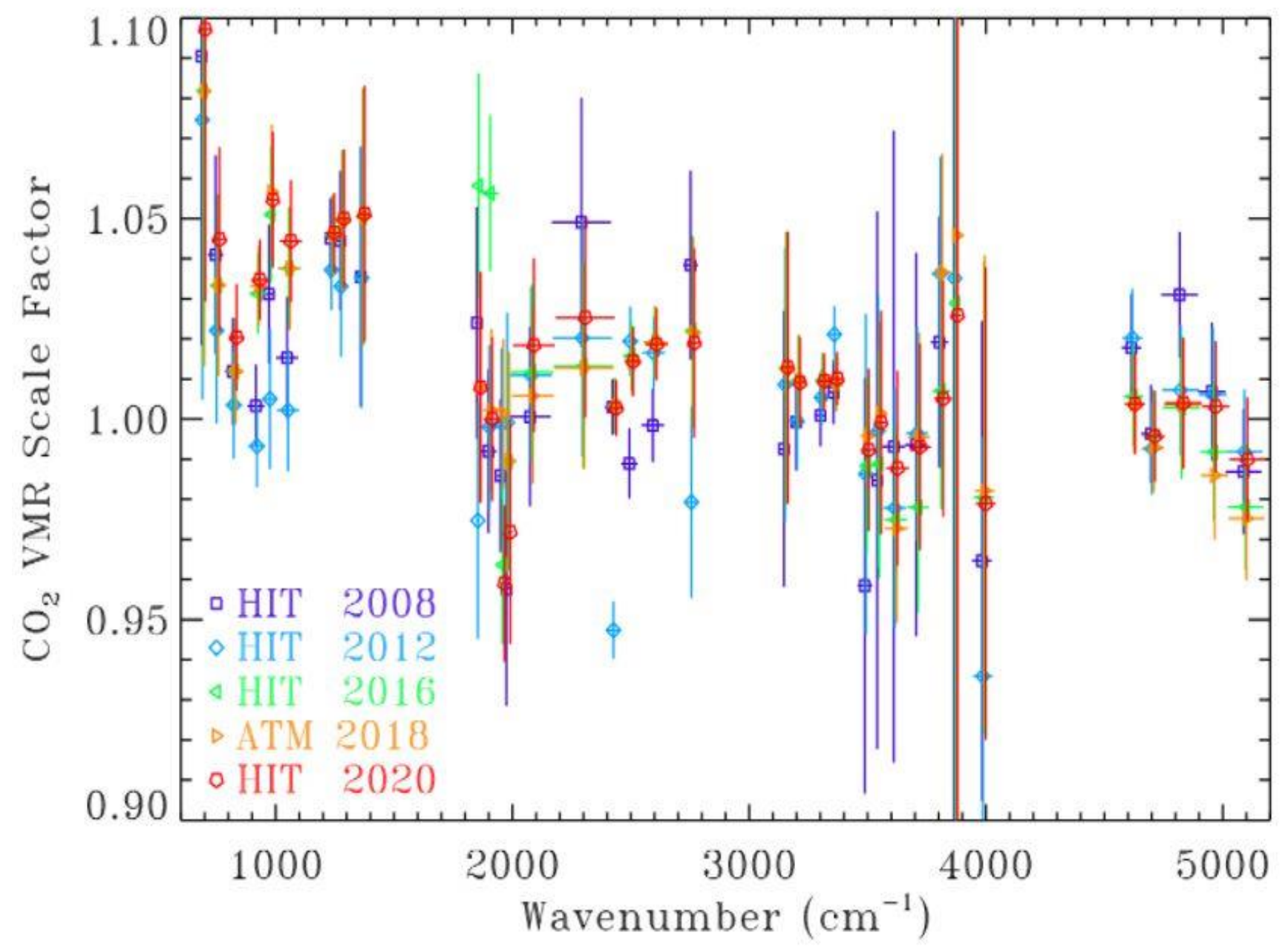


Fig. 6.

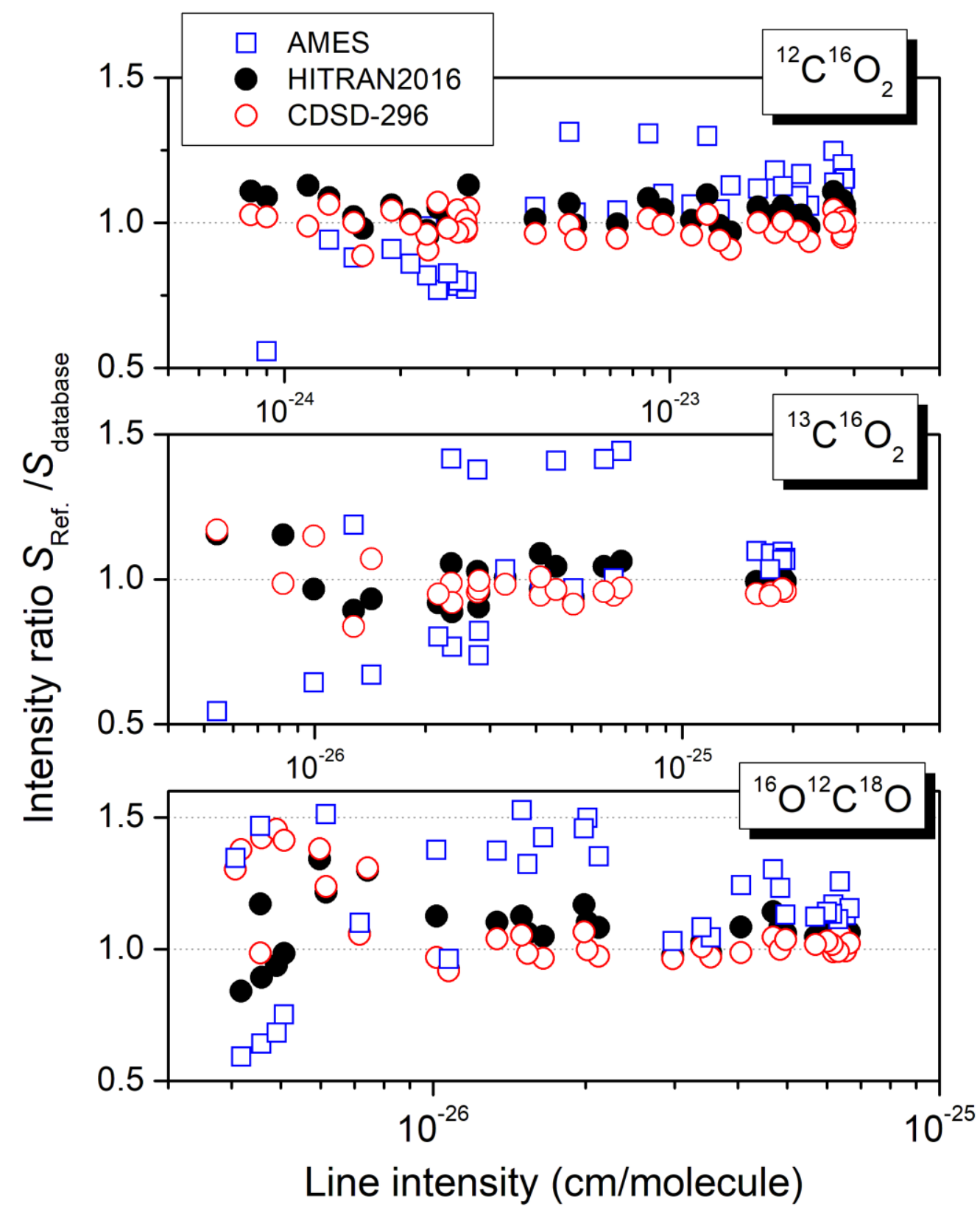


Fig. 7.

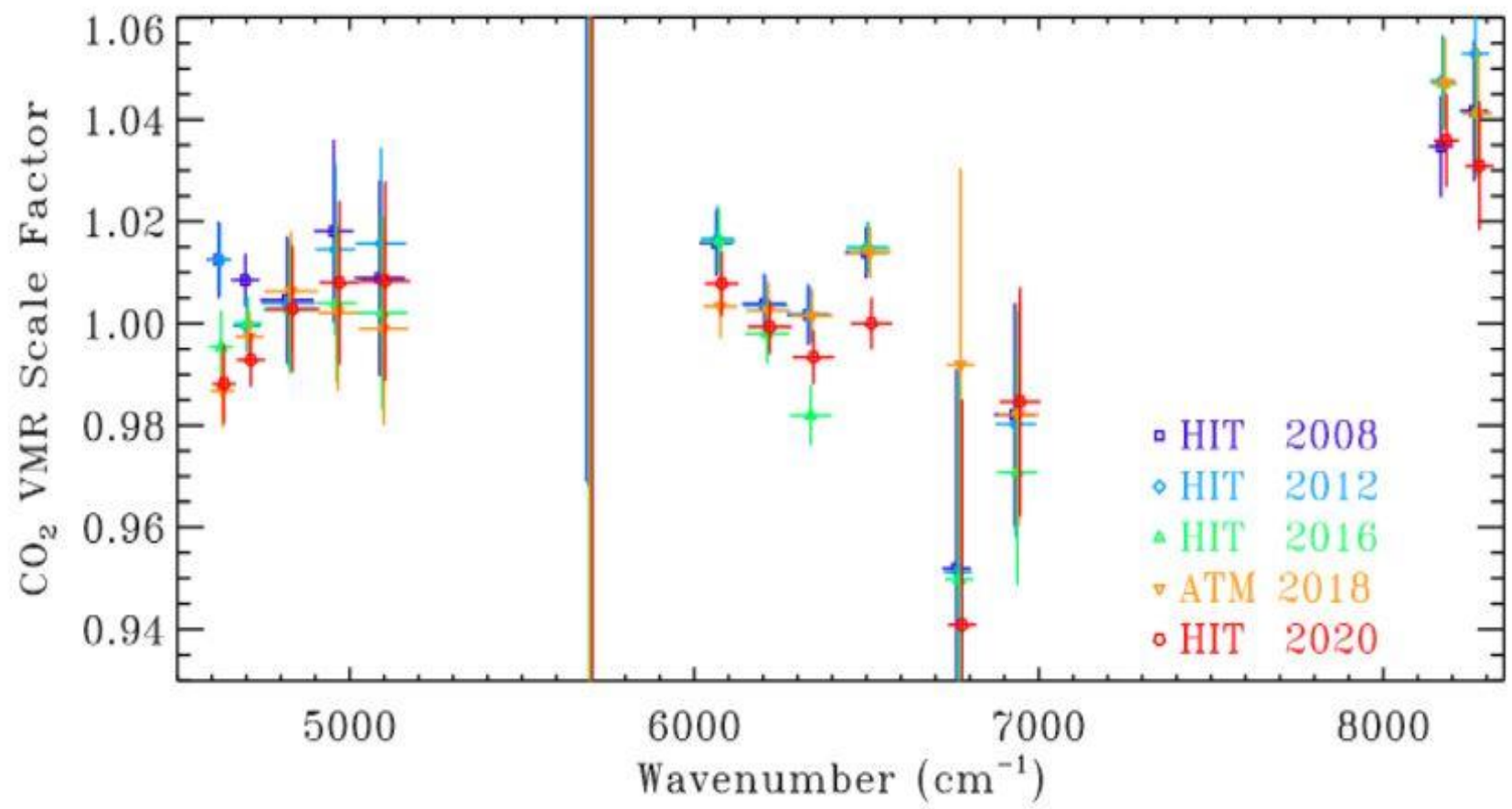


Fig. 8.

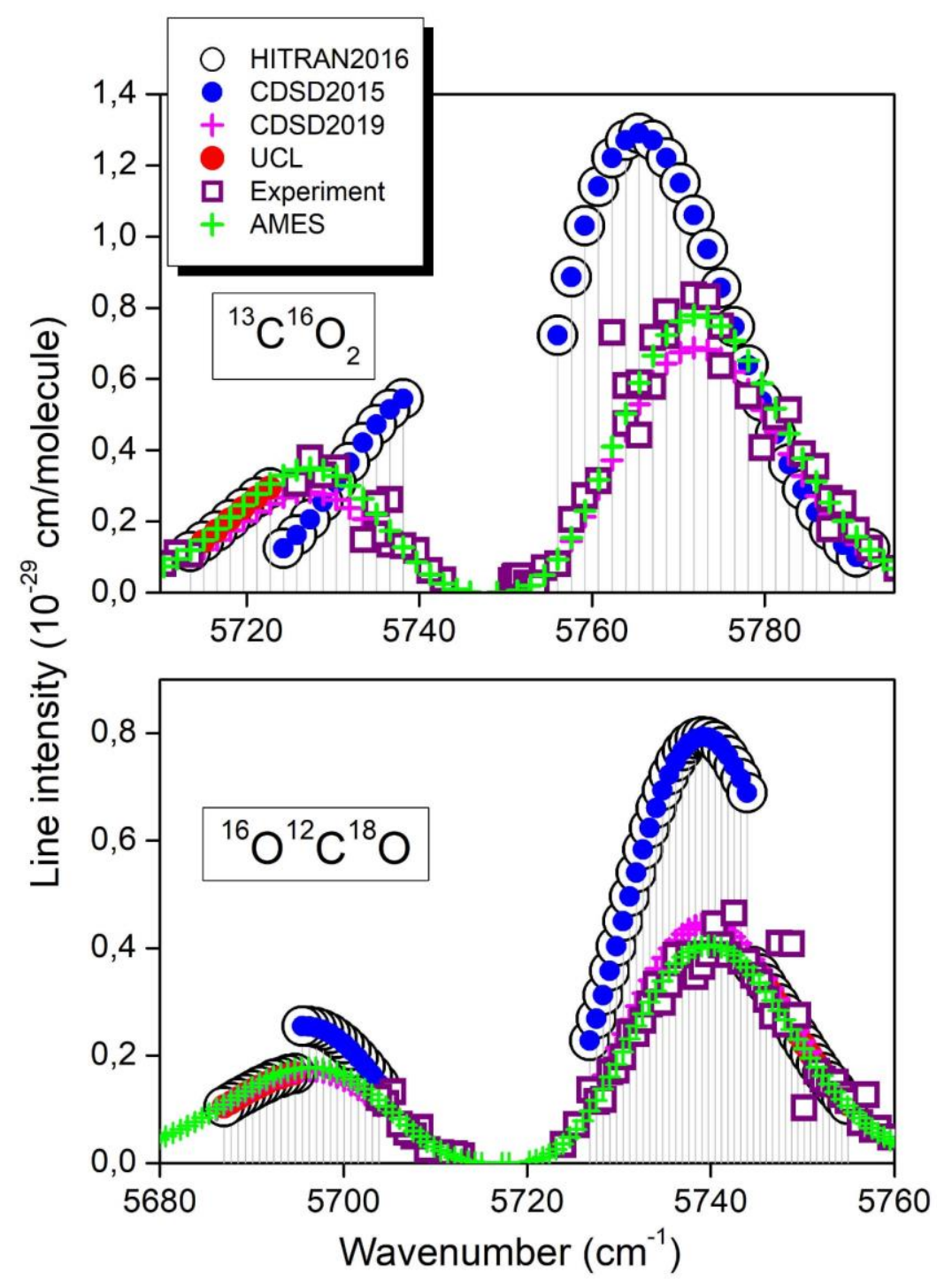




\section{Fig. 9.}

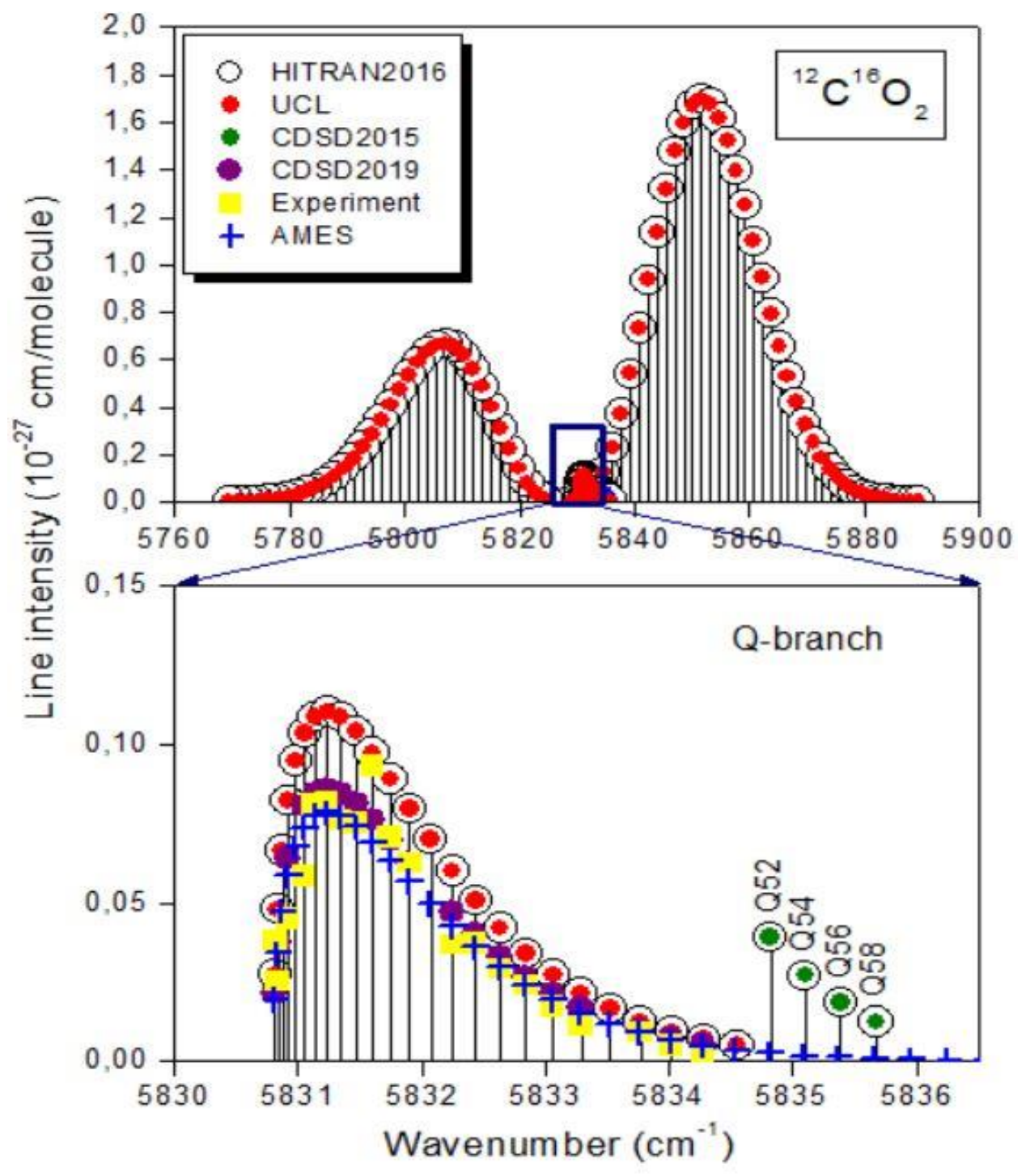


Fig. 10.

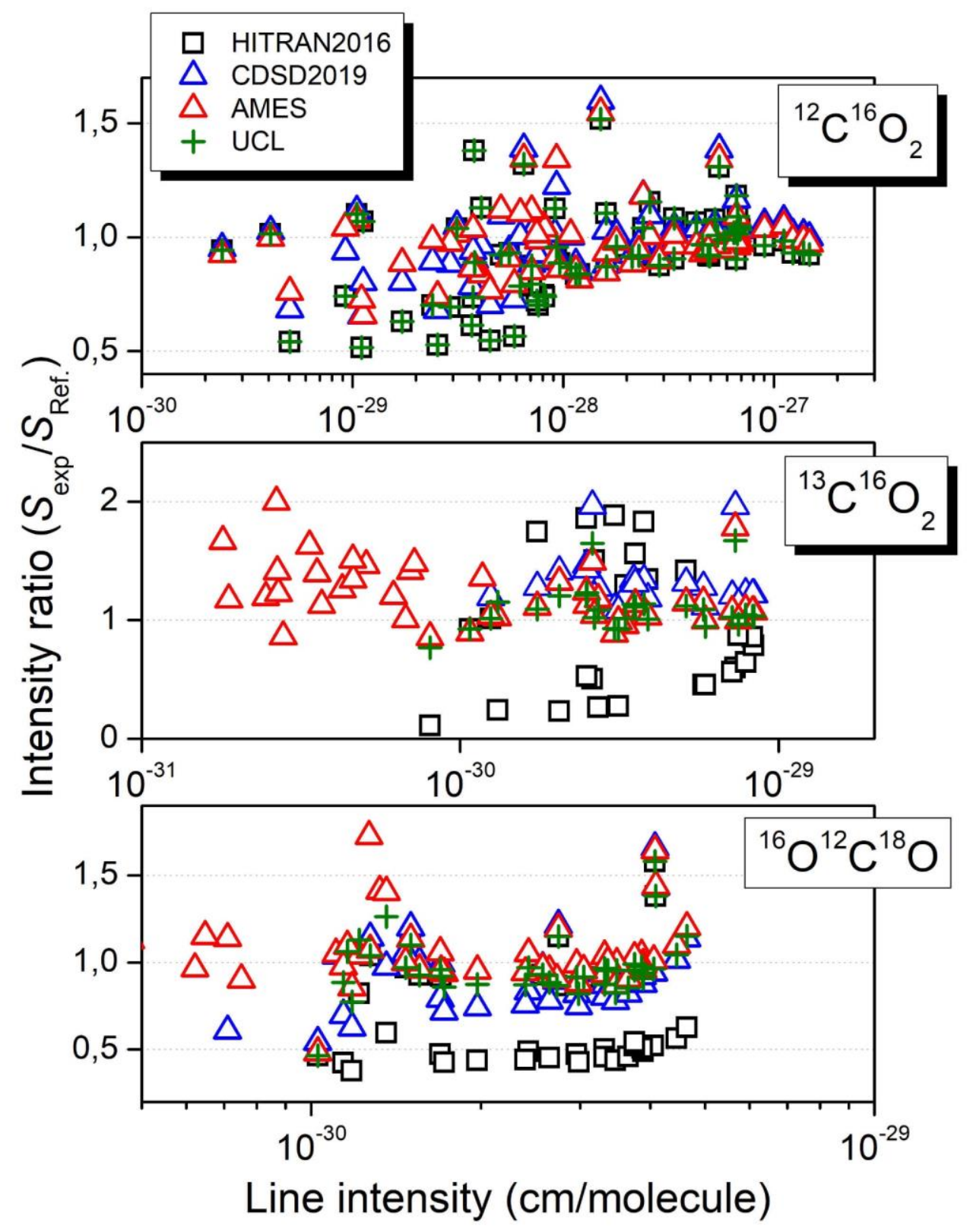


Fig. 11.
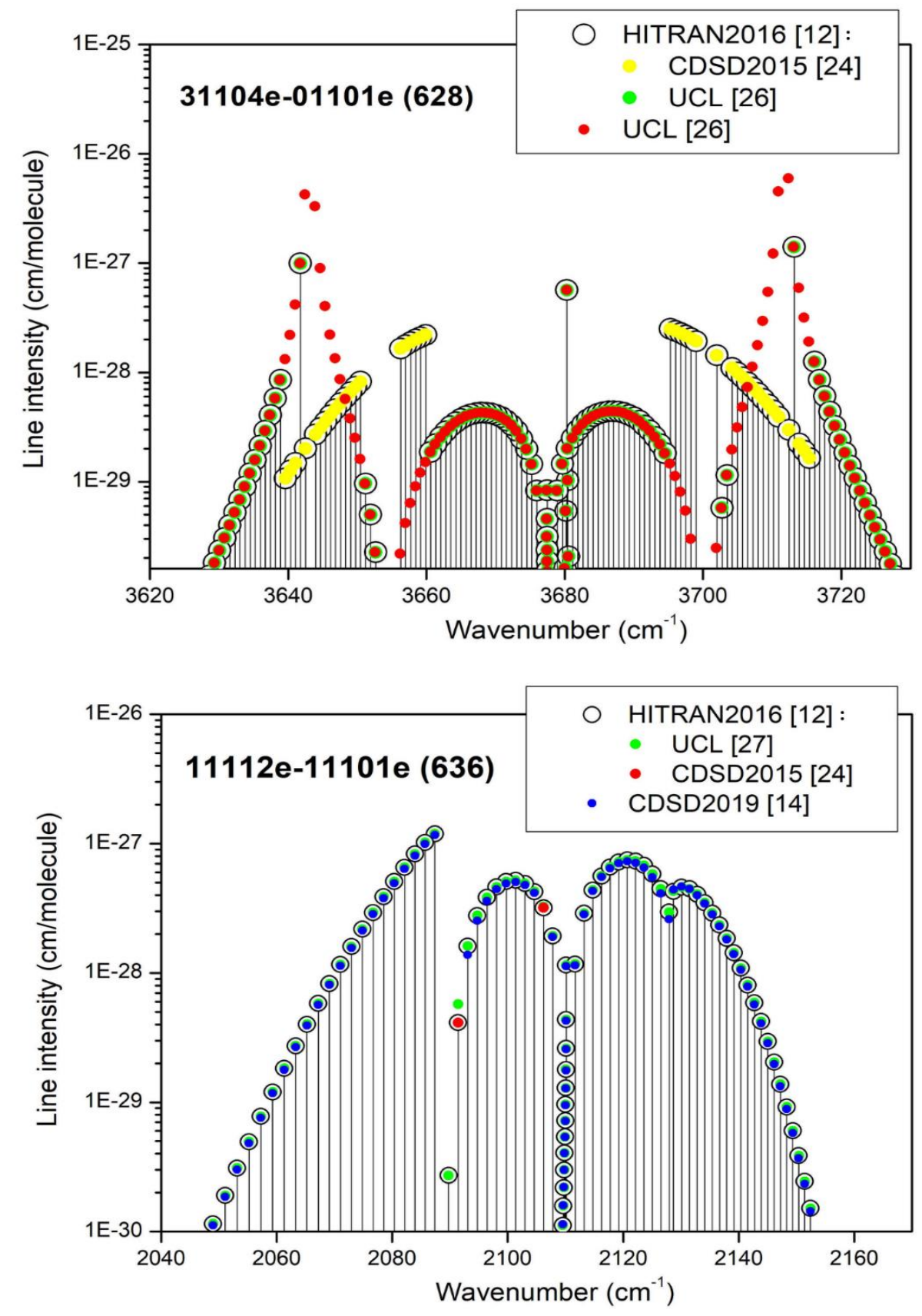


\section{Fig. 12.}
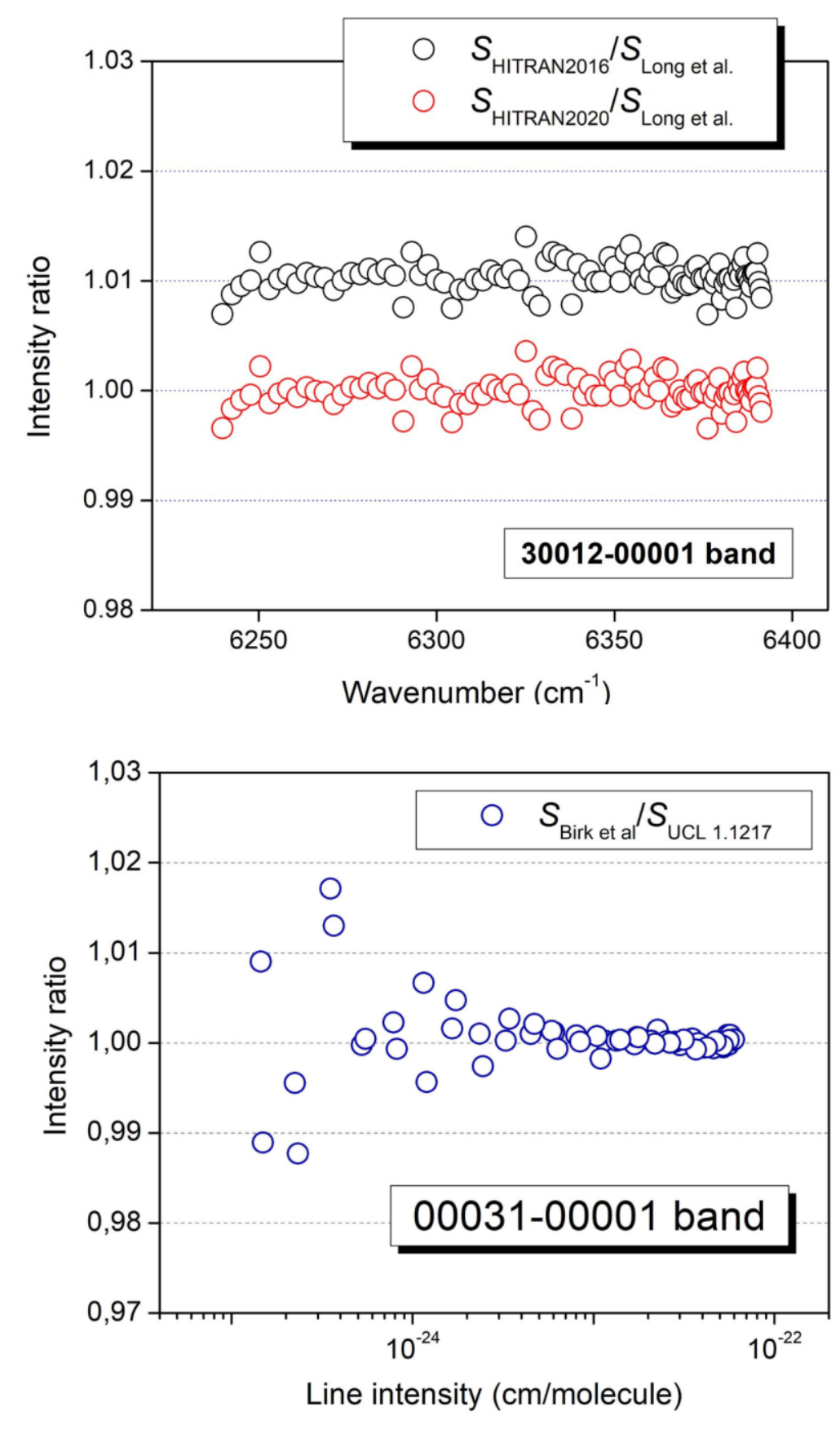
Fig. 13.

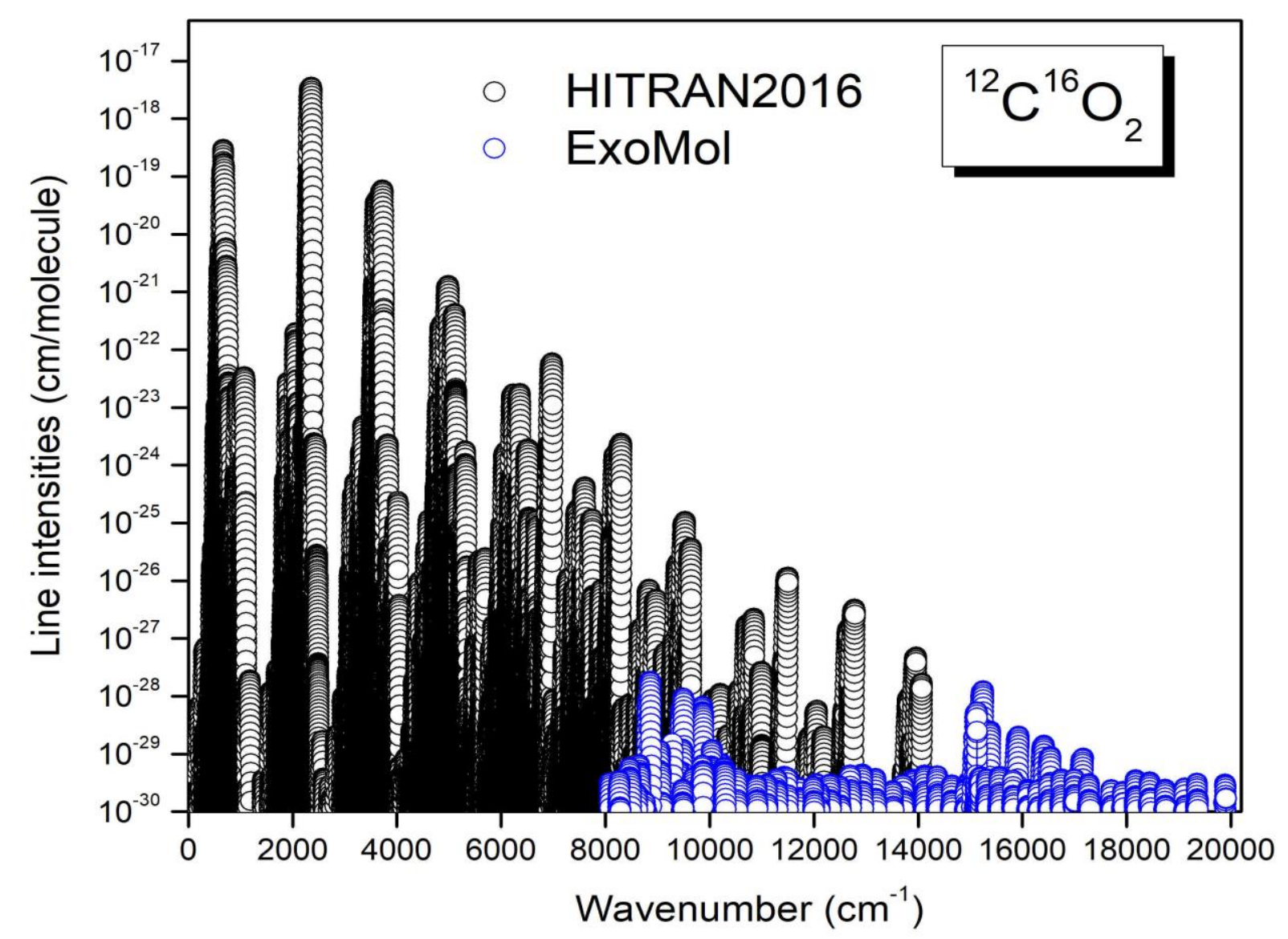


Fig. 14.

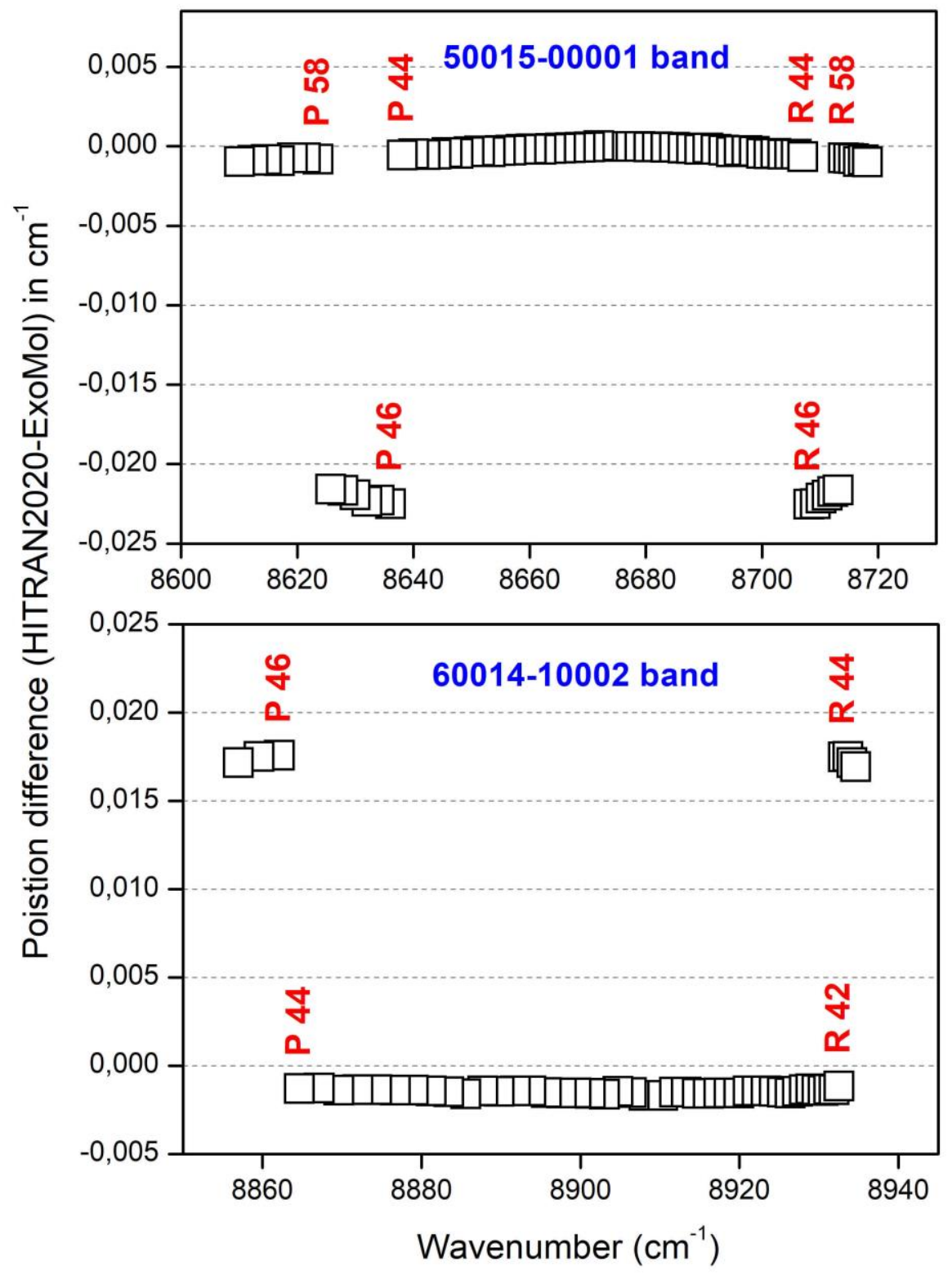


Fig. 15.

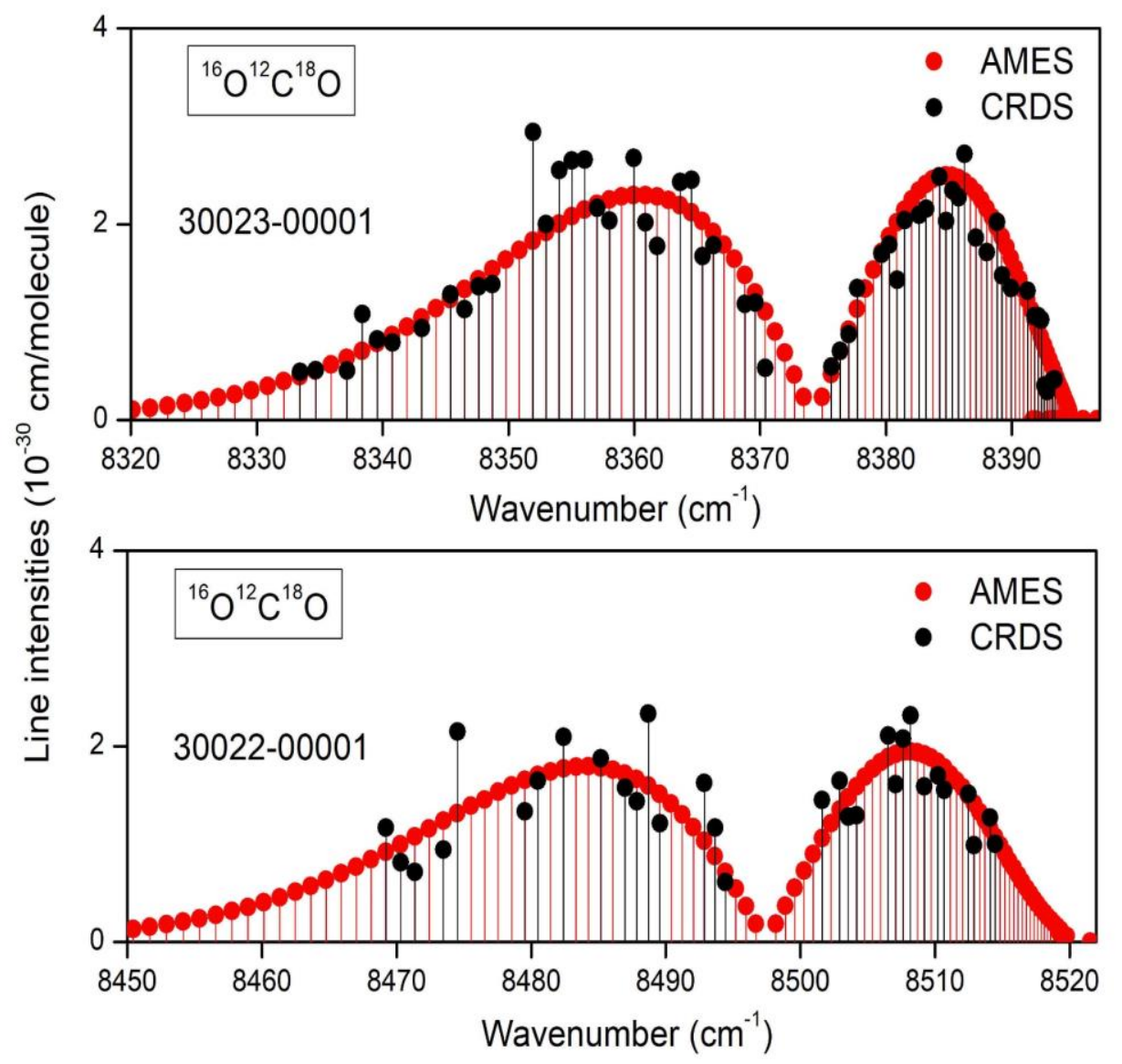


Fig. 16.

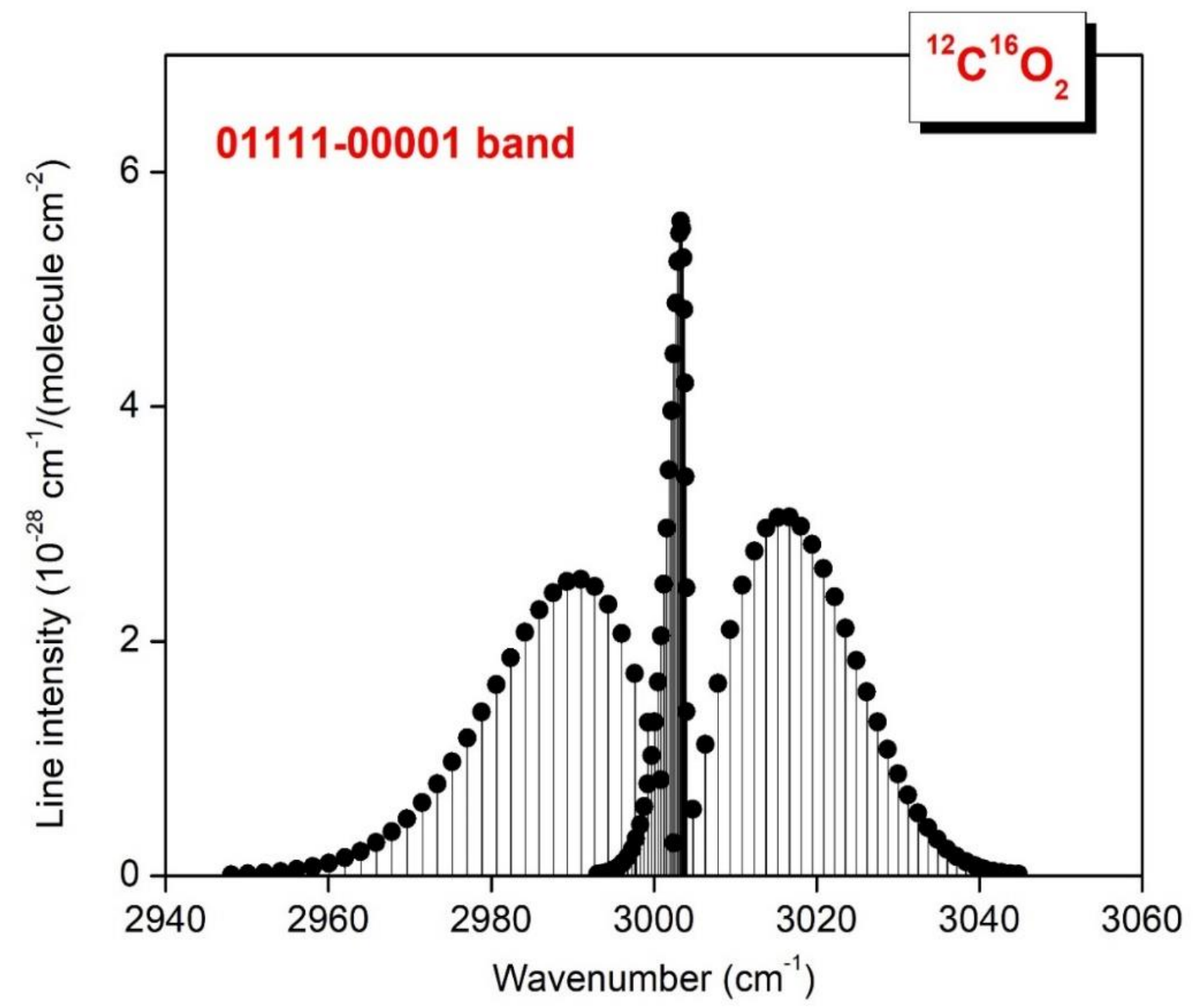





\begin{abstract}
Declaration of Competing Interest
The authors declare that they have no known competing financial interests
or personal relationships that could have appeared to influence the work
reported in this paper.
Declaration of Competing Interest
The authors declare that they have no known competing financial interests
or personal relationships that could have appeared to influence the work
reported in this paper.

Declaration of Competing Interest
The authors declare that they have no known competing financial interests
or personal relationships that could have appeared to influence the work
reported in this paper.

Declaration of Competing Interest
The authors declare that they have no known competing financial interests
or personal relationships that could have appeared to influence the work
reported in this paper.

claration of Competing Interest
personal relationships that could have appeared to influence the work
ported in this paper. repor.

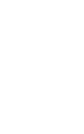

Conflict of Interes

Declaration

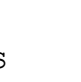
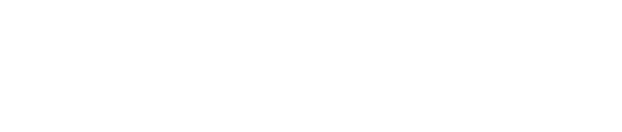


\section{Author Statement}

E.V.Karlovets: Formal analysis, Methodology, Software, Writing - original draft., I.E.Gordon: Supervision, Conceptualization, Methodology, Writing - review \& editing, L.S.Rothman: Writing - review \& editing, R. Hashemi: Data curation, Writing - review \& editing, R.J.Hargreaves: Software, G.C. Toon: Data curation, Software, A.Campargue: Data curation, Writing - review \& editing, V.I. Perevalov: Data curation, Writing review \& editing, P. Čermák: Software, M.Birk: Data curation, G.Wagner: Data curation, J.T.Hodges: Data curation, Writing - review \& editing, J. Tennyson: Writing - review \& editing, S.N.Yurchenko: Data curation, Writing - review \& editing. 
Click here to access/download Supplementary Material Supplementary material.txt 